Portland State University

PDXScholar

Spring 6-14-2018

\title{
A Million Piece Jigsaw Puzzle: Transition Experiences of Foster Youth Accessing Higher Education through Community College
}

Karen A. Sullivan-Vance

Portland State University

Follow this and additional works at: https://pdxscholar.library.pdx.edu/open_access_etds

Part of the Educational Leadership Commons, and the Higher Education Commons Let us know how access to this document benefits you.

\section{Recommended Citation}

Sullivan-Vance, Karen A., "A Million Piece Jigsaw Puzzle: Transition Experiences of Foster Youth Accessing Higher Education through Community College" (2018). Dissertations and Theses. Paper 4413. https://doi.org/10.15760/etd.6310

This Dissertation is brought to you for free and open access. It has been accepted for inclusion in Dissertations and Theses by an authorized administrator of PDXScholar. Please contact us if we can make this document more accessible: pdxscholar@pdx.edu. 
A Million Piece Jigsaw Puzzle: Transition Experiences of Foster Youth Accessing Higher Education through Community College

by

Karen Sullivan-Vance

A dissertation submitted in partial fulfillment of the requirements for the degree of

Doctor of Education

in

Educational Leadership: Postsecondary Education

Dissertation Committee:
Janine Allen, Chair
Tina Anctil
Christine Chaille
Laurie Powers

Portland State University

2018 
(C) 2018 Karen Sullivan-Vance 
Abstract

A college education offers people social and economic benefits, yet youth from foster care backgrounds are less likely than their peers to attain a college education, which places this already vulnerable population at higher risk for a lifetime of living on the margins of society. Foster alumni face multiple obstacles to accessing and persisting in higher education. To facilitate and support the success of this frequently overlooked population, professionals in higher education need to understand these obstacles. Little is known about the experiences of youth with foster care backgrounds as they transition into and through higher education. Although existing research has reported the academic, health, and social effects of having been in foster care, little is known about why foster alumni do not persist in higher education. This study used student-development theory, specifically Schlossberg's transition theory, Tinto's theory of student departure, and Bourdieu's work on social and cultural capital to provide a conceptual framework through which to view the lived experiences of youth with foster care backgrounds. Because, for many youths with foster care backgrounds, the pathway to the baccalaureate degree is through a community college, this study examined and explored the transition experiences of foster alumni about to begin or currently enrolled at an Oregon Community College. The study explored the factors that challenge and facilitate foster alumni persistence towards the attainment of a college degree. 
Dedication

To my parents

A.C and Patricia Vance 
Acknowledgements

I am deeply grateful to the many people who have guided and supported me on this journey. No one completes a doctorate on their own and I was fortunate to have an incredible team who supported me. Your encouragement, support and love through some difficult times has made a difference in me moving forward and completing.

I thank the young people that talked with me about their experiences in foster care, including those that ended up participating in the research and others that chose not to go forward. You opened your life experiences to a stranger and allowed me to ask questions. I remain impressed by your dignity, curiosity, and intelligence. My guiding principle throughout this process has been my desire to understand the experiences of foster youth. Charlie, Gemma, Stephanie, Vincent and Maggie shared their experiences and I thank them and wish them all the best as they continue their journeys in life.

To my beloved parents, A.C. and Patricia Vance for their love and support. My dad passed away before I began my doctoral journey and my mum walked every step of the way with me, until her frail heart could go no further, leaving me to finish the last steps on my own. I was blessed with parents who stoked my natural curiosity and fostered my intelligence, teaching me to be open to the world. I love and miss you every day.

To my family of choice, Katherine Schmidt, Waverly Schmidt, Daphne Vint, Brett McFarlane, and Nicole Kent who have laughed, cried, and occasionally nagged, but have always been on my team, thank you for your constant and unwavering support and love. 
To my cohort sisters, Pat Kenney-Moore and Stephanie Stokamer, we have experienced so much through this process and I value your friendship.

To everyone in the foster care community who met with me over the course of this journey and shared their insight and experiences, especially Dr. Peter Pecora, John Emerson, and David Akinsanya, individuals who advocate and champion foster youth in the United States and Great Britain.

To my former supervisor, David McDonald, for your belief and encouragement along the way and for being an individual who leads with integrity.

To my two colleagues Alex Kunkle and Jesse Poole, who were such a joy to work with and made it possible for me to take time away from my day job to complete my doctorate. I am honored to have worked with you.

A special note of gratitude for my Chair, Dr. Janine Allen, who has and continues to serve as an inspiration for how to be a leader and researcher. Your wisdom, advice, strength, curiosity and ethics are amazing. Finally, my thanks to my committee, Dr. Tina Anctil, Dr. Christine Cress and Dr. Laurie Powers. You gave not only of your time, but also your insights. I could not have had a more empowering and supportive committee. 


\section{Table of Contents}

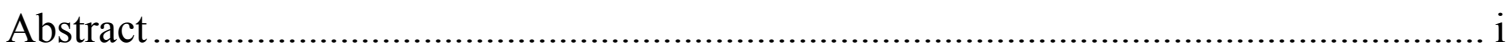

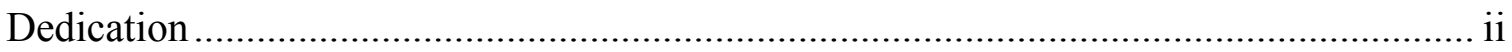

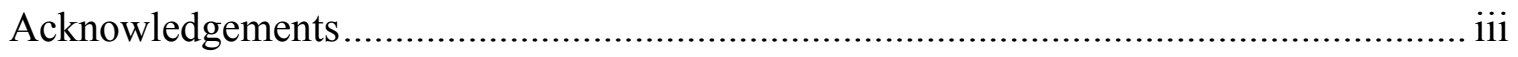

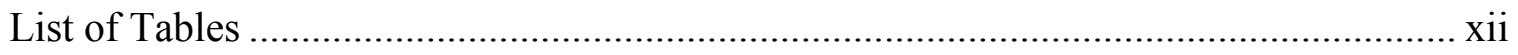

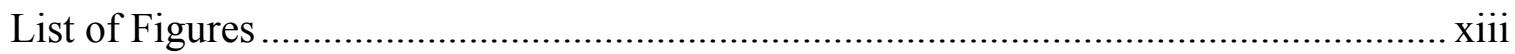

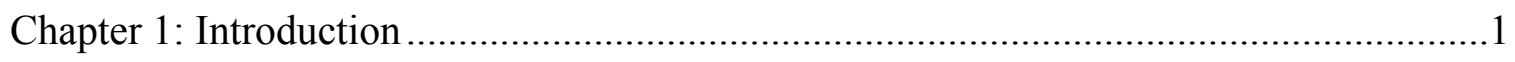

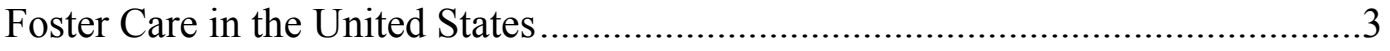

Benefits of Higher Education for Foster Alumni ............................................4

Nonfinancial Rewards of Higher Education .................................................

College Completion Agenda ..................................................................

Educated Work Force .....................................................................................

Foster Alumni in Higher Education ..........................................................

Community Colleges as the Gateway to Higher Education................................ 10

Conceptual Framework of Transitions and Cultural Capital .............................11

Statement of the Research Problem ............................................................. 12

Purpose of the Research ............................................................. 13

Significance of the Research........................................................ 14

Research Methodology and Questions ..................................................... 14

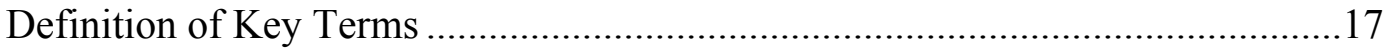

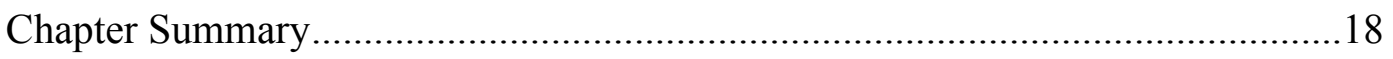

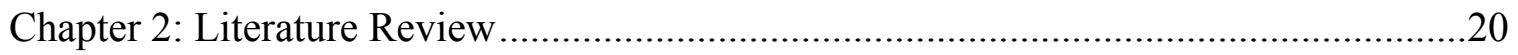

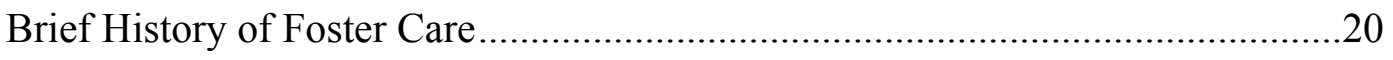


vi

Foster Care Experiences and Outcomes.......................................................22

Multiple Placements.................................................................22

Educational Results...........................................................................24

Mental Health Issues.........................................................................26

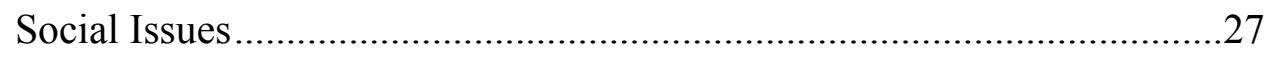

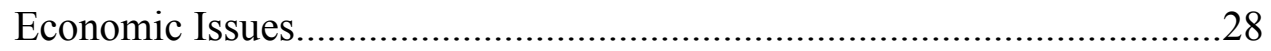

Barriers to Access and Persistence for Foster Alumni Seeking Higher

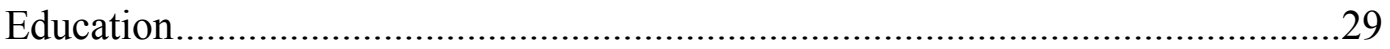

Transition from State Care to Independence .........................................30

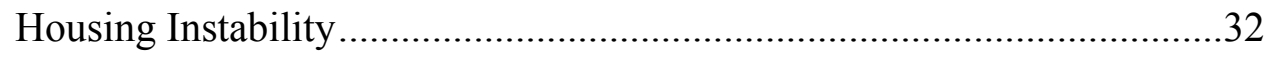

Low Expectations for Success and Stigma Related to Foster Care ...........32

Lack of Knowledge about College ....................................................33

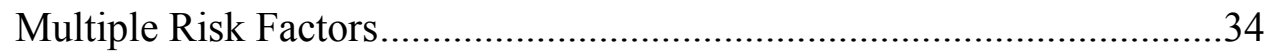

Risk Factors for Foster Alumni........................................................36

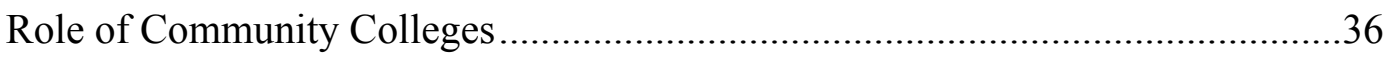

Multiple Messages of Community Colleges........................................3 37

Transferring from Community College ................................................38

Foster Alumni and the Community College Pathway .............................39

Lack of Awareness on the Part of Educators ................................................40

Financial-Aid Support............................................................... 40

Lack of Knowledge by Institutional Agents ......................................41

Theoretical Models for Student Success .......................................................42

Student Retention and Persistence ..................................................42 
vii

Schlossberg's Transition Theory ….....................................................47

Bourdieu's Theory of Social and Cultural Capital .................................55

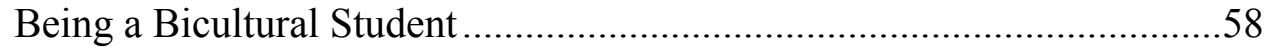

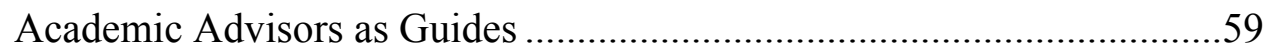

Federal and State Programs That Support Foster Youth in Higher Education ......61

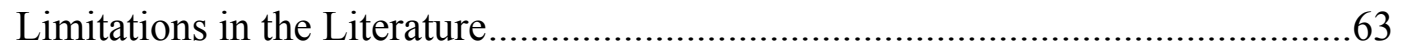

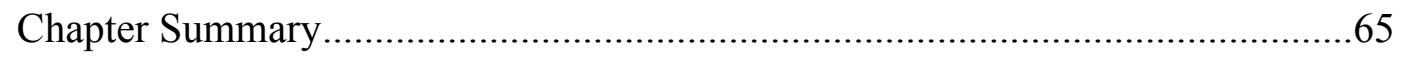

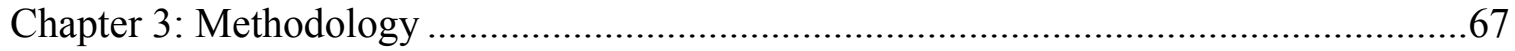

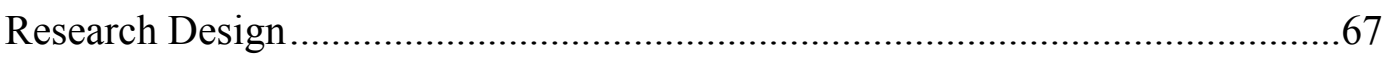

Restatement of Research Questions..................................................68

Existing Quantitative Data Set..........................................................69

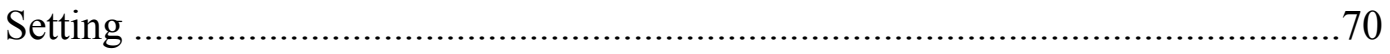

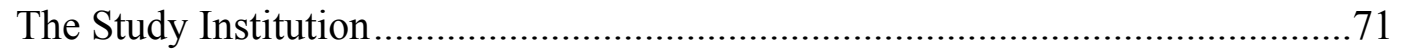

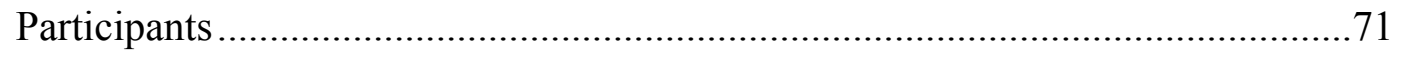

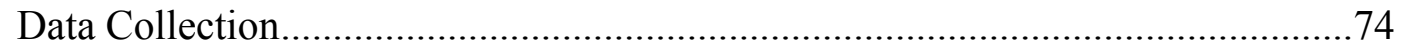

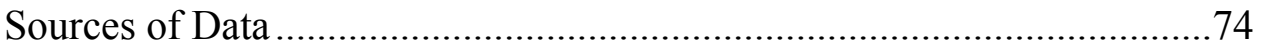

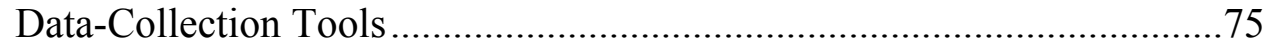

Data-Collection Process .......................................................................... 76

Data-Collection Timeline................................................................ 76

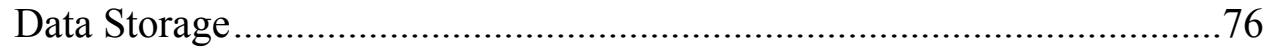

Data-Collection Procedures ............................................................... 77

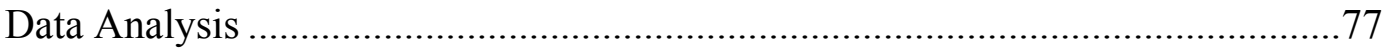

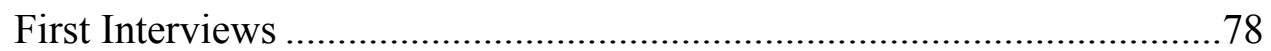


viii

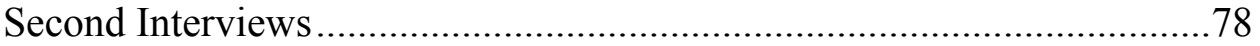

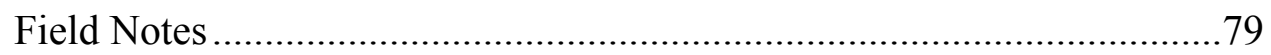

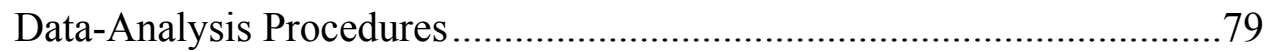

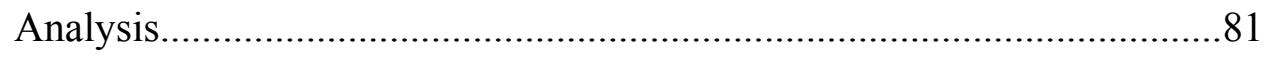

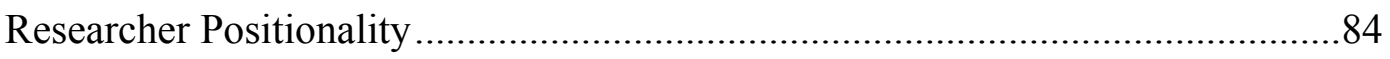

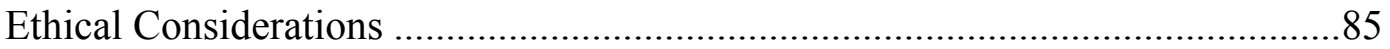

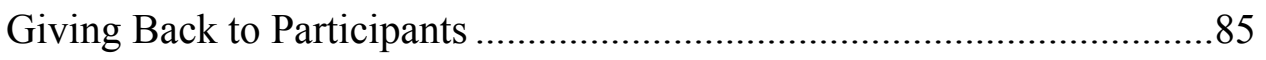

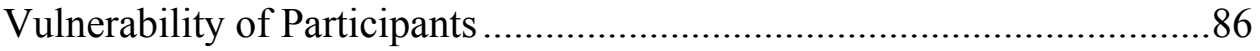

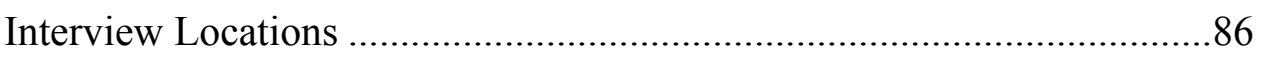

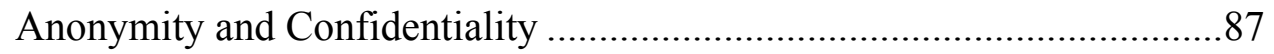

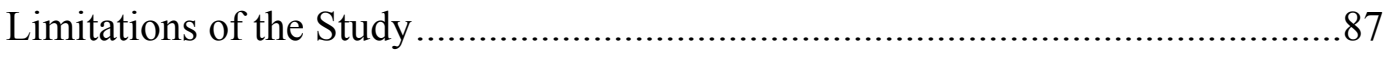

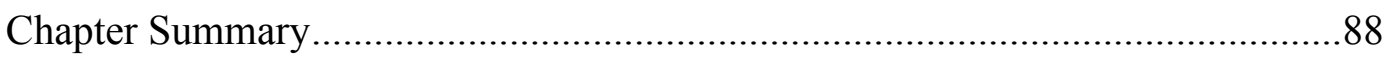

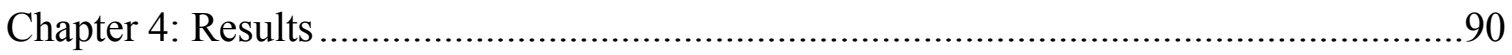

Quantitative Results and Demographics ................................................91

Foster Alumni and the Community College Pathway ............................92

Qualitative Results and Emergence of Themes .............................................95

Emerging Theme 1. From Foster Care to the World (From

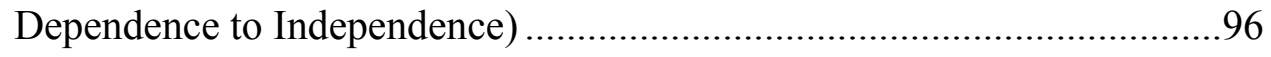

Emerging Theme 2: Moving to Oregon to Start Over ............................104

Emerging Theme 3: The Need to Help Others ....................................105

Emerging Theme 4. Education as a Pathway (Future) .........................107

Emerging Theme 5: The Need to Belong (Somewhere/Anywhere)........110

Emerging Theme 6: Community College as a Safe Haven ....................111 
Emerging Theme 7: Financial Transitions...........................................115

Emerging Theme 8: Academic Literacy ............................................118

Emerging Theme 9: Academic Advisors as Neutral Resources ..............125

Emerging Theme 10: The Effects of Having Been in Foster Care

Impacts Higher Education Success ................................................131

Chapter Summary ..................................................................................... 133

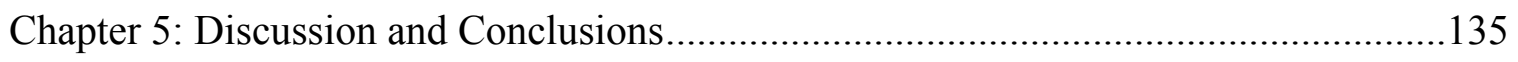

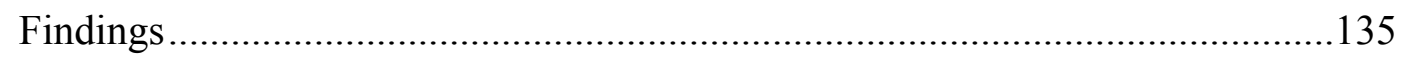

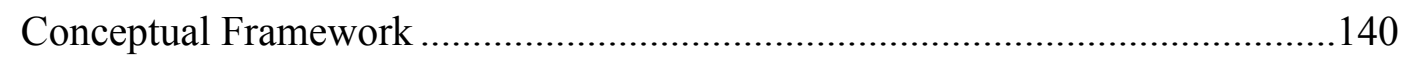

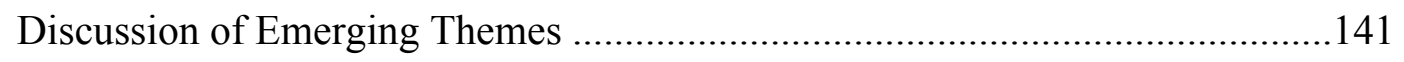

Emerging Theme 1. From Foster Care to the World (From

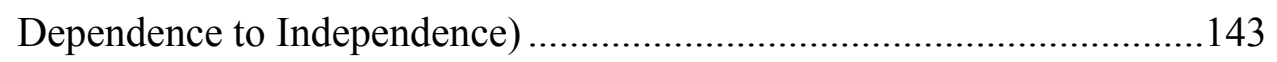

Emerging Theme 2: Moving to Oregon to Start Over ...........................145

Emerging Theme 3: The Need to Help Others ...................................146

Emerging Theme 4. Education as a Pathway (Future) .........................147

Emerging Theme 5: The Need to Belong (Somewhere/Anywhere)........148

Emerging Theme 6: Community College as a Safe Haven ....................149

Emerging Theme 7: Financial Transitions.........................................150

Emerging Theme 8: Academic Literacy ............................................151

Emerging Theme 9: Academic Advisors as (Neutral) Resources ..........152

Emerging Theme 10: The Effects of Having Been in Foster Care

Impacts Higher Education Success ..................................................153

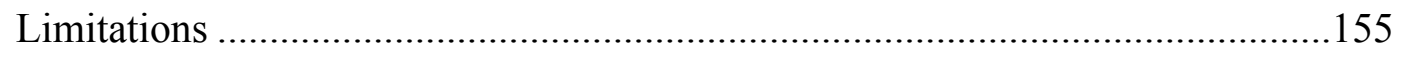


Participants..... X

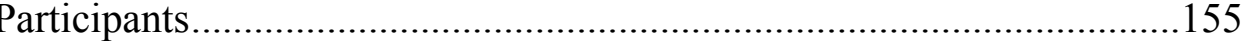

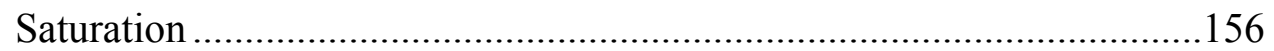

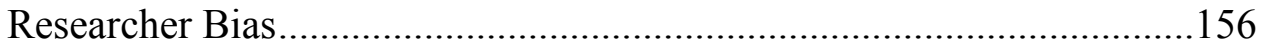

Omission of Race and Ethnicity ........................................................157

Lack of Foster Youth Background..................................................158

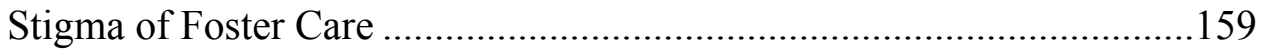

Implications and Recommendations for Academic Advisors, Student Affairs

Personnel, and Higher Education Institutions .............................................159

Implications and Recommendations for Academic Advisors................160

Implications and Recommendations for Student Affairs Personnel ........164

Implications and Recommendations for Higher Education Institutions ..165

Significance for Educational Leaders ...............................................166

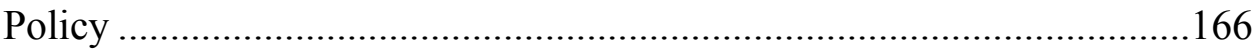

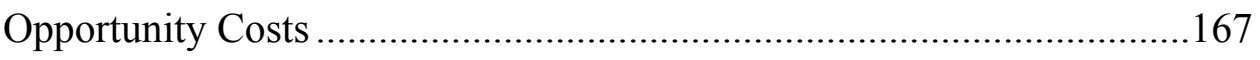

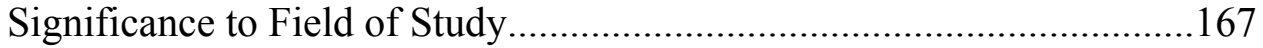

Next Steps in Research ........................................................... 168

Dissolution of Oregon University System .....................................................169

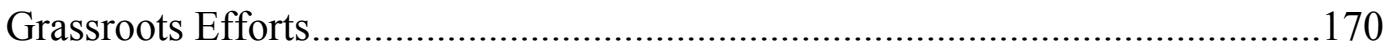

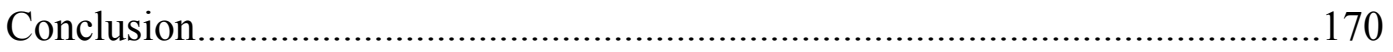

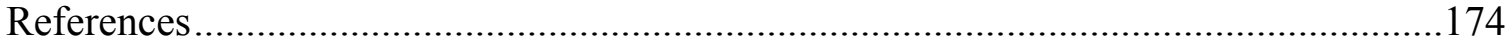

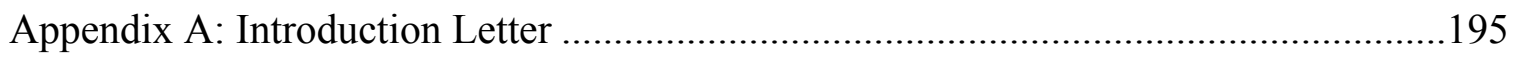

Appendix B: Recruitment Poster-Portland Community College ...................................196 
Appendix C: Letter to Department of Human Services Social Workers Requesting

Permission to Interview Foster Youth in Care......................................................197

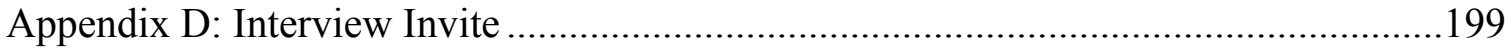

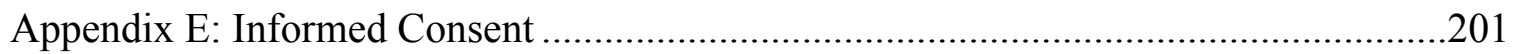

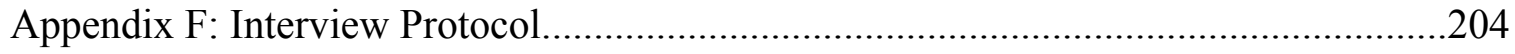

Appendix G: Participant Thank You Letter.................................................................209

Appendix H: Confidentiality Agreement for Professional Transcriptionist ...................210 


\section{List of Tables}

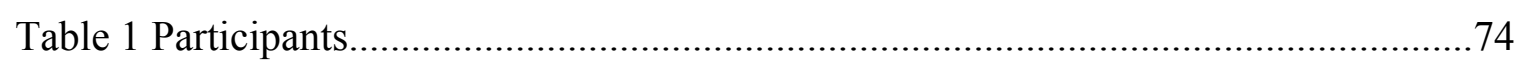

Table 2 Where do Former Foster Care Youth Attend College? ....................................93

Table 3 Results of Chi-square Analysis Comparing Student Type With Former Foster

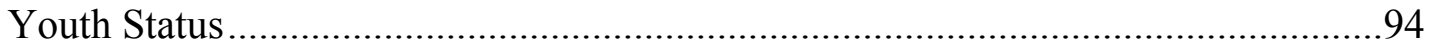

Table 4 Reasons for Attending the Study Community College.....................................95 
List of Figures

Figure 1. Model of foster youth transition from high school to higher education...........138

Figure 2. Schlossberg's Four S's in relation to foster youth transitions in college. ........141 
I can't take for granted what lots of people do. There's a lot I have to learn that most people seem to be born with. The problem is that I don't even really know what I'm missing, and that scares me some.

—Bryan, Foster youth (Toth, 1997, p. 311)

\section{Chapter 1: Introduction}

Each year an estimated 17,394 young people in foster care reach the age of emancipation and leave their state care system (U.S. Department of Health and Human Services, 2015). The futures these young people face, however, can be bleak. Foster alumni are more likely to suffer from mental health disorders than their peers (Barth, 1990; Brandford \& English, 2004; Casey Family Services, 2008; Courtney et al., 2005; Pecora et al., 2005; Pecora et al., 2010. One study showed that 33\% of foster youth lack health insurance; $22 \%$ suffered from housing insecurity; $22 \%$ live at or below the poverty line, which is three times the national average; and 20\% were unemployed (Pecora et al., 2010). Almost 30\% of foster alumni had been incarcerated (U.S. Department of Health and Human Services, 2008). Indeed, without interventions, supports, and opportunities, this already vulnerable population is at higher risk of living on the margins of society.

Attaining a college education is often viewed as providing opportunities for intellectual and social growth and securing a promising future for people (Pascarella \& Terenzini, 2005). Employment provides financial and personal opportunities. A college education may be viewed as essential for those who have been marginalized by society. For young people leaving the foster care system, post-secondary education is an opportunity to attain a more economically and socially secure future. More than any other available opportunity, a college education is an investment that can increase opportunities 
for former foster youth, also referenced as foster alumni, to have bright futures. Higher education facilitates a transition to a future in the mainstream and away from the fringes of society. Individual benefits include higher earnings for all racial groups, regardless of gender. The income gap between college graduates and those who do not graduate from college is significant and increasing, and any college experience creates a measurable financial benefit (Baum, Ma, \& Payea, 2010).

Perhaps spurred by the promising future afforded by pursuing higher education, many foster youth aspire to earn a college degree. Yet few foster alumni enter higher education, and even fewer persist to degree attainment. In a national study, $70 \%$ of foster youth indicated they wanted to attend post-secondary education, yet only $7 \%$ to $13 \%$ begin college (Martin, 2003). Moreover, only 1.8\% of foster alumni who attended college completed a bachelor's degree, compared to $24 \%$ of youth who were not in the foster care system (Pecora et al., 2005).

Although statistics suggest that foster youth face multiple barriers to accessing higher education, they also suggest that access is not sufficient. Foster alumni who do manage to access higher education face barriers to persisting to degree attainment. Indeed, youth from foster care backgrounds are an invisible population: -not only do educators lack awareness of the barriers these students face, educators are unaware of their very existence in higher education. Allen, Smith and Sullivan-Vance (2010) quoted one Oregon University System (OUS) administrator as saying:

There has not been any conversation in the OUS office of which I am aware around the transition of foster-care children into post-secondary education. As you might expect, the more visible underrepresented populations (HispanicLatino/a, African-American and Native American) have our attention and present sufficient challenges to occupy us more than full time. If we knew the size of the 
foster-care student population, particularly in OUS institutions, we would be better able to evaluate the emphasis they should be provided. Are you able to furnish that number?

This research study sought to inform these gaps in knowledge by examining the experiences of foster alumni who transition into community college. The purpose of the research was two-fold. The first purpose was to identify the demographic profile of students who are foster alumni and the kinds of institutions they attend. The second purpose was to explore the experiences foster alumni encounter and the factors that facilitated their success as they transitioned. By becoming aware of and better understanding this group of students, student affairs and academic affairs professionals in colleges and universities can better serve youth from foster care backgrounds.

\section{Foster Care in the United States}

Foster care is designed to help children and youth who have experienced maltreatment, abuse, or neglect by providing them a safe environment in which to live. Children and youth may be taken from their families and placed in foster homes with people who are not relatives, group homes, residential-care facilities, or in kinship care with other family members. In the best possible outcomes, children and youth are reunited with their families, or placed in a permanent home situation that is safe and loving. For many children and youth, the experience of living in foster care can have negative outcomes that may impact them for years to come.

Children and youth in foster care come from all racial and ethnic backgrounds, yet a disproportionate number of them are African American, Latino/a, and Native American/Alaskan Native (R.B. Hill, 2001, 2007). The reasons for this disproportionality, however, remains unclear (Pecora et al., 2010). 


\section{Benefits of Higher Education for Foster Alumni}

People who obtain college educations are advantaged over those who do not in several ways (Pascarella \& Terenzini, 2005). For former foster youth, the advantage may be particularly acute. Higher education may provide an opportunity for youth from foster care backgrounds to create a more stable future. Post-secondary education can facilitate a transition to a future in the mainstream and away from the fringes of society. Individual benefits include higher earnings for all racial groups and for men and women. The income gap between college graduates and those who do not graduate from college is significant and increasing; and any college experience creates a measurable financial benefit (Baum, et al., 2010).

A male college graduate in 1979 earned $49 \%$ more than a male high school graduate, and, almost two decades later, that earnings advantage was $83 \%$ (Tierney, 1992). Pascarella and Terenzini (2005) referred to the occupational status gained by having a college degree as a "bonus" that confers prestige over the work lifetime (p. 447). As Pascarella and Terenzini noted, "the significant occupational status differences between high school and college graduates were sustained over the occupational life span" (2005, p. 447). A bachelor's degree prepares students for management, technical, or professional occupations, which are less likely than other occupations to fluctuate with the economy (Pascarella \& Terenzini, 2005). Positions in occupations afforded by a college degree typically have good remuneration and benefits, including health care. Given that manufacturing jobs in the United States, which once provided living-wage jobs for high school graduates, are becoming increasingly rare, the skills earned from higher education are vital for individual long-term economic and social success. 
Nonfinancial Rewards of Higher Education

Along with the financial benefits that come with graduating from higher education, graduates gain other rewards. College graduates have lower smoking rates, more positive personal health, and lower incarceration rates than those who did not graduate (Baum, Ma \& Payea, 2010). According to a report from the Institute of Higher Education, college graduates save more money, and enjoy greater career mobility, and leisure time (1998). The benefits of college education pass on to future generations (Rowley \& Hurtado, 2002).

Although a college education can positively affect the personal, social, and economic well-being of individual foster alumni who face great challenges in moving into mainstream society, a public good also derives from foster alumni attaining a college degree. One study revealed, for example, that college graduates volunteered more often and were more civically responsible than were peers who did not graduate (Baum \& Payea, 2005). Higher education is associated with lower levels of unemployment and poverty, leading to larger tax revenue and decreases in usage of social services (Baum et al., 2010).

\section{College Completion Agenda}

For many years, the focus of policy makers, educators, and government were on outcomes in K-12 education. Recently, that focus shifted to focusing on post-secondary education and specifically low graduation rates. In the United States, higher education graduation rates have remained at the same level for decades. According to Complete College America, only 19\% of students seeking bachelor's degrees complete their degrees on time and only $5 \%$ of students seeking associate degrees complete on time. 
Rising tuition costs mean students who remain in higher education for extended periods are increasing their debt loads and losing time in the workforce.

For students who access higher education through community colleges, the completion numbers are grim. According to Alstadt, Schmidt and Couturier (2014), 80\% of community college students plan to obtain a bachelor's degree, yet the reality is that only 1 in 10 complete the degree in 6 years. The National Center for Education Statistics (2010) found that transfer students seeking a Bachelor of Arts degree take an additional 1.2 years to complete their degree than students who begin their education at a four-year institution. Some of this may be due to students taking remedial coursework, as $56 \%$ of community college students take developmental coursework (Complete College America, 2016). Additional time to graduation for all students results in lost opportunity costs including increased debt, lost job promotions, and loss of retirement earnings.

Several organizations have focused their resources and outreach on degree attainment. These include the Bill and Melinda Gates Foundation (2008), which aims to double post-secondary completion by low-income students. The Lumina Foundation for Education's (2017, p. 1) goal is to “increase the percentage of Americans with highquality degrees and credentials from the enduring rate of $39 \%$ to $60 \%$ by the year $2025 . "$ The College Board (2011) is also working toward a 2025 goal of increasing the numbers of adults with college credentials from $39 \%$ to $55 \%$. These initiatives and others around the nation focus on supporting and promoting degree attainment, especially among students who have been traditionally underserved, such as students from lower socioeconomic backgrounds, immigrants, first-generation, and under-represented minorities. These organizations can use vast resources to consider issues impacting degree 
attainment in a new light. They can also offer suggestions for improved practice to administrators in higher education.

The national focus has shifted from $\mathrm{K}-12$ and is now on higher education and how to ensure students complete college credentials, certificates, associate's degrees, and bachelor's degrees. Many legislators are examining performance-based funding as an initiative to force post-secondary institutions to consider their practices and policies. One issue with performance-based funding is that it is largely untried, and results are limited. At this juncture in higher education history, it is unclear whether performance-based funding actually improves student-completion rates (Dougherty et al., 2014; Friedel, Thornton, D'Amico, \& Katsinas, 2013). However, the focus on students who have traditionally not been well served by higher education could benefit current and former foster youth.

During President Obama's tenure in office, the president placed higher education access and affordability as top agenda items in the last few years. Speaking at the University of Buffalo on August 22, 2013, he stated,

I think we should rate colleges based on opportunity. Are they helping students from all kinds of backgrounds succeed? How much debt does the average student leave with? How easy it is to pay off? How many students graduate on time? How well do those graduates do in the workforce? Because the answers will help parents and students figure out how much value a college truly offers.

With the completion agenda and performance-based funding initiated across the country, the national spotlight is on higher education. Institutions no longer can assume students who do not graduate are at fault; instead, institutions must consider what they do to support student outcomes. 


\section{Educated Work Force}

Carnevale, Smith, and Strohl (2010) found that, by 2018, 63\% of job openings in the United States will require some post-secondary education. President Obama (2010) directly linked the benefits of education and the effect an educated workforce has on the economy:

I want us to produce 8 million more college graduates by 2020, because America has to have the highest share of graduates compared to every other nation. ... In a single generation, we've fallen from first place to 12 th place in college graduation rates for young adults. It is an economic issue when the unemployment rate for folks who've never gone to college is almost double what it is for those who have gone to college. Education is an economic issue when nearly 8 in 10 new jobs will require workforce training or higher education by the end of this decade.

According to the Lumina Foundation (2017), "the percent of the American population with a postsecondary credential or degree has remained flat for 40 years" (p. 2). In the current competitive global marketplace, it is imperative that the United States develop a knowledge economy and a highly educated work force. If the United States does not improve its college-graduation rates, the country risks losing its competitive edge in the world economy. The situation of former foster youth, therefore, is not only about preparing individuals to succeed; it is also about ensuring the economic success and viability of the nation. Foster youth represent largely untapped potential to contribute to the United States skilled workforce.

\section{Foster Alumni in Higher Education}

One of the predictors for foster alumni continuing to post-secondary education is the educational level of the foster parents. If the foster parent(s) values the benefits of higher education, the chances increase that the foster parent(s) will inspire and help the foster child navigate into higher education. A national survey by Child and Adolescent 
Well-Being Research Group (2001) found that 56\% of foster homes were run by people with a high school degree or less. Low expectations for success in education limit opportunities for foster youth to attend and succeed in college (Wolanin, 2005). Youth in foster care who are not exposed to higher education may miss out on an opportunity that can provide them with stable and productive futures.

Even when foster youth attend college, they face additional barriers to persistence. Foster youth who graduate from high school and have been accepted into college often find themselves homeless as they wait for the fall term to commence (Davis, 2009; Troop, 2012). This happens again during university breaks when residence halls close and foster alumni are once again homeless (Lovitt \& Emerson, 2008; Pecora et al., 2010). Many institutions pride themselves on their "parent" programs, without recognizing that foster alumni may not have parents or families to order them gift boxes or to invite to special weekends (Foster Care to Success, 2012).

Foster youth struggle financially and may not be aware of resources available to them to pay for higher education such as state tuition waivers and Federal Financial Aid and Chafee grants, a federal program that awards $\$ 5,000$ a year for post-secondary education for former foster youth (Draeger, 2007). Foster alumni may not opt to selfidentify their foster youth status on financial aid documents and may struggle to complete the complex forms. Federal financial aid and the Chafee grants program have strict application dates, and foster youth who miss those dates are not able to access those funds. Financial aid officers can, however, connect foster alumni to financial resources that can help them in pursuit of their college education (Draeger, 2007). 
Community Colleges as the Gateway to Higher Education

Community colleges have traditionally served as entry points for underrepresented populations. As Rendón (1992) noted, Mexican-American, firstgeneration college students, did not enter higher education through the front door; instead the access point is a community college. Provasnik and Planty (2008) found that community colleges serve as gateway institutions to a bachelor's degree, especially for students who have been historically underrepresented in obtaining bachelor's degrees.

Community colleges offer students an opportunity to take remedial courses or complete their high school diploma, if necessary (Cho \& Karp, 2013). Students view their course instructors positively in a community college setting (Davies \& Casey, 1999; Gawley \& McGowan, 2006; Vaala, 1991). Students also feel they have more interactions with their community college professors (Davies \& Casey, 1999; Vaala, 1991). In addition, student services at community colleges tend to be friendly and welcoming, making for much support for students (Allen, Smith, \& Muehleck, 2014). The very welcoming nature of community colleges means foster youth may feel a sense of belonging. Community colleges offer coursework at various times including evenings and early mornings, allowing foster alumni flexible class schedules and the ability to maintain jobs. Community colleges also have developmental coursework available for students, allowing them to increase their skills and knowledge in subject areas where they may be academically underprepared. Services for students with disabilities are also available to offer support and accommodations. 
Conceptual Framework of Transitions and Cultural Capital

For foster alumni, going to college involves transitions into the world of higher education. The transitions begin at high school graduation when some foster youth suddenly find themselves emancipated from the foster care system and homeless. Transitions continue through beginning at a community college and then moving on to a four-year university. However, little is known about the transitions foster youth experience through higher education. I used Schlossberg's (1981) transition theory and revised theory (Schlossberg, Waters, \& Goodman, 1995) as part of the conceptual framework for this study, which focused on the transitions foster alumni face. Perhaps more than any other underrepresented group, foster youth struggle with higher education degree attainment. Moreover, students who feel marginalized tend to believe they do not matter (Schlossberg, 1981).

Schlossberg (1981) first posited a model on transitions, based on the work of multiple theorists. At the time, the author considered the complexities involved for adults transitioning. Schlossberg (1981) believed that it was not so much the actual transition, identified as an "event or nonevent" that mattered; rather, how the person interpreted the transition based on "perception of self and of the world" (p. 15) that mattered. Three sets of factors influence transition: (a) characteristics of the transition; (b) pre- and posttransition supports; and (c) characteristics of the individual (p. 15). Schlossberg, et al. (1995) revised the model into a theory that focused on the four S's: situation, self, support, and strategies that help people successfully transition through life events. Schlossberg (1981) asserted that having strong supports during periods of transition helps people through the process. 
Along with Schlossberg (1981), the conceptual framework rests on the role social and cultural capital play in the pursuit of higher education by foster alumni. This includes the broader framework of Bourdieu's work on cultural capital, which is educational (1979), and social capital refers to social networks that can be converted to economic benefits (1986). The accumulation of social and cultural capital provides benefits to individuals. Seita (2001) explored this concept further, describing "family privilege," which references the hidden benefits an individual acquires simply from belonging to a family. Many foster youth lack family privilege. Because this study specifically considered the transitional experiences foster youth face in accessing higher education, social and cultural capital must be considered in the framework.

Underpinning this conceptualization is the role that academic advising may play in supporting foster alumni through the transitions, and, helping them navigate the pathways to degree completion. All students have access to academic advising (Habley, 2004), and the process of advising is one of the most important factors for student success (Kuh, 1997; Light, 2001; Lowenstein, 2005). Academic advising can serve as a resource, such that advisors are institutional agents who can guide and mentor foster alumni through the college experience (Bensimon, 2007; Stanton-Salazar \& Dornbusch, 1995).

\section{Statement of the Research Problem}

Degree attainment for foster alumni is exceptionally low and deeply concerning, given that foster youth frequently emancipate from state care at the age of 18 and must be solely responsible for themselves. Only $2 \%$ of foster youth remain in care after age 18 (U.S. Department of Health and Human Services, 2011), although many states now extend care beyond age 18 (Dworsky \& Havlicek, 2009). To date, much of the research 
conducted on foster youth has focused on the negative effects of being in care. Two longitudinal studies, the Midwest Study (Courtney, Dworsky, Lee \& Raap, 2009) and the Northwest Foster Care Alumni study (Pecora et al., 2010), followed youth for a number of years after emancipation to see foster youth transitions out of care. Little research describes foster youth persistence through higher education. Although studies showed the lack of degree attainment among foster alumni, few studies explain why some foster alumni successfully complete their degrees and others withdraw from higher education. Little is known about the transitions experienced by foster alumni in higher education, especially at institutions that do not have targeted programs and services for youth from foster care backgrounds.

\section{Purpose of the Research}

The study reported here explored the experiences of foster alumni transitioning into and through higher education. The study involved looking at quantitative and qualitative data collected in Oregon to understand the transitions experienced by foster alumni in higher education. Currently, a paucity of descriptive data exists on the experiences of foster youth pursuing a higher education degree in Oregon. Who are foster youth in Oregon higher education institutions? How do foster youth experience higher education? How many are in higher education? Do foster alumni face issues in higher education that are unique to having been in the foster care system? What role, if any, does academic advising play in helping foster alumni persist? The results inform the field and present the voices of foster alumni transitions. 
Significance of the Research

Findings from this research project have implications for the development of support services targeting foster alumni. Multiple audiences may benefit from this research. As a result, student support services may be developed to better support degree aspirations of foster alumni. The academic advising community could be made aware of issues surrounding their role in supporting foster alumni. Because academic advising is a field of specialization and requires advisors to have expertise in working with students from a variety of backgrounds, learning about the issues former foster youth experience is important for advisor training and development.

Higher education professionals have largely ignored issues surrounding foster alumni and the experiences and barriers to academic success they face. This study presents an opportunity for educators, regardless of discipline, to recognize these issues, which may in turn lead them to support promising students who are academically at risk. In addition, state and federal agencies that work with foster youth will be able to access research in determining additional and ongoing support for foster alumni. Finally, the numerous non-profit agencies that work with and provide advocacy for foster alumni will be able to access information that may provide the impetus for collaborative partnerships with institutions to develop programming or professional development for advisors working with foster alumni.

\section{Research Methodology and Questions}

The overarching research question for this study was, "What are the experiences of foster youth who enter higher education through community college as they navigate transitions into and through post-secondary education." Several sub-questions guided the 
study including "What is the demographic profile of foster youth in higher education in Oregon?"

Quantitative Questions:

RQ1. How many current and former foster youth self-identify as such in Oregon higher education in 2010 and 2011 ?

RQ2. What are the gateway higher education institutions in Oregon higher education?

RQ3. What is the percentage of current and former foster youth who selfidentify per institution?

RQ4. What types of institutions are foster youth most likely to attend?

Qualitative Questions:

RQ5. What strategies do foster youth employ to successfully navigate toward degree attainment?

RQ6. What services and resources do foster youth use at the Community College for academic and personal support?

RQ7. What role does academic advising play, if any, in the transitions of foster youth through higher education?

RQ8. Are foster youth connected to an academic advisor and working with them towards either degree completion or transfer to a four-year institution?

RQ9. Are there identifiable patterns of transitions, which foster youth experience in higher education?

To grasp foster youth experiences, the methodological approach in the present study included using two independent sources: I employed survey data from the Oregon Advising Research Consortium to answer the first four questions, and interview data from foster youth in Oregon to answer the last five questions to understand foster alumni experiences. I used grounded theory to analyze the qualitative data gathered through inperson interviews. 
The research design involved using data collected through the Advising Research Consortium, a partnership of nine higher education institutions in Oregon led by Professors Allen and Smith. Leaders at these institutions surveyed students and faculty at 2- and 4-year, public and private higher education institutions in Oregon to ascertain student and faculty attitudes about and experiences with academic advising. The researchers included a question on the survey about whether participants were foster youth to provide data on foster alumni on Oregon campuses. Important caveats relating to RQ1 and RQ3 were that not all current and former foster youth would be expected to have completed the advising survey. Since these surveys provided demographic and descriptive data about self-identified students from foster care in Oregon higher education for analysis; the data were likely incomplete because some current and former foster youth may have decided to not self-identify as former or current foster youth. The decision by foster youth to choose not to self-identify on the surveys, which must be seen as a limitation in this research. Accurate numbers are therefore unattainable, but given the numbers that did self-identify, it is safe to posit that the true numbers are several points higher than shown.

The second part of the research design consisted of two-, in--person interviews with five former foster youth. Participants were currently enrolled in, stopped out of, or were about to begin attending a community college. Stopped out refers to a student not currently enrolled for the academic term, but with the intention to return to the institution. Students were in their first or second year of attendance and planned to transfer to a fouryear institution to get a baccalaureate degree. 
I used grounded theory to analyze the interview data. Strauss and Corbin (1998) stated that grounded theory means "theory that was derived from data, systematically gathered, and analyzed through the research process" (p. 12). Grounded theory does not begin with set ideas, but instead allows the theory to come from the data (Strauss \& Corbin, 1998). For foster alumni who are a silent, unacknowledged minority in higher education, the use of grounded theory gives them a voice to explain their experiences.

In this study, I sought to examine the transitional experiences of foster youth who began their post-secondary education at a community college. I had two main aims for the study. The first aim was to identify the demographic profile of foster alumni and the institutions they chose as the gateways to pursue higher education. The second aim was to identify barriers foster alumni encountered and the factors that facilitated successful transitions into and through higher education.

\section{Definition of Key Terms}

Here, I identify and define the terms, used throughout this paper:

- Foster youth refers to a young person who is currently or has been in the foster care system.

- Foster alumni are people who had been in the foster care system but are no longer in the system.

- Emancipation or aging out refers to leaving the foster care system at age 18 or 21 years. At that age, the state terminates all responsibility toward the young person and the young person is fully responsible for himself or herself.

- Reunification refers to the initial goal of Child Welfare Services, which is to administer support to the family with the aim of reuniting the child/youth with their family.

- Kinship care refers to a child or youth being placed into care with a family member rather than a stranger. This type of care is preferable because they maintain family bonds and cultural identities. 
- Transitions refers to the student's ability to move through changing personal, social, and academic situations.

- Persistence refers to a student's ability to work toward their goal of higher education degree attainment.

- Academic advising refers to the process of a professional or faculty advisor helping a college student identify their educational and career goals and navigate the college or university system to persist toward degree attainment.

\section{Chapter Summary}

This chapter included a discussion of the lack of higher education degree attainment for young people who have been in the foster care system. Foster alumni typically come into higher education with multiple risk factors including educational deficits (Calvin, TeamChild, \& Casey Family Programs 2000; Courtney, Terao, \& Bost, 2004; Pecora et. al., 2010), mental health issues (Courtney et al., 2004; Pecora et al., 2010), low expectations (Krebs \& Pitcoff, 2004; Wolanin, 2005), first-generation status, and lower economic status (Wolanin, 2005). These multiple risk factors can act as barriers to impede their ability to persist toward successful degree attainment.

At the same time, higher education professionals are often ignorant of the needs and issues youth from foster care backgrounds bring to campus, which results in few services directed to help this vulnerable group of students. Although foster alumni have risk factors, they also have great promise, having survived childhoods filled with uncertainty. Every day, young people across the United States age out and leave the foster care system. The clear majority of foster youth who emancipate from the foster care system want to go to college, but few actually persist to graduation (Courtney et al., 2004; Pecora et al., 2010; Wolanin, 2005). Why this discrepancy occurs is not well understood. Using grounded theory to analyze their interviews gives voice to their 
experiences. The next chapter provides a focus on a literature review examining foster care, student-development theory, Schlossberg's (1981) theory of transition, Bourdieu's cultural capital, and academic advising theory. 
When you are in foster care, pretty much your life doesn't matter.

You are the bottom of the barrel.

-Oregon foster alum, 2011

\section{Chapter 2: Literature Review}

In this chapter, I begin with a brief history of foster care in the United States, including the experiences and outcomes of children and youth in care. I then review the literature on the barriers former foster youth face in accessing and persisting in higher education, which includes lack of support from state care to independence, housing, low expectations, lack of knowledge about college, and multiple risk factors that impact student success. From there, I explore the role community colleges serve in educating students, followed by the lack of awareness educators have on issues foster youth experience, which renders former foster youth on college campuses largely invisible and underserved. Finally, I lay out the theoretical models on student success that helped frame this study of former foster youth, including work by Schlossberg, Bourdieu, and Tinto.

\section{Brief History of Foster Care}

The situation of children and youth without families has often meant difficult lives rooted in daily survival. During the 17 th and 18 th centuries, children and youth who found themselves alone in the world had to survive on their own or were indentured to a family. Once the children and youth completed their indentured service, they were free to move on, but at least for the time of their service, they had food, clothing, and shelter. Orphanages were used to house children until children could be indentured or sent out on their own to find work. 
In the 19th Century, Charles Loring Brace developed the concept of orphan trains to relocate children without families to the Midwest, West, Canada, and Mexico (The Adoption History Project, n.d.). Some children were taken in to be members of a family, and others endured yet another form of indentured servitude, often being used as a form of free and inexpensive labor rather than being adopted into a family. The orphan trains continued until the 1930s. Orphanages later fell out of popularity as a way to best serve children and youth without families, or whose families could no longer take care of them, and foster care numbers rose.

In 2016 , the foster-care system housed 437,465 children and youth, with 17,394 youth aging out of foster care (U.S Department of Health and Human Services, 2017). The child-welfare system is a complex structure that is often a confusing and convoluted process for everyone involved including judges, social workers, families, foster parents, and most importantly, children and youth caught in the system. Between 1998 and 2005, 160,000 foster youth emancipated from care (Wolanin, 2005). Each number represents a life of potential, but also a life that comes with many risk factors for pursuing and persisting through higher education.

In October 2008, President Bush signed the Fostering Connection to Success and Increasing Adoptions Act (H.R. 6893) into law. The law promoted permanent families through adoption or kinship/guardianship. Most importantly, the law extended federal support, specifically Title IV-E, for youth in care to 21 years of age. States were inconsistent in meeting this new policy. For many foster youth, the message they received was that they needed to emancipate from foster care at the age of 18 . Beginning in October 2010, the Fostering Connections to Success and Increasing Adoptions Act 
extended eligibility again to the age of 21 to remind states of their responsibility to foster youth. Foster youth must have a plan in place 3 months prior to departure from the system to show they are ready for independent living. As more states are beginning to extend foster care to age 21 , other states are allowing former foster youth to reenter care if they exited at 18 and are struggling to find their way. Providing foster care beyond the age of 18 gives foster youth more stability and time to launch themselves into the world.

Another law that benefits foster youth is the Preventing Sex Trafficking and Strengthening Families Act of 2014, signed into law by President Obama on September 29, 2014. The law aims to improve the situations of children and youth in care and promotes that youth in care be involved in activities that are age and developmentally appropriate. The law also requires states to include youth, starting at the age of 14 , in transitional planning into adulthood. Perhaps one of the most beneficial parts of this law is that it requires states to provide emancipating foster youth with copies of essential documents including their birth certificates, Social Security cards, copies of their medical records, and health insurance information, along with a state identification or driver's license card. Too often, foster youth leaving care do not have these documents, which makes it difficult for them to apply for jobs, complete college-admissions applications, and apply for federal student aid.

\section{Foster Care Experiences and Outcomes}

The experiences of and outcomes for children and youth in foster care can be dismal. Foster care exists to safeguard the lives of children and youth whom the state deems are in serious danger of neglect, abuse, or maltreatment. Separation from family of origin is traumatic for children and youth. Over the past few years, the goal of foster care 
has been to get the family into programming or treatment to address issues aimed at reuniting a child with his/her family. Many biological families want to keep their children with them but may face difficult circumstances; sometimes no services or supports are in place to help families. In cases where reunification is not possible, case workers attempt to place children with family members, known as kinship care. The child or youth, while still being fostered, is in care with a family member, thereby continuing the connection to family, but also aiding in cultural, ethnic, and racial identity. When reunification is not an option, permanency planning to find the child or youth a suitable long-time home is the next step. Ideally, the best option is adoption, but in many instances, families do not sign the paperwork to allow their children to be adopted, thereby placing the child or youth in foster limbo. In many other instances, suitable permanent homes are not found, especially for older foster youth.

\section{Multiple Placements}

Children and youth in care often move from foster home to foster home; a phenomenon referenced as foster care drift (Usher, Randolph, \& Gogan, 1999). Changing foster homes causes foster youth disruption in schooling and loss of relationships (Pecora et al., 2010) and a sense of confusion (Festinger, 1983). Multiple placements caused foster children and youth to experience increased behavior problems (Newton, Litrownik, \& Landsverk, 2000).

Multiple placements negatively impact a child's ability to attach to caregivers, which is believed to be essential for future development (Wulczyn, Kogan, \& Harden, 2003). The reasons for multiple placements are myriad, but for the children and youth involved, the lack of stability and any form of control over their lives must be frightening 
and disorienting. Thus, it does not come as a shock to note that Pecora et al. (2003b) found, in a study with foster alumni, that fewer placements equaled greater success.

\section{Educational Results}

Multiple home placements can lead to multiple school placements, also known as school mobility. The Northwest Alumni study found that $65 \%$ of foster alumni had seven or more school changes (Pecora et al., 2003, p. 26). The Midwest study reported that more than a third of foster youth had experienced five or more changes while in care (Courtney et al., 2004).

Frequent foster care drift can cause school instability and absences. On average, a child needs between 4 and 6 months to recover from a school change. These multiple school changes can be particularly detrimental to academic progress of foster children/youth (Calvin et al., 2000). Drift frequently results in lost school paperwork, causing foster children/youth to miss additional days of school (Choice et al. 2001; Christian, 2003). Research conducted in the Northwest Alumni Study (Pecora et al., 2010 ) found that $30.2 \%$ of foster alumni experienced a high number-10 or moreschool changes while in foster care.

Youth in foster care who had completed the 10th and 11th grades were only reading at a 7 th grade level (Courtney et al., 2004). Findings from the Northwest Foster Care Alumni Study (Pecora et al., 2010), which surveyed 659 foster care alumni, showed that, relative to youth who were not in foster care, foster youth were twice as likely to drop out of high school (37\% vs. 16\%), were less likely to be enrolled in collegepreparatory classes (15\% vs. $32 \%)$, and were frequently academically behind their peers in terms of their academic development by at least one grade level. 
Research also reveals that a disproportionate number of foster youth are placed in special-education services, including those who have not been shown to need the services (Courtney et al., 2004). Yu, Day, and Williams (2002) reported that 30\% to $41 \%$ of foster children receive special-education services. More recent research by Hill (2012) showed that $60 \%$ were diagnosed with a disability. Educational achievement for youth in care who receive special-education services is lower than for youth in foster care only or youth in special-education only (Geenen \& Powers, 2006). Many children in care need tutoring to reach developmentally appropriate levels academically due to frequently changing schools. Instead, however, they have been tracked into special education and, once there, labeled and rarely transitioned back to mainstream education. Foster youth also face higher rates of expulsion and suspension compared to non-foster youth (Smithgall, Gladden, Howard, Goerge, \& Courtney, 2004). The Midwest Study found that $67 \%$ of foster youth had been suspended at least once, compared to $28 \%$ of nonfoster youth (Courtney et al., 2004).

Not surprisingly, high school graduation rates for foster youth are not comparable to their age peers. Festinger's (1983) study of 277 foster alumni in New York found only $65 \%$ graduated, whereas Blome's (1997) longitudinal national study of 167 foster youth showed that only $77 \%$ of foster youth graduated from high school. The Midwest Study showed $58 \%$ of foster youth at age 19 had a high school degree compared to $87 \%$ of peers who were not in foster care (Courtney et al., 2005). Wolanin (2005) compared nine independent studies and estimated that foster youth graduated at 50\% compared to $70 \%$ of youth not in foster care. A consistent theme in much of the literature is the need for advocates, educational supports, and awareness by individuals working with foster youth 
(Casey Family Programs Services, 2008; Wolanin, 2005). Ignorance on the part of advocates, education professionals, and others who work with foster youth can negatively affect educational outcomes (Seyfried, Pecora, Downs, Levine, \& Emerson, 2000).

\section{Mental Health Issues}

Foster alumni have a disproportionate number of mental health disorders. These mental health difficulties can stem from maltreatment from their biological families. Findings from the Northwest Foster Care Alumni Study show 54.4\% of former foster youth had experienced one or more mental health disorders (Pecora et al., 2010, p. 110). Just over $20 \%$ of foster alumni had experienced major depression, and $17 \%$ suffered from a social phobia (Pecora et al., 2010, p. 110). The Northwest study also found that $25.2 \%$ of foster alums suffered from posttraumatic stress disorder; a percentage almost double that of United States war veterans (Hoge et al., 2004; Kulka, Fairbank, Jordan, \& Weiss, 1990). Unfortunately, 33\% of the foster alums in the Northwest Foster Care Alumni Study had no health insurance to assist with the cost of treatment. A history of child abuse indicates less chance of staying enrolled in college and the rates of drop-out begin in the first term of study, whereas the largest attrition occurs in the freshmen to sophomore year (Duncan, 2000). The types of abuse played a role in foster youth attrition; foster alumni who had experienced sexual abuse or multiple types of abuse were more likely to drop-out of college compared to other students (p. 993). Conversely, Banyard and Cantor (2004) found that for young people who have experienced trauma, the act of going to college might result in a decision to address their personal trauma. 


\section{Social Issues}

The process of developing from childhood to adulthood can be difficult for all young people. However, the transition into adulthood can be even more difficult for foster youth. Children and youth who grow up in dysfunctional homes and who do not have the opportunity to bond with loving adults may feel they are at fault for the family dysfunction and are unlovable (Bowlby, 1982).

Foster youth can lack family privilege, a notion loosely based on the concept of White privilege, developed by McIntosh (1988) and defined as "the benefits, mostly invisible, that come from membership in a stable family" (Seita, 2001, p. 131). In a family, parents "who provide consistent affection and discipline foster the development of family privilege. [Family privilege is a] package of assets and pathways that provides us with a sense of belonging" (Seita, 2001, p. 131). Family privilege gives children security, stability, social skills, and insider knowledge about how to behave and navigate in the world, but it is mostly invisible unless one grows up without it (Seita, 2005). Perhaps more importantly, "family privilege provides the chance to hope and to dream" (Seita, 2005, p. 81).

Schultz (1961) used the term human capital to describe the social and educational opportunities accumulated over generations which further problem solving and high-level communication skills within families. Seita (2005) stated that "family privilege is a currency of human capital that compounds its benefits over time" (p. 81). However, stressors within a family unit can diminish the benefits of family privilege.

The social networks many young people take for granted are often unavailable for foster youth. The Pew Charitable Trust (2007) found that 24,000 youth emancipated from 
foster care at 18 years of age without a family which was a 41\% increase from 1998 (p. 1). Foster youth will have spent approximately 5 years in care by the time they age out without ever having been placed in a permanent family (The Pew Charitable Trust, 2007). This leaves foster alumni with fragmented social networks, especially when one considers that most adults foster alumni encounter prior to emancipation are paid to be in their lives.

Female foster youth have higher rates of pregnancy. The Midwest Study found $71 \%$ of female foster alumni had been pregnant by the time they reached 21 years of age while the national rate was $34 \%$ (Courtney et al., 2007, p. 50). The study also found that $62 \%$ of the pregnancies of former female foster youth were repeat pregnancies (Courtney et al., 2007, p. 50).

Foster alumni also face higher rates of incarceration compared to their non-foster youth peers. The Midwest Study found that within 2 years of leaving foster care, one in four foster alumni were in prison (Courtney et al., 2005). The U.S. Department and Health and Human Services (2008) reported that almost 30\% of former foster youth had been incarcerated.

\section{Economic Issues}

Many foster alumni struggle financially upon emancipation from foster care. The Northwest Study found that $33 \%$ of foster alumni lived at or below the poverty line (Pecora et al., 2005). Only 51.9\% of youth in the Midwest Study had a checking or savings account and only 39.1\% owned a vehicle (Courtney et al., 2007). In addition, $26.5 \%$ struggled to pay rent and utility bills and a portion of the young adults also had 
outstanding debts. This included data showing that "two-fifths (=226) reported having 'other' debt, excluding student, auto, and real estate loans" (Courtney et al, 2007, p. 37).

Food insecurity was another sign of financial struggle for foster alumni. The Midwest Study (Courtney et al., 2007) found that foster alumni reported "getting food or borrowing money for food from family or friends" (p. 37). One-quarter of former foster youth had "low to very low food insecurity" (Courtney et al., 2007, p. 38). Establishing financial security takes time and many foster alumni have no resources to call upon when they encounter a financial emergency in the first years after leaving care.

\section{Barriers to Access and Persistence for Foster Alumni Seeking Higher Education}

As shown in the literature, the documented outcomes for children and youth in foster care who age out of the system are dismal. Many foster youth want to attend college. Indeed, foster youth perceive higher education as a path to economic and personal security. Foster youth perceived higher education "as a way of ensuring stability, in terms of food, clothing and shelter" (Hines, Merdinger, \& Wyatt, 2005, p. 387). Although foster youth want to attend college, they are less likely than their peers to do so. Of the 21-year-old foster alumni in the Midwest Study, 30\% completed some college compared to $53 \%$ of 21 -year-old youth nationally (Courtney et al., 2007, p. 26). The Northwest Foster Care Alumni study reported only 1.8\% of former foster youth received a bachelor's degree compared with $24 \%$ of the general youth population (Pecora et al., 2005, p. 36). The completion rate for older foster alumni, 25 years and older, was slightly higher at 2.7\% (Pecora et al., 2010, p. 125).

The United States has about 300,000 foster alumni between 18 and 25 years of age (Wolanin, 2005). Of that group, 150,000 are eligible for college as they have 
graduated from high school, yet only about 30,000 are in higher education (Wolanin, 2005). Foster youth aspire to higher education, yet of those who attend, few persist to graduation. The college drop-out rate is high among foster youth, yet perhaps more than any other resource, higher education degree attainment can offer foster youth a pathway into a life with better economic security. The barriers to accessing and persisting through higher education begin the moment a child is first maltreated and continue throughout the time he or she is in care. Given the percentages of foster alumni with mental health issues, and those who are incarcerated, live in poverty, and struggle daily to make lives for themselves, foster alumni face a host of barriers before they begin the process of attempting post-secondary education.

\section{Transition from State Care to Independence}

For many foster youth, the goal of the foster care system becomes to emancipate them rather than find them permanent homes. In federal year 2005, 69,000 foster youth were poised for emancipation from long-term foster care (U.S. Department of Health and Human Services, 2006). For these young people, a permanent home was no longer an option; instead, exiting the system was their impending reality. The Children's Advocacy Institute (2007) found that parents spend, on average, $\$ 44,500$ on their children after they reach 18 years of age and that, on average, young people do not attain self-sufficiency until the age of 26. Financial and familial support helps young people establish themselves. Foster alumni have no parental or financial safety net to help them navigate the first years of independence. Foster alumni often do not have access to help with guidance on life decisions, financial support in times when funds are short, or the emotional support to help them through trying times (The Pew Charitable Trust, 2007). 
Most young people have parental support to help them transition from high school to post-secondary education and until they are able to support themselves. Psychologist Arnett (2000) proposed a new developmental life stage called emerging adulthood. Specifically, Arnett suggested, "emerging adulthood is a distinct period" beginning in the late teens and continuing through the 20s (p. 469). As Arnett noted, "sweeping demographic shifts" make this period of time between 18 and 25 years of age a defined life stage (p. 469). The age for marrying has increased along with parenthood. Emerging adults are in a stage to discover "possible life directions" (Arnett, 2000, p. 469). Arnett noted that "college education is often pursued in a nonlinear way, frequently combined with work, and punctuated by periods of nonattendance" (p. 471). It is important to note this stage of emerging adulthood because in the situation of foster youth, states deem they are adults at much earlier ages and emancipate them from state care. Whereas one population continues to rely on parental support to help them through this developmental stage, another population — foster youth — is regarded by states as being adults. Thus, the social milieu for foster youth is vastly different from their peers who are not in foster care.

Youth in foster care who are emancipated at age 18 or later at age 21 are suddenly thrust into the world without support through emerging adulthood. Emerging adults are caught between adolescence and adulthood, feeling neither completely one nor the other (Arnett, 2000). Yet, youth experiencing emerging adulthood typically have families to support them as they make the transition from adolescence to adulthood, whereas foster alumni frequently do not have such supports and must be completely responsible for their own lives. 


\section{Housing Instability}

Often, foster youth graduate from high school and find themselves homeless the next day, as the state ends their foster care. As one foster youth in the Pew Charitable Trust Study (2007) put it, “The day after graduation, I was kicked out of my foster home, where I had been living for two years. I was 18 , a high school graduate on my way to college in the fall, and I was homeless" (p. 1). Maltreated foster alumni who emancipated from foster care face periods of homelessness (Courtney et al., 2007; Pecora et al., 2010). In a survey of 659 former foster youth, 22\% had been homeless (Pecora et al., 2005). One-third of former foster youth "had lived in at least three different places, including 20 percent who had lived in four or more" (Courtney et al., 2007, p. 15). The need for services that foster alumni can access that provide a safety net of food, shelter, and support when seeking housing and employment is an idea that would counter housing instability (Courtney, Piliavin, Grogan-Kaylor, \& Nesmith, 2001).

\section{Low Expectations for Success and Stigma Related to Foster Care}

Foster youth often face low expectations for academic success (Martin \& Jackson, 2002; Wolanin, 2005). Foster youth often choose not to discuss their time in the care system for fear of how people will respond to them (Hochman, Hochman, \& Miller, 2004). Some former foster youth feel stigma from having been in care (Hines et al., 2005; Unrau, Seita, \& Putney, 2008). Although foster alumni can and do feel stigma for having been in care, Salazar's research (2011) did not find stigma to be significant in school disengagement. This is not to say that stigma does not exist for foster alumni, but rather that foster identity may be hidden, unlike gender or race, which are visible. 
Often, children and youth in foster care feel shame about their situation, as if they have done something wrong and are being punished. In the media, foster alumni are often portrayed with negative stereotypes. The resultant prejudice caused one foster alumni to comment, "I was apprehensive about telling people I was a foster youth, because people shun you" (Foster Student Panel, 2011). Society's negative perceptions of foster youth can lead to additional stress and low educational expectations by society and by foster youth themselves.

\section{Lack of Knowledge about College}

Foster alumni often do not have adults to talk with about going to college; the decision process that requires long-range educational planning and support (Weston \& Cheng, 2007). Frequently foster youth do not feel encouraged to attend college. Foster alumni can and do lack knowledge about financial aid (R. J. Davis, 2006). Former foster youth may not know even the most basic aspects: that there is free financial aid available to attend college (Dworsky \& Pérez, 2010). Students can miss deadlines to complete the Free Application for Federal Student Aid due to lack of information, along with deadlines for applying for the Chafee or Educational Transfer Vouchers (ETV). Although the ETV gives foster alumni up to $\$ 5,000$ a year, based on need, for school and living expenses, foster youth must apply by certain deadlines or miss out on the cycle. Foster youth must also be enrolled in an institution to qualify for the funds. In addition, foster youth must have accessed Chafee funds prior to age 21 in order to keep receiving those funds until age 23 .

Legacy students, those whose families have previously graduated from college, arrive on campus knowing a great deal of insider knowledge regarding how to work and 
succeed in higher education. What information legacy students lack they can readily access from their families. This insider knowledge gives legacy students an advantage over underrepresented and marginalized populations, such as foster alumni.

\section{Multiple Risk Factors}

Multiple risk factors impact student success in college. First-generation, lower socioeconomic status, immigrant status, English-language-learner status, and academic under preparedness can be risk factors for college success or departure. Maxwell (1980) noted that students underprepared for college were "those whose skills, knowledge, and academic ability are significantly below those of the 'typical' student in the college or curriculum in which they are enrolled" (pp. 2-3). However, Maxwell did acknowledge that under preparedness also "depends on the particular institution-its entrance standards, the expectations of its faculty, and the characteristics of its average student" (1980, p. 3). Students have "wide difference in the preparation and skills required for success in different majors" (Maxwell, 1980, p. 3). For students who may not have been prepared for college, made poor school choices, or need remediation, college may offer an opportunity to collect the educational pieces they missed the first time. However, "the strongly motivated, high-achieving student will succeed despite poor teaching and inappropriate materials, but the underprepared student will not" (Maxwell, 1980, p. x).

King (2004) defined at risk students as a diverse group who fall into subgroups. These groups consist of students who: (a) are academically underprepared with poor preparation, low expectations, and academic failure; (b) have individual risk factors, including neurological, cognitive, health or psychological factors; (c) have familial risk factors, including disturbed family functioning, dependent care, family views on 
education, and financial issues; and (d) have social risk factors of conflict between cultural and ethnic values, and stressful social and peer interactions. Keeling (2003) considered that there is One other group of students that should be added to those considered at risk: millennial-generation students. Millennials lack skills in educational planning, which causes them to be more at risk for academic failure.

Tritelli (2003) reported that " $53 \%$ of students entering our colleges and universities are academically underprepared, i.e., lacking basic skills in at least one of the three basic areas of reading, writing or mathematics" (para. 1). Regardless, McCabe (2000) found that students frequently do successfully complete remediation and continue on with their education. However, academic preparedness is only one element of risk factors impacting student persistence and success (King, 2004). Boylan (2001) stated,

Students fail to do well in college for a variety of reasons, and only one of them is lack of academic preparedness. Factors such as personal autonomy, selfconfidence, ability to deal with racism, study behaviors, or social competence have as much or more to do with grades, retention and graduation than how well a student writes or how competent a student is in mathematics. (p. 1)

Horn and Premo (1995) stated that the risk factors for not persisting in higher education include "delayed enrollment, part-time attendance being financially independent, having dependents, being a single parent, working full-time and being a GED recipient" (p. 20). Further, "having more than one risk factor was strongly associated with lower rates of 1-year persistence [and] having two or more risk factors substantially reduced students' chances of attending for a full academic year" (Horn \& Premo, 1995, p. 21). The effect of risk factors is cumulative in that the more risk factors a student has, the less likely they are to persist in college. Horn and Premo's finding of the 
cumulative effects of multiple risk factors is particularly relevant to foster youth for whom possessing multiple risk factors is commonplace.

\section{Risk Factors for Foster Alumni}

In addition to the risk factors explored previously, foster youth also face risk factors related to having been in care. Foster alumni tend to be disproportionally minority students (Harris, Jackson, O’Brien, \& Pecora, 2009); compared to their non-foster youth classmates, foster youth are less likely to enroll in college-preparatory classes (Blome, 1997). According to a study conducted by Day, Dworsky, Fogarty, and Damashek (2011) "college students who have been in foster care continue to lag behind their peers with respect to college retention and graduation, even when compared to low-income, first generation students" (p. 2340). In another study, students from low socioeconomic status backgrounds and who were first-generation students were almost four times more likely to depart (26\% compared to $7 \%$ ) at the end of their freshman year than students without those risk factors (Engle \& Tinto, 2008). Six years later, the graduation completion rate of first-generation low-income students was only $11 \%$ (Engle \& Tinto, 2008, p. 2).

While each one of these risks is significant, combined together they add up to multiple risk factors for foster alumni to overcome in their quest for postsecondary education. Unfortunately, Colleges may address some of these risks through programming or resources but may be unaware that the students are also former foster youth. This lack of knowledge adds an additional layer of risk.

\section{Role of Community Colleges}

For many underrepresented students, community colleges serve as the gateway to the baccalaureate degree. Indeed, because of their open admission policies, low cost, and 
availability of remedial programs and student-support services, community colleges may very well serve as gateway institutions for foster alumni. Community colleges offer a pathway to higher education for traditionally underrepresented students (Provasnik \& Planty, 2008; Rendón, 1992). Community colleges have open-enrollment policies and are often flexible in scheduling, allowing students to access day and evening classes. Many students who begin at community colleges need developmental or remedial work in subjects. There are opportunities at the Community colleges to take the coursework necessary to make up for educational deficits. However, attending a community college also presents a risk factor for not completing a 4-year degree.

\section{Multiple Messages of Community Colleges}

Community colleges have conflicting messages because their student population is diverse in terms of why they are in school. Some students may be completing a high school degree, others may be actively trying to transfer to a 4-year institution, another group is focusing on vocational and technical training and certification, and still another group is merely taking classes for personal enjoyment. Open enrollment, despite making entrance easy, also serves to bring in students who are not overly interested in academic achievement (Dougherty, 1992). Lack of social integration exists as rarely do community colleges have residential housing (Dougherty, 1992).

Due to the multiple roles a community college plays, students may also get conflicting information on transfer policies, and transfer without talking to their advisors (Richardson \& Bender, 1987). Allen et al. (2014) found, however, that pre-transfer community college students were more satisfied with the advising they received at the community college than post transfer students were with the advising they received at 
their 4-year institutions. Community college students indicated they received more help and had better relationships at the community college and, upon transferring, had difficulty navigating the new system (Allen et al., 2014).

\section{Transferring from Community College}

While the community college offers a pathway to higher education for many students from groups that have been historically underrepresented among college degree holders, attending a community college may also be a risk factor for not completing a 4year degree. Of students enrolled in community colleges, two-thirds state that they want to earn a bachelor's degree (Provasnik \& Planty, 2008). Students who begin at a community college with aspirations of earning a baccalaureate degree are less likely to do so than their peers who begin at 4-year institutions (Dougherty, 1992; Pascarella, Wolniak, Pierson, \& Terenzini, 2003). Of the $56 \%$ of students who enter community colleges with the intention of obtaining a bachelor's degree, yet only $37 \%$ manage to transfer to a 4-year institution (Alfonso, 2006). A few years later, even though $80 \%$ of students in community colleges wanted to obtain a bachelor's degree, the reality was that only 1 in 10 completed a baccalaureate in 6 years (Alstadt et al., 2014).

Students may fail to complete the degree for several reasons. Students take excess credits due to "academic challenges: "F" grades; academic problems: "W/R" grades; poor student choices; transfer problems; unavailable courses; and degree requirements" (Complete College America, 2017, p. 9). In addition, students have "too many choices and too little guidance ... more than 100 majors and hundreds of courses, are uncertain of their major and $45 \%$ of students have not seen a counselor by the third week of the term" (Complete College America, 2017, p. 10). The process of transferring and the inherent 
difficulties in that process may be one reason for the low number of students who transfer successfully and go on to degree completion. Complete College America goes one step further and notes that what occurs is "behavioral economics" in that "too much choiceespecially uninformed choice_-leads to indecision or poor decisions" (Complete College America, 2017, p. 12). Students can be overwhelmed by too many choices.

When students do transfer from a community college to a 4-year institution, they can struggle with the new environment (Dougherty, 1992; Townsend \& Wilson, 2006). Although they have been successful at the community college, the additional transition to a 4-year institution can lead to struggles adapting to a new environment. This transition is often reported as "transfer shock," which can lead to initially lower grades (Laanan, 2001). Students transferring into 4-year institutions report feelings of alienation and a lack of belonging as they transition into a new culture (Bennett \& Okinaka, 1990). The reasons for this alienation may be that students find community colleges more encouraging (Davies \& Casey, 1999; Davies \& Dickmann, 1998) and experience feelings of anonymity at 4-year institutions (Allen, Smith \& Muehleck, 2013; Gawley \& McGowan, 2006; Townsend \& Wilson, 2006).

\section{Foster Alumni and the Community College Pathway}

Data from researchers' surveys indicated that in the State of Oregon Chemeketa Community College, Portland Community College, and Portland State University were three institutions with the highest percentage of foster youth registered as students at the time of survey collection (Allen \& Smith, 2010). At the time of the survey, Chemeketa Community College had $7.5 \%$ of their students identifying as foster youth, Portland Community College had $6.3 \%$ of their students indicating they were foster alumni, and 
Portland State University had $4.1 \%$ of their students indicate they were former foster youth (Allen \& Smith, 2010). Looking at the population of Oregon, it makes sense that these areas would have the highest number of former foster youth. Chemeketa Community College is located in Salem, the state capital and second largest city in Oregon. Portland Community College and Portland State University are located in the largest city in the state.

\section{Lack of Awareness on the Part of Educators}

Perhaps one of the biggest barriers for foster alumni is the lack of awareness by educators. Foster youth are an invisible student population. Although many marginalized student populations have found support, resources, and programming on college campuses to help them navigate through higher education, few institutions have programs or supports for foster alumni. Most practitioners in student and academic affairs pride themselves on their commitment to social justice and creating access for all. Foster alumni, however, appear to be a group that has slipped past the notice of most practitioners. In the last few years, some inroads have emerged into broadening practitioner knowledge. Currently, in higher education, few targeted services support foster alumni, although in the last few years' individuals have begun advocating in various different areas (Draeger, 2007; Emerson, Duffield, Salazar, \& Unrau, 2012; Klefeker, 2010). As former foster youth are virtually invisible at most universities, they lack power to demand action and change.

\section{Financial-Aid Support}

Draeger (2007) wrote about foster youth for financial aid administrators, and many others have worked hard to understand the issues and challenges faced by this 
group. As Education and Transfer Vouchers (ETVs are awarded through financial-aid offices, it makes sense that financial-aid administrators would be supporters of foster alumni. Emerson et al. (2012) published an article in the NASPA Leadership Exchange Magazine about creating campus supports for foster and homeless students. In the field of academic advising one article discussed foster youth support (Klefeker, 2010). Certainly, there are committed educational advocates who are trying to increase knowledge and support for former foster youth; however, faculty, and academic and student-affairs staff are ignorant of the issues foster alums bring to higher education and therefore do not understand the experiences of foster alumni.

\section{Lack of Knowledge by Institutional Agents}

All too often in the literature of higher education regarding persistence, students are held as being solely responsible for success or failure. Bensimon (2007) stated that "we have learned to view inequality in educational outcomes as a problem of student under preparedness, not a problem of practitioner knowledge" (p. 456). Practitioners need to recognize that organizations often create barriers to success for students. Removing those barriers can equalize opportunities for students with risk factors. Stanton-Salazar (1997) explored the significant role that institutional agents play in transmitting knowledge to underrepresented students in higher education. Institutions create culture and policies that impede or help students persist. It is incumbent on colleges and universities to understand their role in student retention (Kuh, Schuh, \& Whitt, 1991). Everyone on campus, from the janitorial crew to the president, can serve as institutional agents to facilitate the transition into and through higher education for foster alumni. The 
lack of knowledge about foster alumni by higher education practitioners is a serious deficit.

The lack of awareness and understanding of the challenges facing foster alumni is not unusual, as in general, higher education seems largely ignorant of this student population. Few institutions ask students to identify their previous foster status. And while financial-aid offices frequently know, due to disseminating Chafee funds, such information often does not go beyond that office. Also, many foster youth opt not to selfidentify. However, this lack of awareness no doubt results in a lack of resources, programming, services, and understanding for foster youth transitioning into postsecondary education.

\section{Theoretical Models for Student Success}

A paucity of research describes foster youth transitioning into higher education. The lack of scholarship in this area, which might help practitioners understand the issues foster youth face and how they confront issues, is no doubt one of the reasons for the lack of knowledge and attention to this vulnerable student population. At most higher education institutions, foster youth are a silent minority of students. However, several student-development theories on student success helped frame this study of former foster youth.

\section{Student Retention and Persistence}

While much is written about persistence and retention, as if they were interchangeable, I differentiate these terms. Retention is the institution's ability to keep a student enrolled and progressing through degree completion. Retention refers to all of the supports the institution offers, including both curricular and co-curricular activities and 
policies and procedures that support and impact the student experience. Persistence is viewed from the students' perspective, based on their ability and drive to move toward degree completion. Persistence includes a student's ability to address academic and personal struggles while still moving forward toward degree completion. According to Berger, Ramirez, and Lyons (2012) "persistence refers to the desire and action of a student to stay within the system of higher education from beginning year through degree completion" while "retention refers to the ability of an institution to retain a student from admission through graduation" (p. 12).

Berger et al. (2012) also differentiate between "voluntary and involuntary withdrawal" and "institutional and system departure" (p. 12). Involuntary departure occurs when a student is no longer allowed to continue at the university. This can occur, for example, if a student has been academically suspended. Voluntary departure, on the other hand is when the student makes the decision to not return to the institution (Berger et al., 2012). Institutional departure is leaving a particular institution, while system departure is leaving higher education entirely. In effect, institutional departure is the difference between stopping out of an institution and dropping out of higher education.

Hagedorn (2012) simplified these definitions by referencing a student as a "college persister or a non-persister" (p. 81). While she acknowledges that these definitions are clear and concise, it is the multitude of pathways that students find themselves on that make issues around persistence and retention complicated (p. 82). Most studies into student persistence and retention have grown and evolved over the decades, now including research on students from various social and economic backgrounds, differences between residential and nonresidential students, and those 
attending 2- and 4-year institutions. Troxel (2017) succinctly stated "Students matter. Academic relationships matter to students. Success leads to persistence. Persistence leads to retention." However, retention and student persistence are complex and multilayered processes with no answers that serve all students.

The first model that framed this study is Tinto's $(1975,1993)$ model of collegestudent departure. Tinto's model is one of the most often-referenced theories in higher education literature. The model is important not only because of its paradigmatic status in higher education research, but also because it is particularly relevant for foster alumni. The model has been widely used to explain reasons for student departure from higher education institutions. Tinto's $(1975,1993)$ view of student retention is based on the individual student's level of "academic integration," influenced by previous academic work, supportive family structures, and students' own characteristics and "social integration." The level of integration is both influenced by and influences students' commitment to the goal of attaining a college degree and their commitment to earning that degree from a particular institution. For foster alumni, multiple placements, switching of schools, and the lack of family privilege makes integrating into the social and academic environments of higher education more challenging than for other students.

For youth who were not in foster care, beginning college finds them in a period of transition from their old norms to new norms. The ability to adopt new norms and behaviors that may be markedly different from those of friends and family determines students' successful integration into the system. Tinto (1993) referred to this as "a period of passage between the old and the new, before the full adoption of new norms and 
patterns of behavior and after the onset of separation from old ones" (p. 97). Tinto (1998) later commented,

Attrition is, for most institutions, most frequent during the first year of college. Nearly half of all leavers depart before the start of the second year. It therefore follows that the impact of involvement upon persistence is greatest in that year, especially during the first ten weeks when the transition to college is not yet complete and personal affiliations are not yet cemented (p. 169).

For some students, the discord between the old and the new can be so jarring as to ensure that they cannot make the transition into higher education. For foster youth, however, college may provide a stability that their former life did not have. At the same time, they may experience differences due to having been in foster care and adaptation to a new life in college can still be difficult.

Tinto $(1975,1993)$ believed that student involvement leads to greater student persistence. Learning and persistence come from a combination of student involvement and effort, inside and outside the classroom (Tinto, 1975, 1993). Tinto continued to review and revise the model of student departure over the years and presented at the 2005 National Conference on Student Recruitment, Marketing, and Retention: "Whereas we once assumed that retention required students to break away from past communities, we now know that for some students the ability to remain connected to their past communities, family, church, or tribe, is essential to their persistence" (para. 8).

Tinto explained that retention is different based on various collegiate factors, including residential versus nonresidential and whether a student was attending a 2- or 4year institution (2006, p. 3). For students at non-residential institutions, the classroom becomes increasingly more important, as that is where they connect with faculty and fellow students. In 2006, Tinto stated that while "access to higher education has increased, 
greater equality in attainment of four-year college degrees has not followed suit. For too many low-income students access to higher education has become a revolving door, the promise of a bachelor's degree unfulfilled" (p. 12). Understanding the persistence of low socioeconomic students is imperative in the overall context of student retention and degree completion (Tinto, 2006).

Understanding of student persistence and retention is changing and evolving, as it has done since higher education leaders became concerned about it more than 40 years ago. Today, educators understand that persistence and retention are complex and multilayered concepts with numerous variables. Even so, there has been criticism as to how persistence and retention has been presented. Bensimon (2007) explained the "dominant paradigm of student success is based exclusively on personal characteristics of students that have been found to correlate with persistence and graduation" (p. 443). Bensimon's criticism notes that professionals are not involved in discussions around student persistence and success (2007).

Tierney (1992) presents a different view and believes that Tinto's model of social integration limiting and that a theory of emancipation and empowerment needs to be developed. He notes that the culture of U.S. higher education reflects "the culture of the dominant society" (Tierney, 1992, p. 608). The second issue that Tierney addresses is that going to college is viewed by many in the United States as a ritual, whereas in traditional cultures "choice does not exist about whether to undergo the ritual; one simply partakes of it" (Tierney, 1992, p. 609). Tierney (1992) critiqued Tinto for not recognizing that the language around student persistence is culturally constructed, as Tinto's focus was on college success at the individual level rather than the collective level. Tierney 
(1999) noted that Tinto's theory focuses on students leaving behind their family, friends, and culture, and assimilating into the college, which Tierney referenced as "cultural suicide" (p. 82). Finally, Tierney (1992) excoriates Tinto for failing to address Tinto’s role as a faculty member and "that he is a "native' studying "native rituals"' (p. 610). Although Tierney $(1992,1999)$ and Bensimon (2007) have valid points in their critiques, Tinto $(1975,1993,1998,2003,2005,2006,2012)$ has revised the model over time. I find that Tinto's theory resonates with foster alumni, who must separate from their past and embrace a new culture. I specifically chose Tinto's theory as part of the framework for this study, because, as noted earlier, Tinto refers to students in "a period of passage between the old and the new" (1993, p. 97). Foster youth are leaving behind what they have known and are adapting to a new world in higher education. They are putting behind them a history of painful experience and in some cases, destructive family functioning. College is an opportunity for foster youth to be in control and to control the story of their life. Going on to college means they can opt to leave their past behind. For this population of students, leaving what they have always known behind them as foster youth can be the first step in healing and the first step in building a new life and integrating. Also, as shown in participants' comments in Chapter 4, sometimes individuals have to leave things behind and separate in order to move forward.

\section{Schlossberg's Transition Theory}

The second theoretical model which frames this study was Schlossberg's (1981) transition theory. Schlossberg (1981) first developed a model for human adaptation to transition to examine and analyze how adults address life transitions. Schlossberg (1981) noted that individuals transition continuously throughout life, yet each person's 
transitions are experienced differently. Schlossberg (1981) was seeking how to understand the transition experience and provide support for individuals during a process of change when people often react differently during a transition. As Schlossberg (1989) later explained, when individuals feel marginalized they tend not to succeed, yet when they perceive that they matter, they achieve. While Schlossberg (1981) initially viewed through the lens of counseling individuals, the work is pertinent in higher education, as students experience multiple transitions, some expected and others not.

In 1981, Schlossberg presented the model for analyzing human adaptation to transition, stating, "A transition can be said to occur if an event or non-event results in a change in assumptions about oneself and the world and thus requires a corresponding change in one's behavior and relationships" (p. 5). The model sets forth "three major sets of factors that influence adaptation to transition: (1) the characteristics of the particular transition, (2) the characteristics of the pre- and post-transition environments, and (3) the characteristics of the individual experiencing the transition" (p. 5). Schlossberg noted that the "three sets of factors interact to produce the outcome: adaptation or failure to adapt" (1981, p. 5).

Schlossberg (1981) referred to transitions in a broad sense, meaning life changes such as marriage, birth of a child, getting a job, graduating, or loss of a loved one, but also the smaller life changes reflected in loss of an opportunity. The author referenced these as events or nonevents. For example, an event could be a job promotion and a nonevent may be the lack of an expected job promotion that leads to a change, which can result in "growth or deterioration" (Schlossberg, 1981, p. 5). What is especially unique about Schlossberg's model is that transition is "defined by the individual" (1982, p. 7). 
So, a similar event or nonevent may result in different experiences for individuals: "A transition is not so much a matter of change as of the individual's perception of change. A transition is a transition if it is so defined by the person experiencing it" (Schlossberg, 1981, p. 7).

Schlossberg's (1981) model posits that as a person moves from an event or nonevent, three groups of factors which influence that individual's adaption to the transitions they are experiencing. The first group of factors is the "perception of the particular transition" and whether the transition is viewed as a gain or a loss, positive or negative, whether it is internally occurring or being forced from outside, whether the timing of the transition is at a good time or not, if the onset is all of a sudden or has been gradually occurring and the duration (Schlossberg, 1981, p. 5). In addition, the "degree of stress" must also be included in the perception (Schlossberg, 1981, p. 5) as "any change-whether primarily positive or negative in affect- involves some degree of stress" (Schlossberg, 1981, p. 8). The second set of factors is the "characteristics of pretransition and posttransition environments," which includes “internal support systems: intimate relationships, family unit, network of friends as well as institutional supports and physical setting" (Schlossberg, 1981, p. 5). The final set of factors is the "characteristics of the individual" which includes "psychosocial competence, sex (and sex-role identification), age (and life stage), state of health, race/ethnicity, socioeconomic status, value orientation, and previous experience with a transition of a similar nature" (Schlossberg, 1981, p. 5). The perception of the transition combined with the pre- and post-transition environments and the characteristics of the individual combine to help move from transition to adaptation. 
Adaptation involves moving through the transition and the ability to reorganize after the transition (Schlossberg, 1981). The ability to move through "depends on: 1) Balance of individual's resources and deficits; 2) Differences in pre- and post-transition environments regarding perception, supports and individual” (Schlossberg, 1981, p. 5). Schlossberg's model "assesses the ratio of resources to deficits, allowing for changes in the ratio as one's situation changes" (Schlossberg, 1981, p. 8). This is important because, in one instance, an individual may move through a transition quickly and easily due the amount of resources available to the individual, whereas at another time, a person may struggle if deficits outweigh resources. Adaptation is easier when resources outweigh deficits.

Schlossberg's (1981) model is important as it set the stage for later work on transitions, which informs this study. In 1989, Schlossberg wrote about "marginality versus mattering" and noted "that people in transition often feel marginal and that they do not matter" (1989, p. 6). People can feel marginalized because they are confronted with an unfamiliar environment in which they may not know how to act. New relationships, routines, and changes in prior roles can cause an individual to feel marginalized. Individuals need to move in, move through, and move out of the transition. In every transition, the individual has the possibility of feeling marginalized (Schlossberg, 1989, p. 7).

In 1995, Schlossberg, working with Waters and Goodman, revised transition theory. The initial premise was that transitions differ from individual to individual, but the process of understanding transitions remained the same. The transition model has three stages: (a) approaching transitions: transition identification and transition process; 
(b) taking stock of coping resources: the $4 \mathrm{~S}$ system; and (c) taking charge: strengthening resources (Schlossberg et al., 1995).

Schlossberg et al. (1995) defined transition, as "any event, or non-event, that results in changed relationships, routines, assumptions and roles" (p. 27); a transition can result in "new patterns of behavior" (p. 28). The authors noted that the "transition is a transition only if it is so defined by the person experiencing it" (Schlossberg et al., 1995, p. 28). Once an event or non-event occurs, which results in change, the type of transition needs to be identified. Is the transition what the individual experiencing anticipated, did not anticipate, or was it a non-event (Schlossberg et al., 1995, p. 28)?

Schlossberg et al. (1995) referenced anticipated transitions as events which an individual would normally expect to happen over the course of their life, such as graduating from high school, starting a job, getting married, the birth of a child, loss of a loved one, and retirement. These are the normal milestones which most people anticipate throughout their lives. Unanticipated transitions involve events that are "not predictable" (Schlossberg et al., 1995, p. 29). These unanticipated events could be a divorce, a serious illness, loss of a child, a natural disaster, or even winning the lottery. Non-event transitions occur when an individual had an expectation that something would happen, and it did not (Schlossberg et al., 1995). Being passed over for a promotion, a miscarriage, a cancer that turned out not to be cancer are examples of non-events. Schlossberg et al. identified four types of non-events: personal, ripple, resultant, and delayed.

Personal non-events are unrealized aspirations, such as never marrying or having a child (Schlossberg et al., 1995p. 30). Ripple non-events are the unrealized aspirations of someone near to us, which, in turn, alters one's assumptions. For example, an individual 
may choose to never marry or have children, thereby denying their own parents the opportunity to host a wedding and later to become grandparents. Our decisions ripple outwards to those around and can impact them. Resultant non-events start off as an event, for example, being pregnant, and then lead to a non-event: the birth leads to complications and the mother loses her child and becomes infertile (p. 30). Delayed nonevents are those that still may occur (p. 30). For example, an individual might have been passed over for a promotion, they might still get a promotion in the future. Schlossberg et al. (1995) noted that the best way to see these transitions is "on a change-no-change continuum rather than as discrete entities. In other words, the issue is how much they have altered one's life" (p. 30).

Along with type, context is important for understanding transitions. Schlossberg et al. (1995) noted that understanding the relationship between the individual and the event or non-event is essential. Is the transition happening to the individual or to someone else, is it personal or interpersonal, or does it involve the public? For example, a person may be excited about their own retirement, but sad for a colleague who is laid off of work. Understanding the context of the transition affects reactions to the transition.

Finally, the impact of the transition is most important (Schlossberg et al., 1995). To understand an individual's situation, an assessment of the "transition's impact on relationships, routines, assumptions and roles is probably the most important consideration in understanding a given situation" (Schlossberg et al., 1995, p. 35). A decision to not have a child may have a bigger impact on family members or friends.

The second stage of the transition model is Taking Stock of Coping Resources: The 4 S System (Schlossberg et al., 1995). The 4 S System refers to situation, self, 
support, and strategies: factors that contribute to how an individual handles transitions (p. 47). These factors can be assets or liabilities and the ratio of assets to liabilities can inform why individuals can react differently to the same transition and why an individual can react differently to the same transition at different times in their life (p. 49). If an individual's liabilities outweigh their assets, the person may struggle with a transition they previously handled easily.

In the $4 \mathrm{~S}$ System, the first $\mathrm{S}$ refers to situation, and each individual's situation is unique to them; however, situations include trigger, timing, control/source, role change, duration, previous experience, concurrent stress, and assessment (Schlossberg et al., 1995). Trigger refers to what caused the transition, and timing is how it relates to the individual's "social clock," assessing if the individual can control. Are there pieces of the transition that the individual can control and how long will it last (Schlossberg et al., 1995, p. 53)? The situation includes whether the transition results in a role change for the individual, whether the person has addressed similar transitions, and whether they have additional stress in their life.

The second $\mathrm{S}$ refers to self, as in what the individual brings to the transition (Schlossberg et al., 1995). Schlossberg et al. (1995) identified two overarching characteristics which are important for how individuals cope with transitions: personal and demographic characteristics and psychological resources. Personal and demographic characteristics are "socioeconomic status, gender, age and life stage, health and ethnicity" (Schlossberg et al., 1995, p. 58). These demographics play a large role in how people view and experience transitions. Psychological resources include "ego development, outlook—optimism and self-efficacy, commitment and values" (Schlossberg et al., 1995, 
p. 58). People approach a transition from their own reference point. People use their level of maturity, their outlook — optimistic or pessimistic — and their personal values to face transitions. An individual will bring different personal resources to a transition.

The third S in the transition model is support (Schlossberg et al., 1995). Multiple forms of support include "intimate relationships, family units, networks, friends, and institutions and/or communities of which individuals are a part" (Schlossberg et al., 1995, p. 67). One question to ask is does the individual have a variety of types of support available to them? Support can help a transition, but lack of support may hinder the transition. For example, moving to a new community may mean the loss of a social network, thereby making the transition into the new community more difficult.

The last $\mathrm{S}$ in the $4 \mathrm{~S}$ System is strategies. Coping strategies allow an individual to identify ways to work through the transition. Schlossberg et al. (1995) noted that "effective copers are flexible and utilize a number of methods" and that "ability to cope is not a trait, but a dynamic process constantly in flux throughout the continuing process of appraisal" (p. 74).

Referenced as "potential resources," people can identify and use situation, self, strategies and support when experiencing a transition (Schlossberg et al., 1995, p. 26). Perhaps most striking is the concept that, regardless of the type of transition or where one is in a transition process, each individual's response will be unique, based on a personal 4 S System (Schlossberg et al., 1995). Student and academic affairs professionals using this transition model can help students focus on their potential resources to positively work through transitions. For students, strengthening resources is a powerful message of self- 
empowerment, enabling individuals to continue to increase their skills and resources, helping provide the assets needed to successfully move through life transitions.

Schlossberg (1981) found that when individuals experience a transition, the greater the distance between the old situation and the new situation can cause the individual to feel marginalized. For foster alumni coming into a new culture of higher education, this distance between old and new norms may make the transition into and through higher education difficult. Given the differences between community colleges and 4-year institutions, foster alumni may find the transitions difficult and not have the supports and strategies needed. Successful transitions occur when students feel that they matter to someone at the university. Without this feeling of mattering, a student will feel marginalized by their educational experience and consequently not persist to graduation.

The lives of many foster youth have entailed a series of transitions. They transitioned from their biological family to a foster home or foster family. They may have transitioned between different foster families once in the system. They transitioned through schools, often multiple times, and they transitioned out of high school and are trying to transition into college. If any population truly understands transitions, it is foster youth, as they have lived transitions from the point of entering care.

\section{Bourdieu's Theory of Social and Cultural Capital}

Another theory that is particularly important and served as part of the conceptual framework for this study is Bourdieu's theory of social and cultural capital. Social capital indicates connections people make and can be converted often to economic benefits (Bourdieu, 1986). Cultural capital, however, is educational (Bourdieu, 1986) and "proficiency in and familiarity with dominant cultural codes and practices" 
(Aschaffenburg \& Mass, 1997, p. 573). Students who are first-generation college students or from lower socioeconomic backgrounds, which includes many foster alumni, often find they lack the correct social and cultural capital to be successful in college (Walpole, 2003).

Students who have strong social and cultural capital know how to navigate through the dominant culture, as they are familiar and can read the signals. Even the most basic elements, such as, knowing how to tie a tie for a young man or what silverware to use at a formal dinner, can evoke feelings of not belonging or lacking insider knowledge. Students who grow up in homes with social and cultural capital often view college as an expectation which is discussed by their family. When students with social and cultural capital run into a problem on campus, their families can inform them where to go and how to negotiate situations. Social capital gives people connections and opportunities (Bourdieu, 1986). It is not that Foster youth do not have social or cultural capital, it is just not the types that will help propel them forward.

Bourdieu $(1973,1986$,$) looked at how habitus and cultural capital can explain$ individual agency. A Bourdieuian framework shows the reproduction of existing class and social structures where families pass on core knowledge. As Bourdieu (1986) stated "The social world is accumulated history" (p. 241). Thus, students accumulate social and cultural capital from their family units, which provide them currency for moving forward in life to attain their social position or an even higher position. Bourdieu notes that life is not "simple games of change offering at every moment the possibility of a miracle" (Bourdieu, 1986, p. 241). Instead capital accumulates over time and generations and has 
"a potential capacity to produce profits and to reproduce itself in identical or expanded form” (Bourdieu, 1986, p. 241).

Cultural capital "refers to specialized or insider knowledge which is not taught in schools, such as knowledge of high culture, and to educational credentials" (Walpole, 2003, p. 49). The power of cultural capital cannot be overlooked when examining the experiences of foster youth in higher education as they may often lack this form of capital. Bourdieu (1986) stated clearly that "the transmission of cultural capital is no doubt the best hidden form of hereditary transmission of capital" (p. 246). Students who have social and cultural capital from their families are imbued with skills, attitudes toward learning, and habits that benefit them in the pursuit of tertiary learning (Bourdieu \& Passeron, 1979). These same students also have another set of skills including know-how, and “good taste” (Bourdieu \& Passeron, 1979, p. 17). As Bourdieu and Passeron stated, "Cultural privilege is manifest when it is a matter of familiarity with works which only regular visits to theaters, galleries, and concerts can give" (1979, p. 17).

Bourdieu (1986) found that "social capital is the aggregate of the actual or potential resources which are linked to possession of a durable network" (p. 248). People belong to networks that produce membership in a "family, class or a tribe or of a school, a party" (Bourdieu, 1986, p. 249). The amount of social capital an individual has is based on the size of their network. Bourdieu noted that "the network of relationships is the product of investment strategies, individual or collective, consciously or unconsciously aimed at establishing or reproducing social relationships that are directly usable in the short or long term" (1986, p. 249). 
Lack of social and cultural capital makes it difficult for foster youth to transition and navigate into the culture of higher education. Bourdieu and Passeron (1979) stated that "all teaching, and more especially the teaching of culture (even scientific culture), implicitly presupposes a body of knowledge, skills, and, above all, modes of expression which constitute the heritage of the cultivated classes" (p. 21). Hard work and applying oneself is not all that is needed to be successful academically. Instead, the invisible structures in society must be examined as they can impede the progress of students with little to no social and cultural capital. Many foster youth lack cultural capital in the higher education environment, causing a deficit in knowledge, skills, and insider ways of being and doing.

\section{Being a Bicultural Student}

Bicultural often refers to students whose parents are of different cultures or immigrant students caught between the cultures of their parents and the new culture in which they live. Foster youth who enter college are bicultural, as they are entering a world of the mind, different from the world they knew before. Foster youth are also entering a world with a different social context from the world to which they were accustomed as a foster youth. Higher education institutions expect students to adapt to the culture of the college and deny their own culture (Rendón, 1992). The past students bring with them should be valued (Rendón, 1992). However, in the case of foster youth, they may not want to value their past or even acknowledge it. Even so, foster youth are bicultural and, as noted earlier in this chapter, foster alumni lack the social and cultural capital that allows them to easily assimilate into the world of academia (Bourdieu, 1986). 
Foster youth are moving from the outside in (Schlossberg, 1989; Schlossberg et al., 1995; Tinto, 1975, 1993) — from the fringes of society_developing social and cultural capital to help navigate a new world (Bourdieu, 1986), and at the same time attempting to respect their bicultural status by bringing all of themselves, past and present, to college (Rendón, 1992). Although foster youth come into college with at-risk factors, foster youth also have great promise. The process for foster youth is about the transitions they experience and make, not about moving from one environment to another. Rather the process is about a redefinition of transitions as positive, using all of the capital they have acquired and with no devaluing of their foster experiences.

\section{Academic Advisors as Guides}

Higher education is a unique culture in and of itself (Strayhorn, 2015). Higher education has "its own codified language" and a "shared understanding" (Strayhorn, 2015, p. 58). To understand the culture, students need "cultural navigators" to help them move through the experience (Strayhorn, 2015, p. 59). Academic advisors play the role of guides and cultural navigators, helping students understand the higher education culture they have entered and to become successful at not only navigating the institution, but also academically.

According to Crookston (1972) academic advising is also focused on "facilitating the student's rational processes, environmental and interpersonal interactions, behavioral awareness, and problem-solving, decision-making, and evaluation skills” (p. 12). Crookston espoused a developmental approach to academic advising contrary to the prescriptive approach whereby the advisor is in charge and tells the student what to do. He noted that students are not empty vessels but come with their own life experiences. 
Rather than an authoritarian approach, developmental advising allows the advisor and the student to engage and contribute to learning.

Frequent interaction with faculty and staff had a positive impact on student success (Astin, 1984): "student involvement refers to the amount of physical and psychological energy that the student devotes to the academic experience" (p. 518). Involved students tend to study more, be engaged in both curricular and extra-curricular pursuits, and are actively connected to the campus, while uninvolved students are the opposite (Astin, 1984). I include involvement theory because students who are involved are more likely to use academic advising, and advising is a resource all students can use to actively navigate the higher education system.

Kuh (2008) stated that "Every advising contact is a precious opportunity for a meaningful interaction with the student.” (p. 79). Light (2001), a professor at Harvard, noted that "good advising may be the single most underestimated characteristic of a successful college experience" (p. 81). The study that Sima and Inman (2013) conducted found that Students received academic advice from a variety of sources including advisors, friends, family, faculty and staff in support areas. For foster youth who do not have access to family for advice, the role of the academic advisor may be more pertinent to helping foster youth navigate through higher education.

Tinto (2012) suggested that institutions should provide a blend of individual, group and online advising to ensure the greatest possible use of advising resources to improve student success. White (2015) stated that "the purposes of academic advising accommodate all students so that they can make reasoned demands as they set and enact the goals of their lives" (p. 270). Advising is most effective in promoting student success 
when integrated into academic-support services and when it is sensitive to the developmental needs of a diverse student population (Kramer, 2003).

\section{Federal and State Programs That Support Foster Youth in Higher Education}

For foster alumni, there are Several direct federal programs that support them. This includes Independent Living Programs (ILPs) designed to teach foster youth the skills they will need to live independently. However, much depends on whether foster

youth are informed about the service, decide to avail themselves of the service, and the level of services offered.

For foster youth planning to attend college, there are financial resources to help them pay for higher education. The Free Application for Federal Student Aid asks for parental information and signature, which is often yet another barrier for foster youth. The recently enacted College Cost Reduction and Access Act of 2007 (P.L. 110-84) eliminated this barrier to aid for foster alumni beginning in the 2009-2010 academic year and for subsequent years. A financial aid administrator can verify the former foster youth's situation; however, a foster youth must be willing to tell a financial-aid officer their situation. Foster youth may want to disassociate from their past and opt not to reveal their foster youth status, which in turn can result in difficulties accessing financial resources.

The free financial aid form allows students to apply for federal and state aid to cover the cost of tuition. Aid may be made up of loans, grants, and work study participation. The federal financial-aid form is complex and foster alumni may struggle to complete it. In addition, the form asks students to self-identify if they are wards of the 
court and foster alumni may not understand why they are being asked and opt to not fill that question out, thereby depriving them of additional funds.

One program that significantly and positively impacts foster alumni in higher education is the John H. Chafee Foster Care Independence Program, also known as Chafee Grants or Education and Training Vouchers program. Chafee Grants were a part of the Foster Care Independence Act of 1999, and, although federally funded, they are administered by each state. The program provides up to $\$ 5,000$ annually to foster alumni. The Foster Care Independence Act of 1999 was specifically designed to help foster youth successfully transition from care. The Chafee Grants can be used with a variety of services including career exploration, vocational training and living skills, and personal and emotional support. For foster youth in higher education the grants can be utilized for housing, books, tuition, and other related expenses.

In addition, states are now considering free or reduced tuition rates for former foster youth to promote higher education. While there are initial outlay costs, there is a direct societal and economic impact, as students with degrees tend to earn more and will pay more in taxes over their lifetimes. Oregon, for example, passed House Bill 3471 (Relating to higher education, 2011), which requires colleges and universities to waive tuition and fees for foster alumni. The bill also directed the Oregon Student Assistance Commission, a state agency that promotes college access through information and financial support, to put foster alumni at the head of the line for receiving Oregon Opportunity Grants.

Although there are college and university programs specifically designed to meet the unique needs of foster alumni, they are relatively few. The programs that do exist are 
usually started by an individual with a personal connection to foster youth; in some cases, someone who has actually been through the foster-care system. The Guardian Scholars (n.d.) program at California State University, Fullerton, was begun in 1998 by businessman Ron Davis. The program, which started with three students, has now expanded to more than 20 colleges in five states and combines public- and private-sector funding to aide foster alumni in fulfilling their aspirations to achieve a college degree. One criticism of these programs is that they can only take a select number of students, which means most foster youth do not have access. In addition, these programs often require significant funding to run, which many public universities do not have the ability to provide.

Additional resources on campus that foster alumni may use include tutoring services, counseling and health services, and academic advising. The majority of these services are free to students, with the exception of counseling and health services, as in some colleges, students are required to pay for services. Retention is aided by foster youth having stable living, support in academic areas, institutional commitment, and social involvement (Salazar, 2011).

\section{Limitations in the Literature}

Student development theory helps practitioners explain the experiences of different student groups as they go through higher education. Tinto's $(1975,1993)$ work focused much on the previous life experiences of students, including their academic work and ability to integrate socially. However, Tinto also stated that students need to let go of their past in order to integrate into higher education. For foster youth, this can be empowering and a start at building their own life. Bourdieu (1986) noted that social and 
cultural capital give individuals hidden advantages in the world. Foster youth largely lack social and cultural capital and unless they have someone who can teach those invisible skills, they may be lacking all their lives. Salazar (2011) found that even for foster youth who achieved and received a college degree, having been in foster care continued to play a role in their lives and moderated the benefits of their education.

Transition theory offers a way for foster alumni to navigate higher education by using the 4 S System: situation, self, support, and strategies (Schlossberg, 1981; Schlossberg et al., 1995). Foster youth are not blank slates, and many of the skills they have learned in foster care can help them in navigating the landscape of higher education. Analyzing the situation, assessing the self, enlisting support, and developing strategies is a framework for foster alumni to cope with the many transitions they will face in higher education.

Academic advising, while providing a natural place on every campus for advocates, has, as a field, remained largely silent about foster youth. Possibly, advisors see foster care as a birth-to-emancipation process and lack understanding of the multiple and often negative outcomes for children and youth who have been in the care system. The lack of practitioner knowledge may lead advisors to not support or advocate for foster youth in ways that would be most beneficial for foster youth persistence in higher education.

Much of the literature to date on foster youth has focused on the outcomes associated with having been in the foster care system. Little research has been conducted about the experiences of foster youth as they transition through higher education and attempt to persist toward degree attainment. Programs that directly support foster youth 
have been shown to be helpful, but those programs often require substantial funding and many institutions do not have the resources to support such programs.

Using existing student-development theory, Tinto's theory of student departure (1975, 1993), Schlossberg's transition theory (1981), and Bourdieu's social and capital theory $(1973,1986)$ may explain some of the experiences of foster youth. However, because foster youth have not been researched specifically through these conceptual lenses, it is currently unknown whether these theories really are applicable to foster youth. Thus, the research project presented here is specifically geared toward foster youth transitions to higher education to gain a deeper understanding of foster youth experiences. This research is particularly important to higher education personnel, especially institutional agents who are on the "front lines" of supporting former foster youth directly, such as academic advisors. Arming advisors and other support personnel with knowledge and understanding of the experiences of foster youth pre- and post-college transition is vital to ensure supports are in place for this vulnerable student population.

\section{Chapter Summary}

Many foster youth aspire to attend and graduate from a post-secondary institution, yet few achieve their goal of degree attainment. The moment a child or young person is placed into care, the chances of them going to college, and graduating, decrease. Multiple foster-home placements, childhood trauma, school mobility, low expectations, lack of educational advocates, and mental health issues combine to create serious barriers to graduating from high school and accessing higher education.

For those foster alumni who manage to get into college, very little is known about their collegiate experiences. Being entirely responsible for themselves, working, 
navigating a new system, and persisting academically can be overwhelming for foster alumni. While there is research to show the low bachelor's degree attainment rates of youth formerly in foster care, there is little research explain what happens to foster youth as they transition through higher education, especially with regards to youth who are in institutions that do not have specific foster alumni programming.

Tinto's theory of student departure $(1975,1993)$, Schlossberg's transition theory (1981), and Bourdieu's cultural capital $(1973,1986)$ provided a conceptual framework to explore the transitions foster youth face in higher education and how cultural capital impacts those transitions. The following chapter sets out the present study, exploring the experiences of foster youth pursuing higher education through the gateway of community college. This study considered foster youth, their pathway to college, transitions, and the role of institutional agents as potential educational advocates. 
Chapter 3: Methodology

A better understanding of the experiences of foster alumni in higher education is necessary to not only comprehend their transitions, but also provide practitioners with information to design programming and supports to help this vulnerable student population. The research to date on foster youth has largely focused on outcomes of having been in foster care. Little research describes the transitions foster youth experience as they progress into and through higher education. This chapter lays out the methodology used in this study to examine the experiences of a small group of foster alumni as they transitioned into higher education at a community college in order to better understand their experiences and challenges.

\section{Research Design}

When a problem is complex, and a need exists for comprehensive understanding, then a qualitative approach is appropriate. Qualitative research explores "the meaning individuals or groups ascribe to a social or human problem" (Creswell, 2007, p. 51). In designing a qualitative study, a researcher needs to gather data in ways that are sensitive to the study participants and then analyze the data inductively to find themes. The study then gives a voice to participants and contributes to the literature "or provides a call for action" (Creswell, 2007, p. 51).

The paradigm that shapes my views is constructivist, which "assumes a relativist ontology (there are multiple realities), a subjectivist epistemology (knower and respondent co-create understandings), and a naturalistic (in the natural world) set of methodological procedures" (Denzin \& Lincoln, 2011, p. 13). The goal of constructivism is to look at the participants' experiences of a situation and how they understand and 
interpret their experiences (Creswell, 2009; Erickson, 1986). As a person who was not in foster care, I can never truly know the educational experiences of the participants I interviewed; however, my role as researcher was to interpret "the meanings others have about the world" (Creswell, 2009, p. 8).

Unlike other forms of research, which begin by positing a theory, the constructivist approach looks instead to develop a theory from the data (Creswell, 2009). The theory should follow from data, not precede data (Lincoln \& Guba, 1985). Criteria for constructivism include trustworthiness, credibility, transferability, and confirmability (Lincoln \& Guba, 1985). The structure for this qualitative study was grounded theory, specifically constructivist grounded theory. Charmaz (2014) stated "a constructivist approach places priority on the phenomena of study and sees both data and analysis as created from shared experiences and relationships with participants and other sources of data" (p. 130). The goal of a constructivist study is to look at how people construct meanings (Charmaz, 2014). For example, in this study, I researched how foster youth constructed meanings of their transitions to higher education.

\section{Restatement of Research Questions}

This study sought answer one overarching research question: What are the experiences of former foster youth who enter higher education through community college as they navigate transitions into and through post-secondary education? Several additional questions helped guide this study and came from student-survey data, interviews with participants, and researcher observations, which were all used in the analysis. These sub questions were divided into two sections: with the first section covering the quantitative descriptive data from the advising research consortium, and the 
second section covering the qualitative questions. The quantitative information provide a snapshot of the numbers of foster youth in higher education institutions in Oregon during 2010 and 2011.

\section{Existing Quantitative Data Set}

In order To better understand foster youth transitions and their experiences as they persist through higher education, I used existing quantitative data from the Oregon Research Advising Consortium surveys to develop a descriptive demographic profile of this group of foster alumni enrolled in Oregon higher education. As noted at the beginning of this chapter, Descriptive data on foster youth in the Oregon University System is largely non-existent. I collected qualitative data through interviews with foster alumni to better understand their lived experiences as they transitioned into and through community college.

The quantitative data used to describe the population came from a research consortium of 2- and 4-year colleges and universities, private and public, in the State of Oregon, involved in a multi-institutional study on academic advising. I was a member of the research consortium led by Drs. Allen and Smith from Portland State University. The purpose of the work was to explore student and faculty attitudes about and experiences with academic advising. Nine institutions participated in the research: Chemeketa Community College, Concordia University, Eastern Oregon University, Portland Community College, Oregon State University, Portland State University, University of Oregon, University of Portland, and Western Oregon University.

I sought to answer quantitative and qualitative questions, as follows:

Quantitative Research Questions: 
RQ1. How many current and former foster youth self-identify as such in Oregon higher education in 2010 and 2011 ?

RQ2. How many foster alumni were in Oregon higher education at the time the surveys were administered in 2010 and 2011 ?

RQ3. What is the percentage of current and former foster youth who selfidentify with the institution?

RQ4. What types of institutions are foster youth most likely to attend?

Qualitative Questions:

RQ5. What strategies do foster youth employ to successfully navigate towards degree attainment?

RQ6. What services and resources do foster youth use at the Community College for academic and personal support?

RQ7. What role does academic advising play in the transitions of foster youth through higher education?

RQ8. Are foster youth connected to an academic advisor and working with them towards either degree completion or transfer to a 4-year institution?

RQ9. Are there identifiable patterns of transitions, which foster youth experience in higher education?

\section{Setting}

Community colleges are the gateway to higher education for many foster alumni (Allen and Smith., 2011; Casey Family Programs, 2008). The community college from which I selected participants for this study had a larger percentage (6.3\%) of former foster youth than any of the other eight institutions in the study conducted by the Oregon Research Advising Consortium (Allen \& Smith, 2011). In addition, the study institution had no specific program to support former foster youth. At one point, the study institution did have an office specifically for foster youth, but that was closed due to lack of funding. While programs like The Guardian Scholars are successful, I was interested in the 
experiences of foster alumni at institutions that did not have specific advocacy and support programs in place for foster youth at the time of data collection.

\section{The Study Institution}

I recruited and selected research participants from a metropolitan community college, hereafter referred to as the study institution. The study institution is a large postsecondary institution with multiple campuses located in an urban area in the State of Oregon. The study institution serves a large and diverse student population through a variety of certificates and associate's degrees. The total head count for the institution was 89,903 students. As a community college, the study institution serves multiple roles within the community including providing an educational opportunity for students to pursue an associate's degree, track toward a bachelor's degree, take remedial courses, complete a certificate, new skills development or personal enrichment.

\section{Participants}

I recruited interview participants from the study institution through a variety of methods. I contacted the financial-aid director to ask them to tell any possible research participants about the study (see Appendix A). I included a flyer in the letter and asked that the flyer be posted in an area of high student traffic (see Appendices B and C). I posted flyers at the different study institution campuses. Each campus had its own policies for approval and length of time for postings, so I ended up posting several times to recruit interview participants. By posting flyers, participants could self-select if they wanted to participate in the study.

I also contacted the Oregon Foster Youth Connections organization, which

provides advocacy and resources for foster youth aged 14-25. I asked them if I could post 
flyers at their center, put a notice on their webpage, and put posts on their Facebook page, asking for participants. The Oregon Foster Youth Connections were very supportive of the project and posted information about the study. I was also put in contact with the Better Futures Project, run by Drs. Geenen and Powers at Portland State University. The Better Futures Project is a tri-county research project that works with foster youth through a federal grant. I was put in contact with some foster alumni through that program. Finally, I reached out to foster alumni I already knew and asked them to inform friends who were foster alumni that I was looking for study participants.

As noted above, I completed recruitment for potential interview participants in several ways to elicit the most responses and a largely random sample. When potential participants contacted me, I followed up with a phone call or e-mail to verify their eligibility for the study and to explain the study in greater detail. Several potential participants went through the initial stages, but then withdrew prior to participating in the interviews being conducted.

The initial criteria for research participants included a minimum age of 18 , but not older than 25 years of age. The reason for selecting this range is that the age group of 18 to 25 is either currently in care or most recently out of care. As to federal financial aid, students may still be considered "dependent" until they reach age 25 , which means their parents are still expected to support them. Foster alumni do not have that same support and may be at their most vulnerable in that 7-year time period from late teens to mid-20s. I need to note that one participant informed me they were 25 years old, yet later during the interview told me they were 26. While I could have dropped that participant from the 
study, their experiences were valuable and provided needed and additional insight into the transitions of foster alumni, so I kept them in the study.

Research participants for the study could have still been in foster care or may have emancipated from care; however, all of the participants who opted to continue with the interviews had all exited the foster care system at the time of the initial screening of participants. Ideally, I wanted a mixture of both current and former foster youth in the interviews, but I only had youth who had exited foster care that chose to take part in the study.

Participants for the study needed to be students entering or currently enrolled at the study institution, have been in foster care a minimum of 3 years, and experienced at least two placements during their time in care. Initially, because I was researching the lived experiences of foster youth in Oregon colleges, I expected that the study participants would be emancipated from foster care in Oregon. However, my first three participants were from out of state and I kept them in the study because I thought their experiences were worth being examined. I expanded on their pathways to Oregon in Chapter 4.

Once participants passed the initial screening, I sent them, by e-mail, the interview-invite form (see Appendix D). The interview-invite form invited participants to take part in the study, laid out the purpose and goals of the study, and the delineated the requirements of participants. When I sent the interview-invite form to participants, I also e-mailed interested participants the informed-consent form (see Appendix E), which I collected from them at the beginning of the first interview. 
The informed-consent form again explained the purpose of the study and the risks involved, and there was a signature line for participants to sign agreeing to take part in the study. At that time, I scheduled a time and location to meet with the study participant, review and go over the process for the interview to ensure that the foster youth understood the study, and to answer any questions they had prior to commencing the interviews.

I list participants in Table 1, in alphabetical order of their pseudonyms.

Table 1

Participants

\begin{tabular}{lll}
\hline Pseudonym & Gender & Age \\
\hline Charlie & Male & 19 \\
Gemma & Female & 21 \\
Maggie & Female & 26 \\
Stephanie & Female & 23 \\
Vincent & Male & 24 \\
\hline
\end{tabular}

\section{Data Collection}

\section{Sources of Data}

In grounded theory, no set number of interview participants is required; instead, the researcher continues "until theoretical saturation takes place" (Strauss \& Corbin, 1998, p. 292). I needed to see how many potential research participants were interested in partaking, but at the minimum, I planned to interview between four and ten students. I gave myself a range because I did not know how many students would respond to my request to be interviewed. I planned to interview each student twice.

During the first interview, I asked participants a set of interview questions (see Appendix F) focused on the four S's proposed by Schlossberg (1981): situation, self, 
support, and strategies. These questions inquired into some background of their

experiences in care, but the focus was primarily on their experiences in accessing and persisting in college. The purpose of the second interview was to clarify responses or ask for additional information.

I conducted the interviews in public places. Interviewees selected the location for their interviews, but for their protection and mine, interviews took place in neutral public locations including coffee shops, parks and at the study institution campuses. The participant and I mutually agreed on locations.

I wanted to write notes during the interviews but ended up writing notes after each interview. Taking notes during interviews made participants uncomfortable and was distracting, stopping the flow of conversation. I stopped writing field notes during the interviews and wrote immediately after each interview. I wrote my field notes and observations down so I could look back on them for reference.

\section{Data-Collection Tools}

To fully collect the words of the participants, I opted to record the interviews using two small, discrete digital voice recorders. The reason for two was to minimize the chances of losing data in case one digital voice recorder malfunctioned. The interviews were transcribed by a professional transcriptionist, but I listened to the interviews and compared them to the transcripts to ensure that no information was missing prior to analysis. I also validated the accuracy of the interviews by asking participants to review their transcribed interviews and make any corrections, if necessary. 


\section{Data-Collection Process}

Potential participants received an informed consent form explaining the research study. Interested participants were asked to read and sign the consent form at the first interview, prior to the interview commencing. Interviews to collect data were determined at a mutually agreeable time and location, agreed upon by both the participant and researcher. At the start of each interview, I reminded participants that they were not obligated to complete the interview, they could refuse to answer any question, they could ask for the digital voice recorder to be turned off, and they could stop the interview at any time. The comfort and confidentiality of the participants was essential.

\section{Data-Collection Timeline}

The timeline for collecting data began upon IRB approval in December 2013 and continued through summer 2014. Analysis of the data was ongoing throughout the collection of data. Data analysis concluded when saturation was reached in late spring 2015. I then wrote the results.

\section{Data Storage}

All collected data were held in the strictest confidence. Participants received a numeric code during the data analysis and were given a pseudonym when referenced in the study. I placed informed-consent forms in a locked file drawer to which only I have access. The digital voice recorders were uploaded onto a disk, that was locked in a file cabinet as a backup system. I stored interview transcripts, memoranda, and coding on a secure network server that is password protected and backed up nightly. Three years after the end of the study, all materials will be destroyed. 


\section{Data-Collection Procedures}

Data collection consisted of quantitative and qualitative data. The first phase consisted of the quantitative demographic data which was collected from the Oregon Research Advising Consortium led by Allen and Smith in 2010 and 2011. Allen and Smith allowed me to include a question on their surveys which asked students to selfidentify if they were ever in foster care. Students may not have wanted to identify that they were former foster youth, so it was safe to assume that the numbers are higher than those reported; however, many former foster youth did respond to the question.

While only nine institutions were involved in this research, it does provide a view of some of the numbers of former foster youth in higher education in Oregon. The nine institutions that participated in the research were Chemeketa Community College, Concordia University, Eastern Oregon University, Portland Community College, Oregon State University, Portland State University, University of Oregon, University of Portland, and Western Oregon University. These institutions include 2- and 4-year post-secondary institutions, specifically community colleges and private and public universities. Student populations at the institutions ranged from a few thousand to over 30,000 enrolled students. Of the nine institutions, 28,147 students took part in the surveys.

\section{Data Analysis}

I used grounded theory to analyze the experiences of former foster youth in transitioning through higher education. Grounded theory was developed by Sociologists Glaser and Strauss (1967). With grounded theory "a researcher does not begin a project with a preconceived theory in mind" (Strauss \& Corbin, 1998, p. 12). Instead, the researcher allows the theory to emerge from data (Strauss \& Corbin, 1998). 
Strauss and Corbin's (1998) approach to grounded theory is a structured approach toward developing categories. Charmaz (2006) continued to build on the work of Glaser and Strauss (1967) and Strauss and Corbin (1998), but supported "flexible guidelines, not methodological rules, recipes and requirements" (p. 9). Charmaz (2006) allowed the researcher a more fluid and less rigid approach. Due to so little being known about the lived and transitional experiences of foster alumni in higher education, I thought grounded theory was the best way to approach the data. With no preconceived ideas, with this theory allowed for the voices of foster youth to emerge.

\section{First Interviews}

Qualitative data collection involved interviews with participants. At the onset of the meeting, I again told participants were told the purpose of the study, again gave them the informed-consent form to sign and offered them a copy of the consent form to keep. I gave each participant a \$20 Visa gift card as reciprocity. Participants and I then began the interviews. Interviews were approximately 60 to 90 minutes in length and I asked at regular intervals whether the participants needed a break. The interviews were recorded on two digital voice recorders to ensure I heard participants' words correctly and as a backup in case one recorder failed or malfunctioned during an interview. I then had the interviews transcribed by a professional transcriptionist.

\section{Second Interviews}

I conducted the second interviews in a similar manner to the first with a meeting in a mutually agreed upon public location. I again reminded participants that they could refuse to answer a question or stop at any time. The interviews were again recorded on two digital voice recorders to ensure capturing participants' actual words. I used the 
second interviews to elaborate or clarify information gathered in the first interview. All but one of the participants continued to the second round of interview questions. The one who did not continue gave no reason and chose not to respond to e-mail and text requests to set up a second interview. After two attempts at contacting the participant, I stopped, as it was the prerogative of participants whether they wanted to continue with the interview process or stop.

\section{Field Notes}

I attempted to take some field notes during the first interview and quickly realized that it made the participant uncomfortable, so I stopped. I continued not to take field notes during other interviews in an effort to put participants at ease. Instead, immediately following each interview I went somewhere quiet and wrote down my impressions, thoughts, and ideas regarding the interview while it was still fresh in my mind. I used the field notes, in conjunction with the transcripts, to formulate my questions for the second interviews.

\section{Data-Analysis Procedures}

Data collection and analysis occurred simultaneously through ongoing coding and memoranda. The first step, however, was to have the interviews transcribed. After the interviews were transcribed, I listened to them to ensure they were accurate, and no words or pauses were left out of the transcript. I then had participants check the transcript. None of the participants made requests to alter their transcripts. After transcription, microanalysis of the text began whereby I examined each line to begin open coding in order to identify concepts (Strauss \& Corbin, 1998). 
After that step I began open coding, which is the "analytic process through which concepts are identified and their properties and dimensions are discovered in data" (Strauss \& Corbin, 1998, p. 101). Microanalysis of data, which is "detailed line-by-line," is an important first step in coding as it is the start of developing categories (Strauss \& Corbin, 1998, p. 57). Open coding is followed by axial coding, which Strauss and Corbin (1998) described as the "process of relating categories to subcategories along the lines of their properties and dimensions" (p. 123).

Selective coding, which is the "process of integrating and refining the theory," then followed axial coding (Strauss \& Corbin, 1998, p. 143). Memoranda provided my thoughts, analysis, and questions that spurred additional collection of data. Memorandum writing began at the first stage of data analysis and continued throughout the research, taking several forms such as code notes, operational notes, and theoretical notes (Strauss \& Corbin, 1998).

Memos were written throughout the data analysis and interpretation, as they are a tool that allows the researcher to record "thoughts, interpretations, questions and directions for further data collection" (Strauss \& Corbin, 1998, p. 110). After open coding of texts, I began axial coding, which allows a researcher to "look for answers to questions such as why or how come, where, when, how and with what results" (Strauss \& Corbin, 1998, p. 127). The goal was to begin to understand what was occurring in the phenomena (Strauss \& Corbin, 1998) and then to look at the categories, properties, and dimensions that were beginning to emerge. The final step was selective coding, which Strauss and Corbin (1998) defined as "the process of integrating and refining the theory" 
(p. 143). Once theoretical saturation occurred, I began to construct theory, based on the data provided by participants.

\section{Analysis}

Data analysis began simultaneously with the collection of interviews and writing of field notes after each interview. Once the interviews were professionally transcribed, I reviewed them with the audio files to ascertain that the words of the participants were accurate. Once that was completed I then printed the transcripts and began to review each interview.

Initial coding. To begin analyzing the data, I started with initial coding, which as Charmaz (2006) notes allows for us to remain "open to exploring whatever theoretical possibilities we can discern in the data" (p. 47). The object at this stage was to examine

the data. The initial codes were meant to be "provisional, comparative, and grounded in the data" (Charmaz, 2006, p. 48). At this point in the analysis it was important not to attempt to define categories and instead remain open to what the data were actually saying. In addition, Charmaz stated that there is a "code for coding which consists of: remain open; stay close to the data; keep your codes simple and precise; construct short codes; preserve actions; compare data with data and move quickly through the data" (p. 49). Being open to what the data is saying is vital, but also balancing that with being close to the data is important (Charmaz, 2006).

Line-by-line coding. Line-by-line coding or microanalysis allows for the researcher to go through the data at a micro level, analyzing each line of data (Strauss \& Corbin, 1998). One issue with line-by-line coding is that not all lines are complete sentences, nor are they guaranteed to have data of value (Charmaz, 2006, p. 50). Even so, 
there is value to line-by-line coding as it allows the researcher to remain open and detect subtle shifts in the dialogue. A pause here or there may seem, initially, to have no value, but considered in conjunction with the entire line, may reveal data. The information gathered at this stage can help the researcher develop questions for later interviews (Charmaz, 2006, p. 50). Charmaz noted,

Following flexible strategies help you code: breaking the data up into their component parts or properties; defining the actions on which they rest; looking for tacit assumptions; explicating implicit actions and meanings; crystallizing the significance of the points; comparing data with data; identifying gaps in the data (p. 50)

The purpose of line-by-line coding also involves moving toward fit and relevance. Grounded theory requires that both those criteria are completed as part of analysis. The research "fits the empirical world when you have constructed codes and developed them into categories that crystallize participants' experience" (Charmaz, 2006, p. 54).

Relevance occurs "when you offer an incisive analytic framework that interprets what is happening and makes relationships between implicit processes and structures visible" (Charmaz, 2006, p. 54).

By conducting thoughtful coding, a researcher is more likely to leave out personal fears, motivations, or issues, especially if the researcher has first-hand knowledge of the area being studied. Researcher preconceptions and participants' assumptions can be left behind, and the data looked at in new ways (Charmaz, 2006). Researchers must constantly check their biases to ensure they are not inserting their viewpoint into the data or analyzing the data from their own experiences.

In vivo codes. Grounded theory refers to the usage of special terms by participants as in vivo codes (Charmaz, 2006). By closely monitoring the language of 
participants during coding it allows for the researcher to see in vivo codes as a "symbolic marker of participants' speech and meanings" (Charmaz, 2006, p. 55). However, not all in vivo codes will necessarily prove useful in the later stages of analysis. The key is to treat in vivo codes like any other code by comparing and analyzing them (Charmaz, 2006, p. 55). Participants may believe that the terms they are using are used widely when that may not be the case. Thus, a researcher must "look for their implicit meanings and attend to how they construct and act upon these meanings" (Charmaz, 2006, p. 55). Charmaz suggested that in vivo codes be unpacked not only to "understand implicit meaning and actions but also to make comparisons between data and with your emerging categories" (2006, p. 55).

Axial coding. Strauss and Corbin (1998) utilize axial coding in order to relate categories to subcategories, specifying properties and dimensions. As Charmaz (2006) noted, "initial coding fractures data into separate pieces and distinct codes" (p. 60), while axial coding takes the disparate pieces and brings them back together (Strauss \& Corbin, 1998). Axial coding answers the questions of "when, where, why, who, how and with what consequences" (Charmaz, 2006, p. 125).

Memoranda. Memoranda were written throughout the data analysis. Memoranda provide the researcher with a space to write down ideas, thoughts, and observations. Memoranda, or as Charmaz (2006) refers to them, "informal analytic notes" (p. 73) are part of the process. Writing memoranda serves several roles including being "the pivotal intermediate step between data collection and writing drafts of papers" and as a prompt "to analyze your data and codes early in the research process" (p. 73). Memoranda allow researchers to converse with themselves as new concepts and ideas can surface through 
this process (Charmaz, 2006, p. 73). Memoranda are meant to be "spontaneous and not mechanical" written in an "informal, unofficial language for personal use" (Charmaz, 2006, p. 80). Perhaps the most important aspect of memorandum writing is that it forces the researcher to "stop other activities; engage a category, let your mind rove freely ... and write whatever comes to you" (Charmaz, 2006, p. 81).

Selective coding. According to Strauss and Corbin (1998) selective coding is the point at which the researcher can begin "the process of integrating and refining the theory" (p. 143). As noted earlier, open coding is when the researcher focuses on developing categories and properties, followed by developing categories and subcategories in axial coding (Strauss \& Corbin, 1998). Integration then becomes the "interaction between the analyst and the data" (Strauss \& Corbin, 1998, p. 144).

\section{Researcher Positionality}

An important action of qualitative research is for the researcher to be transparent and acknowledge personal biases. In this spirit, my interest in foster youth comes not from any type of personal connection, but rather a broader professional goal to help traditionally underrepresented students gain access and persist through post-secondary education. As a first-generation student, I identify with students who have struggled to attain an education. My professional work as an academic advisor involves helping students to navigate the policies and procedures of the university, defining their educational and career goals in line with their personal values while persisting toward degree completion. My focus on this research project comes from a desire to learn more about the experiences of foster youth in order to provide services and supports for them, 
but also to educate fellow practitioners who may be largely ignorant about this invisible student population.

\section{Ethical Considerations}

I am aware of several ethical considerations involved in studying a vulnerable population. As a group, foster alumni are marginalized and have had little control over their own lives. I asked foster alumni to share their personal stories with a stranger. For some foster alumni, revisiting their past may be extremely painful and cause distress by bringing up past trauma. Because of the nature of the study, I needed to be respectful of participants' experiences. I have not been in the foster care system, nor do I have any experience in that area, so in order to be transparent, I needed to acknowledge that to my participants. I upheld the highest standards of ethical inquiry as I pursued and conducted interviews with participants.

\section{Giving Back to Participants}

The foster youth I interviewed gave me their time, perspectives, and stories, and I needed to find a way to honor their generosity. The concept of "reciprocity" deals with how and in what way the researcher gives back to their study participants (Creswell, 2007). How does the researcher make participants feel valued for their role in the study? I struggled with this issue as I recognized that monetary gifts may cause a participant to alter what they would say to please the researcher. After careful consideration, however, I felt that offering a small gift card in the amount of \$20 per participant allowed me to honor their time and energy, yet was not such a significant amount that it would alter participants' responses. Participants received the gift card even if they decided after the 
first interview or at any time in the process to withdraw from the study. At the conclusion of the interviews, I sent each participant a thank you letter (see Appendix G).

\section{Vulnerability of Participants}

While the study questions mainly focused on participants' experiences in college, some questions focused on participants' experiences in foster care. It is reasonable to expect that some participants would become emotional when discussing their past. I planned ahead and had contact information for counseling services at the study institution with me when interviewing and also that of a local agency, in case the interview took place on a weekend and the study institution's counseling center was not open. If a participant became visibly upset during an interview, I planned to stop the process and refer them to counseling. I also recognized that I needed, if possible, to end the interview on a positive note (as suggested by Charmaz, 2010) and conclude each interview in such a way that the participant did not feel it was abrupt (aligned with Creswell, 2007).

\section{Interview Locations}

Finding an appropriate setting to conduct in-depth and personal interviews is difficult. I needed to balance my support for participants to feel safe along with my own personal safety. Although coffee shops are neutral locations, they also provide a great deal of background noise, which can make it difficult to hear the participant responses. Also, coffee shops provided an opportunity for a participant to be seen by someone they knew. At the same time, offices or classrooms may shift the power differential and the participant might have felt uncomfortable in such a setting. Even so, I allowed the participants to determine meeting locations and they each chose locations that provided some privacy while also being public. I conducted interviews in coffee shops, city parks, 
and at the study institution in the student union. The outdoors was a perfect neutral area. In the event of inclement weather, we found a quiet place on campus or another neutral location for the interview. I offered participants a cup of coffee or tea as a gesture of goodwill and to make the interview appear less formal and intimidating.

\section{Anonymity and Confidentiality}

Participants in the study needed to know that their personal information was being kept confidential. Therefore, each participant had the informed consent form explained to them, and only I and my doctoral advisor had access to those forms, as they were locked in a file. I assigned each participant a numeric code for the transcription process and later assigned a random pseudonym for the dissertation to maintain their confidentiality. While I coded each participant numerically and then gave them random names, I also attempted to remove any identifying traits. I cannot guarantee anonymity as participants themselves may discuss with others their participation in the study. Research participants were, however, allowed to review their transcripts and add or delete anything they did not wish included.

\section{Limitations of the Study}

The present study contributes to the field; however, it has limitations. The first limitation was the small number of participants. Ideally, I would have liked more participants, as the sample was small; the study ended with five participants. In grounded theory, numbers of participants vary. The goal is that theoretical saturation has occurred, and no new data is forthcoming (Strauss \& Corbin, 1998). In addition, participants willingly self-selected to take part in the research. 
Initially one of the goals was to interview foster youth who were still in care along with those who had exited. While plans were made to be able to interview current foster youth, none ended up participating in the study. The data of youth currently in care and transitioning to higher education would have been valuable to the study.

Another limitation is geographical in that I only invited youth in the State of Oregon and specifically in a metropolitan area to participate. Interviewee responses in rural areas and in other states might yield different results. Even so, the results of this study may begin to help in examining the lived experiences of foster youth as they transition into and through higher education. Additional suggestions for further research are addressed in Chapter 5.

\section{Chapter Summary}

Foster youth who begin higher education have already survived difficult life transitions; however, the act of going to college means even more transitions for this vulnerable population. The numbers of foster youth who receive their bachelor's degree are exceptionally low, yet little is known about how foster youth experience their transitions into and through higher education. Academic advisors are natural allies for foster youth, but it is possible that foster youth do not use or see them as educational supports. There is ongoing national advocacy for educational supports and institutional agents to help foster alumni overcome barriers and persist (Casey Family Programs, 2008; Emerson et al., 2012).

This chapter outlined the methodological approach to the study of the experiences of foster youth as they transition into and through higher education. The goal was to come to an understanding of the transitions foster youth experience in college. Given that 
community colleges are often the gateway to higher education for foster youth (Allen et al., 2011; Casey Family Programs, 2008) I interviewed foster alumni at the study institution to better understand the transitions foster youth experience.

I used grounded theory to analyze the data and generate theory as to the experiences of foster alumni in college. While the outcomes of being in foster care are well documented, what happens to foster youth in college is not well known. This study makes a small contribution to a better understanding of foster alumni in higher education. Thus, the work may play a beginning role in informing practitioners as well as helping identify possible implications for policies and practices moving forward. 
Chapter 4: Results

The purpose of this qualitative study was to consider the transitions of former foster youth in accessing higher education through a community college by using grounded theory to develop emerging themes, thereby giving foster youth a voice in their own experiences. A final sample of five former foster youth participated in interviews, answering open-ended questions to describe their educational and transitional experiences. In addition, quantitative data from the Oregon Research Advising Consortium provided a snapshot of the demographics of foster youth in Oregon higher education in $2010 / 2011$. The purpose of embedding a question on the research survey asking whether youth had been in foster care was to provide the numbers, unknown by the Oregon University System, of foster youth in higher education in Oregon, and also to identify the gateway institutions providing a pathway for foster youth.

The research questions for this study provided participants the space to discuss their experiences transitioning into higher education. The overarching question for this research was What are the experiences of foster youth who enter higher education through community college as they navigate transitions into and through post-secondary education. The question provided the framework for a series of open-ended questions asked during initial interviews, which provided participants opportunities to discuss their own experiences transitioning into higher education through a community college. The format also allowed participants to expand on or clarify their experiences during the second interview. 


\section{Quantitative Results and Demographics}

As evidenced by a quotation from the Oregon University System official, whose comments suggested foster youth were not even on the radar; foster youth are, for the most part, invisible in the state and they have not received attention from practitioners, administrators, or policy makers in post-secondary education. That lack of attention led me to ask the following research questions:

RQ1. How many current and former foster youth self-identify as such in Oregon higher education in 2010 and 2011 ?

RQ2. What are the gateway higher education institutions in Oregon?

RQ3. What is the percentage of current and former foster youth who selfidentify with the institution?

RQ4. What types of institutions are foster youth most likely to attend?

The quantitative data was collected from the advising research consortium of which I was a part, along with Drs. Allen and Smith. There was a question embedded in the survey which asked students whether they had been a foster child. The numbers and percentages shown are from those students who answered the survey. The actual numbers may be higher, as not all foster youth may have chosen to self-identify. The results clearly show that Chemeketa Community College had the highest number of foster youth at $7.5 \%$ and Portland Community College had the second highest number with $6.3 \%$. Portland State University and Western Oregon University with 4.1\% and 4.0\% respectively, also showed significant numbers of former foster youth in attendance. However, it must be noted that the numbers at Portland State University indicated that, as the largest public university close to Portland Community College and in the largest urban area of the state, foster alumni are transitioning to Portland State University to 
complete degrees. The large number of former foster youth at Western Oregon University is not surprising, given that the midsized public university has a mission to serve traditionally underrepresented students. Also, Western Oregon University is close to Salem, the second largest metropolitan area in the state. Thus, the mission and location of Western Oregon University makes it an attractive institution for foster youth. Based on the data collected, nearly $5 \%$ of students enrolled in higher education in Oregon selfidentify as having been in foster care.

\section{Foster Alumni and the Community College Pathway}

Data from the surveys indicated that in the State of Oregon, Chemeketa Community College, Portland Community College, and Portland State University were the three institutions with the highest percentage of foster alumni registered as students at the time of survey collection. The gateway to higher education in Oregon for former foster youth is through the community college. Looking at the population of the state, it makes sense that these areas would have the highest number of former foster youth, as the institutions are located in the most populous areas. Chemeketa Community College is located in Salem, the state capital, and the second largest city in Oregon. Both Portland Community College and Portland State University are located in the largest city in the state.

Table 2 shows the institutions in the academic advising consortium where foster youth opted to attend college. Not all students who responded to the survey answered the question regarding foster youth status. Also, not all students who began the survey completed it. 
Table 2

Where do Former Foster Care Youth Attend College?

\begin{tabular}{lrrrrrc}
\hline \multirow{2}{*}{\begin{tabular}{c} 
Have you ever been a foster \\
\multicolumn{1}{c}{ child? }
\end{tabular}} & \multicolumn{1}{c}{$n$} & \multicolumn{1}{c}{ No } & \multicolumn{1}{c}{ Yes } & $\%$ & \multicolumn{1}{c}{ Total } & $\%$ \\
\cline { 2 - 7 } Chemeketa Community College & 2,246 & 92.5 & 182 & 7.5 & 2,428 & 100 \\
Concordia College & 418 & 96.8 & 14 & 3.2 & 432 & 100 \\
Eastern Oregon University & 1,127 & 96.2 & 45 & 3.8 & 1,172 & 100 \\
Oregon State University & 3,701 & 97.8 & 84 & 2.2 & 3,785 & 100 \\
Portland Community College & 9,320 & 93.7 & 622 & 6.3 & 9,942 & 100 \\
Portland State University & 2,572 & 95.9 & 110 & 4.1 & 2,682 & 100 \\
University of Oregon & 3,497 & 98.0 & 72 & 2.0 & 3,569 & 100 \\
University of Portland & 1,558 & 98.4 & 26 & 1.6 & 1,584 & 100 \\
Western Oregon University & 1,401 & 96.0 & 59 & 4.0 & 1,460 & 100 \\
Total & 25,840 & 95.7 & 1,214 & 4.5 & 27,054 & 100 \\
\hline
\end{tabular}

Table 2 only gives an estimate of the number of former foster youth in Oregon higher education institutions, as not all Oregon institutions participated in the advising consortium. In addition, some former foster youth may have opted to not self-identify. However, based on the above numbers, additional institutions would have similar results, showing that community colleges have higher percentages of former foster youth attending.

Table 3 presents the results of a Chi-square analysis in which I examined whether participants' responses to the survey question "Have you ever been a foster child?" was associated with the type of school from which he or she entered the university (student admission type): directly from high school, a community college, or another 4-year institution. Chi-square analysis was statistically significant, suggesting an association between having been a foster youth and the student's admission type. To examine if former foster youth status aligned with specific student types, I calculated 2 by 2 
contingency tables from the data and conducted individual chi-square analyses. Results showed that participants in the survey who had not been a former foster youth were nearly twice (1.99) as likely to enter a university directly from high school $\left[\chi^{2}(1)=\right.$ $31.550, p<.0001]$, whereas those who had been in foster care were nearly twice $(1.88)$ as likely to be community college transfer students $\left[\chi^{2}(1)=22.360, p<.0001\right]$. Although the results were not as robust, chi-square analysis showed that former foster youth were somewhat more likely (1.39 times) to be transfer students from other 4-year institutions $\left[\chi^{2}(1)=4.140, p<.042\right]$.

Table 3

Results of Chi-square Analysis Comparing Student Type with Former Foster Youth Status Former foster youth

\begin{tabular}{lcrrrrc} 
& \multicolumn{2}{c}{ No } & \multicolumn{2}{c}{ Yes } & \multicolumn{2}{c}{ Total } \\
\multicolumn{1}{c}{ Student admission type } & $n$ & $\%$ & \multicolumn{1}{c}{$n$} & $\%$ & $n$ & $\%$ \\
\hline Direct from high school & 5,788 & 61.7 & 123 & 44.9 & 5,911 & 61.2 \\
Community college transfer & 2,170 & 23.1 & 97 & 35.4 & 2,267 & 23.5 \\
$\begin{array}{l}\text { Transfer from other 4-year } \\
\text { institution }\end{array}$ & 1,428 & 15.2 & 54 & 19.7 & 1,482 & 15.3 \\
Total & & & & & & \\
\hline Note. $\chi^{2}(2)=32.861, p<.0001$. & 9,386 & 100.0 & 274 & 100.0 & 9,660 & 100.0 \\
\hline
\end{tabular}

If the gateway to higher education for former foster youth is through community colleges, then what are the additional reasons they attend community colleges? Table 3 presents the reasons former foster youth gave, through the survey, for attending community college. The data suggested that the reasons former foster youth attended community colleges did not differ appreciably from those of other students.

To examine whether a participant's response to the survey question "Have you ever been a foster child?" was associated with identifying the reason for attending the community college as being to "earn credit toward a bachelor's degree," I calculated a 2 
by 2 contingency table from the data presented in Table 3. Chi-square analysis showed no significant association: former foster youth are not more or less likely than their peers to give the reason for attending the study community college as to earn credit toward a bachelor's degree.

Table 4

Reasons for Attending the Study Community College

\begin{tabular}{lrrrr}
\hline & \multicolumn{2}{c}{ No } & \multicolumn{3}{c}{ Yes } \\
\cline { 2 - 5 } \multicolumn{1}{c}{ Have you ever been a foster child? } & \multicolumn{1}{c}{$n$} & \multicolumn{1}{c}{$\%$} & $\%$ \\
\hline Earn credit toward bachelor's degree & 5,418 & 58.2 & 356 & 57.3 \\
Learn English & 102 & 1.1 & 9 & 1.4 \\
Take ABE/GED class & 30 & 0.3 & 5 & 0.8 \\
Complete certificate or career technical program & 1,911 & 20.5 & 114 & 18.4 \\
Take course for personal interest & 218 & 2.3 & 12 & 1.9 \\
Explore educational opportunities & 207 & 2.2 & 24 & 3.9 \\
Take class for HS credit & 125 & 1.3 & 8 & 1.3 \\
Improve writing, reading, math skills & 81 & 0.9 & 14 & 2.3 \\
Learn skills to get or keep a job & 432 & 4.6 & 25 & 4.0 \\
Explore new career area & 781 & 8.4 & 54 & 8.7 \\
\hline
\end{tabular}

\section{Qualitative Results and Emergence of Themes}

The foster youth in this study ranged in age from 18 to 26 years; three participants were female and two were male. At the time of the study, one participant was homeless and two had minimum-wage jobs to support themselves. One participant had a skilled job but was working under 20 hours a week and the final participant was using financial aid to pay tuition and living expenses. Several themes emerged from the data following analysis. 


\section{Emerging Theme 1. From Foster Care to the World (From Dependence to Independence)}

Most young people beginning college face multiple changes as they are developing and maturing away from their families. Foster youth face an especially difficult transition as they are often on their own with no safety net of a family to care for them if they struggle. In addition, foster alumni are in the process of trying to become independent yet also reconciling their experiences in foster care and their feelings toward their birth families whilst trying to attend college.

For each participant in the study, the transition from complete dependency on the state to independence was overwhelming, and in some cases traumatic. The transition represented a period of disequilibrium for the foster alumni and, at the time of the study, some of them were still trying to make sense of their experiences in care. Vincent explained it this way.

I would describe it as a million-piece jigsaw puzzle. Um I say that because when you are in foster care, it's crazy because like you have all these people trying to tell you what your life is about and not because it has any particular disposition toward your experience or towards you as a person, but because they are doing their job. And that is to fulfill a role in a court of law. Now what happens when everyone tries to tie those things together, because there are a few things going on you know. ... But also, the relationships themselves get pretty tangled, because people start doing other people's work. ... You never know which way you are going especially when a case worker is telling you where to go physically in the world.

Vincent stated he was a "product of the State of Oregon" and was "jaded" from having been in the system. The foster alumni in this study spent anywhere from 3 to 16 years in foster care and the number of foster care placements were from three to the top number of 16 , ranging from individual foster homes to group homes. 
Gemma reflected on her foster home placements by commenting that she often felt out of place and misunderstood.

They just treated me like I was an alien because I guess I didn't live up to their expectations. Maybe they were looking for fulfillment through trying to help someone. It was kind of more for their own personal needs, like they needed to feel helpful and giving, because they weren't exactly receiving from me, that they just kind of took it personally, and just thought something was wrong with me. Eventually I ran way.

Gemma went on to state "How can you be that dense to not see right in front of your face that a child is not feeling well and not console them or try to understand or help them?" When Gemma left her final foster home, she moved in with a boyfriend and a friend. She noted that it was her first experience "living on my own." The situation with the boyfriend turned controlling and eventually Gemma moved out to take care of herself. She commented that after the experience of living with her boyfriend and his friend she became a "total feminist."

Family of origin. For each participant, the pull of their biological families was still at play in their lives. While several of them could talk unemotionally about the neglect and abuse they experienced, they still yearned for connection with family. Even though some of the foster alumni recognized they had to choose between their own lives and that of their parents, the fractured family relationships still troubled them. Vincent voiced this when he said, "What has hindered me is probably my separation from my family and my desire to know what they are doing, but then also being very cautious about that situation, so oftentimes feeling timid in times of stress."

Other participants had to address mental health and alcohol and substance-abuse issues in their families, which had a negative impact. Gemma commented "With my mother's extreme mental illness, she became very abusive towards me, emotionally and 
physically. My father was just totally out of it all the time.” At one-time Gemma ran

away to live with other family members in Oregon, but they also struggled with alcoholism.

There has always been a lot of dysfunctional family dynamics. That's what I did, I ran way up there, up here, and I lived with my aunts and my step-uncle for a while. ... Like I said my parents were never there for me, to guide me. ... Nobody was there to guide me or tell me that I shouldn't do this. I did these things because I was too young to decide and also, because I had such low self-esteem. That way when I ran away, it was not only from the dysfunctional household, but I was running away from my past.

When Oregon did not consider Gemma a resident, she was sent back to the home state.

When she arrived by train "nobody came to pick me up like they said they would at the train station. Just no one showed up that day. I am, wow, nobody really gives a shit to help me."

For Maggie, being alone and feeling alone all the time was difficult to overcome. When asked what had been least helpful in her experiences, she replied, "Probably not having any parents, not having family support." The holidays proved especially difficult.

I don't have a lot of help. It is just myself. ... Especially you know how you have like the holiday break or you have a Thanksgiving Day off, and it is really hard not having like - it is painful, not having a family to go home to.

Maggie talked about foster youth trying to form a family of choice through other

relationships. She acknowledged that those attempts are often unsuccessful and

detrimental to the welfare of the foster youth.

And typically, we choose pretty co-dependent, not-good relationships. So, I think if there was some way-I don't know if it is possible to not choose a boyfriend when you are that age, because you just want to be loved, but I think if you could focus on yourself and like really nurturing yourself rather than trying to jump into a relationship or jump into a group of friends that you think are your family, but really, they are not. If I could have focused more on myself and recovering from my childhood wounds rather than try to be social and going to parties and trying to cover up all those painful spots that I never dealt with. 
Gemma had similar comments and talked about moving from her last foster home in with a boyfriend who turned out to be controlling.

It is one of those situations where you are dating them for over a year. They seem really nice and kind all the time while you are dating them. Then when you move in with them, it is like he became a totally different person. He became really controlling with me.

For Gemma, this experience was negative, but also "very intense and powerful." Moving out and breaking up with her boyfriend allowed Gemma the opportunity to take control and move on with her life.

Taking the first steps out into the world as an adult is frightening, but even more so when young people do not have a family support system on which to rely. The pull of the biological family remains deeply embedded and each of the participants felt mixtures of sorrow, anger, fear, and aloneness.

Trust issues. Several participants noted they struggled to trust people as they felt that everyone in their life in foster care had been paid to be there. Even individuals who were paid to be there often did their job with a focus on the process instead of the best interests of the foster youth. Vincent summed this feeling up succinctly:

I guess there are a lot of people looking out for me, and, um, they are really looking out for the status of the court date ... versus trying to help me.... When you are in foster care, it's crazy because like you have all these people trying to tell you what your life is about, and not because it has any particular disposition toward your experience or towards you as a person, but because they are doing their job.

Vincent noted that coming out of foster care meant that you were on "shaky ground" and trying to find your balance in the world. He described his experiences in foster care as "intense" "traumatic at times" and a "million-piece jigsaw puzzle."

Again, not really having anyone there when you exit care, at least someone who has already been there for a long time, it is really hard to see the momentum that 
life is taking you. I didn't really have a good bearing or mental compass to kind of direct me into the direction I wanted to go.

Gemma articulated her feelings about having been in care as being invisible to society at large, noting that most people are unaware of the foster care system. Gemma equated the experience of exiting foster care as being "anonymous."

Yeah, foster children are obviously at a great disadvantage from the beginning compared to most people. They don't get a foot ahead in the race, in life, so yeah it is very common that they get left behind a lot of times. ... Yeah, there has always been that sense of kind of being an under-class in society.

Academic preparation. None of the participants in the study thought they had the academic support in high school to prepare them for college. In addition, though some participants had a small number of foster home placements, all but one had multiple school placements, which impacted their school performance. Vincent commented "The school placements, I don’t even know, a lot."

Maggie said "I think when I graduated; my transcript was ridiculous, like ten schools total for junior high and high school. It was really bad.” Multiple school placements left the participants in a position of trying to catch up academically with their peers. Maggie commented,

Definitely made me think I was like a slow learner, because every time I would go back to school and start into a new classroom, um, I felt like I was behind. It wasn't because I was stupid, or I wasn't smart. It was just that I had missed curriculum, or sometimes districts teach different or they would repeat the same curriculum, so I felt like I was getting too much of something or wasn't getting enough. So, it wasn't consistent for my grade level.

Surviving foster care. Several of the participants talked about their view that they had survived foster care and felt free. Even though they had come from situations of neglect, abuse, or maltreatment, their feelings about their experiences in foster care were 
genuinely negative. Participants with the highest number of placements had the least satisfaction with having been in care.

Vincent had 14 placements in foster care including residential facilities and foster homes. He described his experiences in foster care as "intense, traumatic at times." Stephanie found herself living with a foster family that treated her like an unpaid maid. Finally, a new caseworker understood her situation and moved her into another home. For Stephanie, this was empowering because she found her voice to speak up against something she believed was unfair.

So, I felt like if you speak up and you make sure you are heard, whether with your caseworker or with your attorney at the time, make sure you are heard because they may say what they feel is right for you, but it is not coming from you, from what you know is right for you. I found out the hard way, which I should of spoke up from the beginning.

Vincent articulated it this way, "What I mean by that is that with my foster care, it is kind of like a mind state that I had to have that wasn't really about living so much as surviving." He noted that there is "miscommunication and failure to communicate" in the system and that "you never know which way you are going especially when a case worker is telling you where to go physically in the world."

For Charlie, his time in foster care was traumatic. He figured out quickly that in order to survive in group homes he needed to fight. He stated "I just learned to fight when I was in group homes because you had to do that to make it pretty much. You had to fight, so I was good at it."

Some participants believed no transition plan was in place for them upon leaving the foster care system. Charlie commented "when I graduated high school they couldn't 
keep me there anymore, so they pretty much just got rid of me." Maggie's transition from foster care to independence was especially harsh:

So, when she (social worker) knew that I was just coming up on my birthday to emancipate, I didn't hear anything. It was just, "Ok, go to court on this day." Why do I go to court? I have no idea what emancipation really means. It just means the state is just they have no- they are not required to look after you anymore. Nobody explained anything to me. So, then I go to court and then the judge said, "You are emancipated, you are free, goodbye" Ok, what does this mean? So, it was just like, you are out and one less person that I have to worry about.

Several of the participants wanted to prove that the people who did not believe in them when they were growing up were wrong. Stephanie said, "I want to be able to make something of myself and prove those that were not behind me 100 percent and were down-talking me, to prove them wrong and let them know like, I made it."

Positive role models. Several participants had a concerned adult in their lives who believed in them and encouraged them to succeed. For Maggie, it was her high school principal who saw that she was intelligent and would make a point of commenting on her intelligence. As she stated, "He was the only one who would say that kind of thing to me."

Stephanie had a teacher in high school who constantly monitored her and let her know she was on Stephanie's side. The teacher understood that Stephanie was struggling and pushed her to keep going.

I would, of course, try to duck and dodge her and she would tell me, "You know, it's not everybody that's not trying to be there for you. You just have to open up your eyes and see it." ... She made sure I graduated on time. I do thank her for that because I feel if I didn't have that extra support, I probably would be a dropout somewhere, doing God knows what.

Stephanie was also fortunate in that from the time of her first foster home her foster mother told her, "Be who you want to be, go to college, fulfill your dreams." 
Stephanie had people believing in her and encouraging her to go and pursue her dreams.

In addition, Stephanie had another motivator; she is also a mother.

I'm looking forward to completing college and this is a big goal for myself, not only for me, but also my children. I feel if I do this, they can see. ... I have two little people who count on me and I have to finish it, no excuses. I just have to go for it and finish no stopping.

Vincent had support from a friend he met in high school and the friend's father.

Vincent also believed he was fortunate to connect with the Independent Learning

Program (ILP) just prior to exiting care.

I was just lucky enough, in the nick of time, right before my case was closed to get assigned to ILP, because no one told me about this, no one did. That is what I'm talking about, people thinking it is other people's job to tell people things. That is a very important part. Again, it is a million-piece puzzle, because you have to go back and pick up these pieces.

Vincent used the "million-piece puzzle" and "mental compass" metaphors repeatedly in his interviews. For Vincent, the experience of being in foster care left him feeling he was picking up pieces of a puzzle to put his life together. He recognized that there is information, which has been lost or not passed onto him, and he is constantly finding or looking for the pieces.

Like each of the participants, Vincent was lacking in cultural capital. He fully recognized that basic pieces of information are missing from his life and experiences. Vincent, like the other foster alumni, felt frustration in knowing he lacks knowledge, compounded by the fact that others hold that knowledge and foster alumni are unaware even what the knowledge is. The mental compass Vincent references in his interviews represents his internal process. He explained 'I didn't really have a good bearing or mental compass to kind of direct me into the direction I wanted to go." 


\section{Emerging Theme 2: Moving to Oregon to Start Over}

One interesting result of this study was the fact that three of the participants had moved to Oregon from another state. Initially, my goal was to interview youth who had been in the State of Oregon foster care system, but the first three respondents who went through to the interview stage had moved to Oregon from another state. I found this intriguing and wanted to know their rationale for leaving their home states, along with their experiences. There were, however, unforeseen consequences for the foster alumni who made the decision to move states, which I will discuss further in another emerging theme.

For each of the three foster alumni who moved to Oregon, it became apparent in their interviews that moving went deeper than going somewhere to start over again, although that was part of their reasoning. A more urgent element to relocate out of state was self-preservation in that the foster alumni believed they needed to move away to save themselves. Putting distance between themselves and their former lives was vital to them. Their biological families were disruptive to their well-being and each of these young people left in order to survive and build a new life. Charlie commented about his biological mother "I just couldn't do it anymore. She was killing herself slowly and I didn't want to sit there and watch it happen. I left. I saved up enough money to get on the bus and I left." Charlie made the choice to get as far away as his funds were able to take him and arrived in Portland homeless and not knowing anyone. As Charlie noted "this is as good a place as any when you have nothing." He had no support system in place at the time of the first interview, but by the second interview, he was tapping into some community resources that were beginning to help him. 
Some participants felt guilty at choosing themselves over their biological families, something which Maggie struggled.

Yea, um, I just [county] is so overwhelming. ... I felt like if I didn't get out of the bubble, I just needed to get away and study. Oregon, it is like there is nobody up here, nobody up here, compared to [county]. It is really sad for me to get away from my younger siblings because they are still in and out of foster care and they are still in a very precarious situation. It is very hard for me to separate myself from them, but I felt like I needed to in order to finish school and to really study. So, I think it was really good for me, for my education it is great. But emotionally it is really hard for me to not be depressed and feel that separation and that trauma again ... so I applied here because Oregon looked amazing and I just wanted to get out of [state].

Gemma, along with Charlie and Maggie, left her state and came to Oregon.

Gemma had bounced back and forth between foster care in her home state and Oregon, so she was familiar with Oregon and chose to come to Oregon. Her last foster family was in Oregon, but she expressed no desire to return to her home state. Leaving that state meant leaving behind her family and the neglect she endured.

\section{Emerging Theme 3: The Need to Help Others}

A consistent emerging theme with each of the participants was their desire to help other people. In some ways, the foster youth sought to make sense of their experiences with their families and in the foster care system and helping others provided them an outlet. Perhaps for the foster alumni in this study, looking at taking something negative and turning it into a positive was one way of coping with their experiences. For example, if they underwent such difficulties, then maybe there was something good to come from all the pain they experienced as children and youth. Gemma was planning to obtain her associate's degree and then transfer to a public 4-year university to pursue a career in a field where she would be helping people. 
Everything about it made sense to me, who I was, and it would provide me a way to be able to reach out and help people. This is also really important to me. I really want to help people in need in some way, just because of everything I've been through.

Vincent also felt a strong pull to help other people. At the time of the first interview, he was considering pursuing a degree as an emergency medical technician. Highly articulate, Vincent expressed an inquisitive nature and was open to learning. His rationale for being an emergency medical technician was based on his desire to help others. He stated that he "just kind of have this have an inner calling to help people who don't know how to be helped." Vincent commented, "I am really drawn to helping people" and that he "really wanted to be there for someone in their darkest time." He acknowledged, "I want to survive and want to help other people survive." Vincent went on to say:

What I mean by that is that with my foster care, it is kind of like a mind state that I had to have, that wasn't really about living so much as surviving. ... Other than that, just kind of have this inner calling to help people who don't know how to be helped.

Even though Charlie was homeless at the time of the interviews, he still had time to volunteer with an organization at the study institution. While it was certainly a way for him to make connections, it also allowed him the opportunity to help others. When asked why he volunteered, Charlie responded, “I just volunteered, because, I don’t know, just thought I'd do something nice." Interestingly Charlie opted to help at a multicultural event at the community college. Although While he was admitted to the study institution, he had not yet begun classes there. When asked if he was part of that multicultural group, he responded no and explained his rationale for volunteering: "No, just help out, I guess. I don't have a lot of [inaudible]. That doesn't mean I can’t help out when I can.” 
Maggie almost died when she was in her teens and ended up in hospital due to medical neglect from her biological family. She remembers her time there.

I just remember thinking, I hope there is a God out there, I'm not sure, but I remember pleading with like the universe, "if you save me and let me live, I will be a physician and save other kids in my spot and have empathy and try and save people."

Maggie's experience led her to want to follow a career path in medicine and focus on helping other children in similar situations.

\section{Emerging Theme 4. Education as a Pathway (Future)}

For each of the participants, pursuing higher education signified a life away from their past and toward a more stable future. At the same time, participants could not always articulate how education would benefit them, but they felt strongly that obtaining a degree would give them opportunities in life they did not currently have. College represented freedom from poverty, but more importantly, personal freedom and a lack of dependence on others. Maggie was able to articulate the situation.

So, I feel like if I don't go to college I have nothing else to really fall back on. I really need to build my own career, so I have a life and finances. So, college represents having a life outside of poverty and foster care. College represents fun times-I don't know, I love school. I love learning. I love, it's like my whole happiness. I feel very happy when I am in college. I know that I'm being educated, which I love. And I just feel very lucky.

Gemma commented that she did not "want to be dependent on some man" and education would allow her to pursue her love of learning and redefine herself.

I always wanted to go (to college) because I always loved learning and just being an intelligent person. ... I think another reason is I thought it was a way for me to become a new person, like I finally have control over my own life.

The pursuit of a college education represents control over her life, which up until then had been controlled by others. College was one of the first big life experiences Gemma 
was choosing for herself. Gemma went on to explain "I guess I just kind of knew inherently that it was a ticket to freedom, that it was a way to have control over my own life."

Stephanie had a very clear idea of why she wanted to attend college: to take care of her children and also make them proud of her.

I'm trying to be the best mom and set a good example for them, and not go the route that my mother went. I want to let them know that they are loved and I'm trying to stay out of trouble, just getting my - I have my high school diploma and now I'm trying to go for my associates and then go from there.

In addition, Stephanie recognized that she could also be a role model for others. She stated, "My goal is to set an example for my daughter and for my little sister and for anybody else that looks up to me." Of interest, is that Stephanie recognized that she had a support system in Portland and if she left to attend college elsewhere she might get caught up partying and end up back in Portland with nothing to show for her college endeavor. She stated, "like my best bet was to stay here." Many of her friends were choosing colleges because their friends were going there, but Stephanie had a defined sense of self and recognized she would be better off staying in Portland where she had support.

I was, "Well if I do go somewhere else out of state it is going to be for me and I'm probably not going to go where everybody else goes." Then I was just saying I should just stay here, because I have a lot of family. Like I said, all my support is here.

Vincent had academic aspirations and wanted to achieve good grades and get on the honor roll, which was important to him, but more important was his desire to connect with people. He stated, "I want to do that because it also will help me to reach out to 
more people and connect to more people." Vincent goes on to express that education is vital to him.

If I go to school, somehow it is going to make me a better human being. It is going to make me more informed, perhaps. It is going to do all these things. It is going to provide all these things. Mainly it is going to provide a bigger paycheck for me and that is not enough of an incentive for me to go to school. I want to go to school because I want to learn. ... I want to be with people and I want to read some of the books that they recommend to me. I want to build these connections.

Vincent wanted to have "shared experiences" with his fellow students. He viewed education as a pathway to connecting with other people.

During the course of the first interview, Charlie mentioned that he chose to go to college to learn a skilled trade. He had recently lost a good friend and wanted to build something as a form of dedication to his friend and the dreams they shared. Of all the participants, Charlie was the most confused about how the community college works. He acknowledged that he would like to study Italian and history, but he had no sense of how one obtains a 2-year degree. Charlie mentioned he would like to eventually transfer to a 4-year institution but was unclear how to transfer or even how to plan for it. Charlie's statement suggested that not only is he lacking in educational-planning skill, but that he is living in the moment, afraid that if he makes plans he will be disappointed.

The way I see it, if I plan something, I pretty much set myself up to fail, because anything could change within that time period and just throw you all off. So, like I said, expect the unexpected. I live pretty much every day at a time, a day at a time, so I don't really think ahead.

At the same time, Charlie mentioned that applying to the community college was "different, complicated," but Charlie was aware that his confusion was due to his lack of experience with such a process. Charlie found the entire experience to be intrusive and uncomfortable. 
Too many questions - they are asking a lot about, I don't know, certain personal things. They give you the decision whether you choose to talk about them or not and I didn't, but I mean, I don't know, they are trying to get all the input they can.

For each of the foster alumni, education was a pathway out of their former life in foster care and on to a different life. While they often did not have that life defined and clear in the mind's eye, nevertheless the pathway leads to a life away from foster care and one where the foster alumni get to make their own decisions and choices.

Subtheme to 4: Nothing to lose. For several of the participants there was recognition that while college represented a defined pathway to a better future, at the end of the day they had nothing to lose by pursuing post-secondary education. Their feelings were best expressed by Maggie.

Plus, I have nothing. I don't have parents. I don't have grandparents. I don't have a family that's, "We will help you financially," I don't have a home to go to I mean. My strategy is that I have nothing to lose, because I have nothing.

\section{Emerging Theme 5: The Need to Belong (Somewhere/Anywhere)}

The experiences in foster care and with their biological families had left hidden scars on each of the participants. While foster care ends, the ramifications of the trauma experienced by participants continued beyond emancipation from care. Each foster youth in this study talked about being alone. Maggie said "It is still painful, and I still feel alone. I feel you are the only one looking out for yourself kind of thing."

Each of the participants had an overwhelming need to belong. Charlie was volunteering, not only to help out, but to develop a sense of community of which he could be part. Maggie's first foray into higher education in Oregon did not go well, as she found the university she applied to unwelcoming.

I asked them if they had any foster care advisors or anybody that I could talk to about like, any advisement people. And they were just like really busy. They 
actually got me enrolled but they enrolled me in the wrong classes. So, the enrollment was really bad. And luckily, I still applied to [community college], so I was like emailing all these professors saying, "Hey, can I drop in on your class and maybe add?" The [community college] was totally like, "Yeah, let's add you, come on in." They were more helpful.

Instead, Maggie, who had fortunately also applied to the study institution as well as the university, went to the community college and found a welcoming and friendly environment from fellow students, faculty, and staff.

Vincent became involved in a student club on campus and found that a positive experience. He noted "I really wanted to get involved." Vincent went on to say, "I looked into a lot of the services, because again, it was a support system I was looking for.”

Of the participants in this study, only Stephanie had a regular support system of

friends, former foster family, and educational advocates who made her feel supported and loved. She stated, “And I just love it, because as long as I know I am loved and I get that support with just a call or attention. ... I have it, I've got it, I'm okay."

\section{Emerging Theme 6: Community College as a Safe Haven}

Each of the participants was looking for a place to belong and they found their experience at the community college to be a safe haven. The community college where the participants were enrolled or planning to enroll had several campuses that provided for the students a welcoming community, making the study participants feel comfortable and valued. The environment from the physical space to the institutional agents was open and helpful.

Maggie noted that when she first attempted to go to a 4-year university in Oregon, the reception she received made her feel like a nuisance. Maggie, having been to a 
community college before, was applying to both a university and the study institution and ended up attending the community college due to the help she received there.

Charlie chose the study institution due to the program, but also loved the physical space of the campus, as he found it beautiful and peaceful. As noted earlier in another theme, the campus environment led him to volunteer. Charlie would not have done so had he not felt the campus was a safe and welcoming place.

Vincent found that the community college was open to understanding his story and he felt no judgments made about him being a foster youth. He got involved on campus and felt connected, which helped him. Vincent commented "They took the time to understand my story and where I was coming from and they gave me a chance. I really appreciated it." At one point, the study institution had instituted an office to support foster alumni and Vincent was aware of that office and the staff. He spoke highly of staff knowledge about foster alumni and connections with students; however, the program closed due to lack of funding. Although Vincent and the other participants noted that foster alumni need to have the right to choose whether they want to access such services, Vincent felt the office did a great deal of work to support foster youth.

Gemma also mentioned she had heard good reviews about the office and was disappointed it was no longer open to serve foster youth. Gemma initially began her studies at another community college, but kept hearing good things about the study institution, which led her to transfer.

I just kept hearing so many good things about [community college] and they had so many more options compared to the other community college. I don't know, just something about it, the motto, and I guess just also the way they treat their students. Just everything about it, I just had a really good feeling. That is why I kind of wanted to start here. 
Subtheme to 6: You have to study. The transition into higher education, whether through the community college or a university, is typically difficult for students. Most students experience a period of disequilibrium during their adjustment to higher education. Some foster youth in this study struggled academically. When asked what surprised her about going to college, Maggie commented:

Surprised me? It's really hard, it is hard intellectually. Everything is so easy, like take these 5 steps and blah, blah, blah, you are done, ahh great. But like I don't think people really tell you like how to study.

Maggie went on to say that if she had received information on how to study in the beginning it would have made a big difference. But, as it was, she felt she wasted time because of her lack of study skills.

But this is how you should study, this is how you should think about homework or how not to study, how to waste your time. I took a lot of classes, like remedial classes that I had to retake because I didn't really know how to study in college. So, I wasted probably a year and a half, having to retake classes.

Subtheme to 6: From surviving to thriving. While Vincent had struggled academically and as a result financially with his initial time at the study institution, during the course of the two interviews he was preparing to return to the community college after stopping out. He noted that he had not "applied myself." His time off had allowed him the time to take stock of what he really wanted from his education and working a low-wage job had further cemented that he wanted to succeed. He recognized that he was in survival mode, trying to make enough money to pay his bills. At the time of the second interview, Vincent had met with his academic advisor, petitioned for reinstatement, and was already planning the grades he wanted to achieve when he returned to campus. When asked what the study institution did to make him feel supported Vincent stated, "Mainly they just provide people with a voice." 
Vincent frequently used the term "mental compass" as a tool that parents provide to help steer a child in the right direction. He commented that the mental compass represents "A will to live and to make a difference." Parents provide the mental compass that shows a child what he or she means to them.

They know, that, yeah, there are some things worth striving for in this lifetime, and more importantly that failure is okay and that with a mental compass, once you get out of high school and you are not with your parents anymore, that you have some idea of who you might want to be.

At the same time, Vincent was struggling with fear and doubt, which got in the way of thriving. The fear and doubt he expressed was a holdover from his life in foster care and learning to accept himself for who he is now.

Gemma received a scholarship from the community college foundation, which had a positive influence on her. For one of the first times in her life she received something positive from having been in foster care. Winning the scholarship felt good to her and helped her believe in herself in a way she had not previously.

I think a lot of foster youth feel that way going through the system [feeling alien], living with different people. I think just even when they go out into the world, because they are used to feeling like an alien for so long, just hard to relate to people and kind of just not loved, that it makes it harder for them to actually be themselves when they go out in the world. It takes a while for them to feel good again.

She "never expected that I was going to win a scholarship." Gemma acknowledged that the scholarship made her feel worthy as a foster youth. She never felt challenged in high school, but felt college would be a different experience.

I always wanted to go because I always loved learning and just being an intelligent person. I love reading. I was a bookworm all of my childhood. My nose was always stuck in a book, so I was just excited by that. I think another reason is I thought it was a way for me to become a new person. Like I finally have control over my own life. I can finally start my own life. I can be myself 
now. I don't have to be who I was in the past and not having anyone controlling me or anyone hurting me anymore, like this is my life now.

Her teachers at the study institution, winning the scholarship, and "meeting other likeminded students" helped Gemma move from survival mode to thriving in college with active plans to transfer to a 4-year university.

When asked what sort of dreams or goals he had for himself growing up, Charlie responded "I didn't, just pretty much tried to survive when I was younger. I guess. I pretty much grew up fast.”

All of the participants were struggling on some level with trying to believe they were good enough. Coming from fractured family lives and not having the most essential relationships in their lives be supportive of them was a huge burden to overcome. Of this group of participants, only Stephanie had a consistent support group. The rest of the participants, while moving from surviving to thriving, saw education as the pathway to get achieve their goals. It would be naïve to assume that their self-doubts were erased by attending the community college, the support from faculty, staff, and the campus community was helping them build self-belief. For each participant, learning to reach out and access services played a huge role in their ability to move beyond survival mode.

\section{Emerging Theme 7: Financial Transitions}

For foster alumni, financial literacy is merely one piece of a more complex area of financial transitions. Issues around finances were consistent across participants. They ranged from one participant who, at the time of the interviews, was homeless and living in a shelter to others who were working at minimum-wage unskilled jobs to pay for housing and food, let alone trying to pay for tuition and books. Only one of the 
participants had a skilled job that paid well, but even that was difficult as the participant was working less than 20 hours a week.

Stephanie took a unique approach to her financial aid and fully comprehended that it was paying for her to be in school. She viewed her financial aid this way: "It's like an income. You are getting paid for passing. It's basically like your allowance. You achieve something, you accomplish it, and you get the money for it." Stephanie recognized quickly that passing her classes meant her financial aid kept coming. At the same time, Gemma realized some financial support existed for foster youth. Gemma was surprised by a scholarship that was specifically for youth who had been in foster care and she won the scholarship, which had a big impact on her.

I actually won a scholarship last year, here from the (study institution) for foster children. Yeah, I was so excited. That was really a huge opportunity. So that is a positive experience that I've had, as a result of being in foster care for a while.

One issue that emerged for Gemma was that her move from another state to Oregon meant unintended negative consequences in that she lost out on the Chafee Grant for foster youth.

I found out here in Oregon I don't qualify for the Chafee because I was technically a [state] resident, just here in the system. I was always considered a [state] resident. I tried getting Chafee through here, but I couldn't. So, I contacted [state] and I finally was able to get through to the supervisor of the department that controlled the Chafee there. She said I didn't qualify because the way they structure their financial need; the way they calculate it was different than most. She said it shows that you don't have a need, because they calculated my student loans as a source of income, and because of that they didn't want to give me their Chafee grants, and they said also because there is a long list of recurring recipients, so I would have to get in line.

This situation was particularly upsetting for Gemma as she needed her student loans to pay for rent, tuition, and living expenses. For Gemma, the ramifications were exacerbated because Oregon now gives free tuition to foster youth in Oregon. Gemma missed the cut 
off for that aid by 3 months. Gemma fell through the cracks in the system. Not only was she denied financial resources that would help her through her education, she also felt lied to by the foster care system.

The whole time I was in foster care I was being told, "You know, in the end you are going to get some kind of educational benefit from it." So, when I got out of the system, no, that was a lie.

For Gemma, this served to reinforce her lack of trust in the system and with systems in general. She felt betrayed again by her experiences in foster care.

Charlie also struggled to understand financial transitions. While he applied for financial aid, he believed he would not get much, but that he could take out a student loan. He seemed vague and unsure of the process. When asked about the Chaffee Grant, Charlie responded,

I applied for it, but since I was in [state], I had to call the counseling office which I don't know the number to, and they have to transfer the stuff over here. It is a big process that I have to go through and that would be too much work just to get the grant. It is a grant, isn't it?

Charlie's lack of knowledge about the financial-aid process, the amount of money he was entitled to through the Chafee Grant, and what appears to be little help from the financialaid office left him feeling confused. He commented that "Everything I've wanted; I've either worked for-I'm not into taking free stuff." Charlie lacked the social and cultural capital to understand that applying for financial aid was not about taking "free stuff" but rather about helping him get his education. Having no supports in his life at the time of the interviews also meant he did not have adults who could have explained the process to him, providing Charlie with a way to pay for his education.

Vincent also lacked financial literacy and ended up struggling financially. At the time of the first interview, he had stopped out from the study institution and was working 
full time at an unskilled job, but Vincent planned to return to the study institution shortly. Vincent was put in touch with the ILP just prior to his case being closed and, due to the late connection, lacked solid information about Chafee and the ILP. Even though his goal was always to go on to college, none of the paid professionals in his life informed him of his rights to access Chafee and ILP. Only by chance at the last minute did he get information. Vincent initially attended another community college in Oregon, but the staff at that college was unfamiliar with the Chafee program and he left that institution prior to attending the study institution. Vincent summed up his lack of financial knowledge this way:

I didn't have to pay for college and I had a considerable amount of money to live on and I didn't know what to do with that income. I wouldn't say I mis-used it, so much as I just didn't really know what I was doing with it.

Trying to navigate the financial resources caused Vincent distress and brought up the feelings of the "million-piece jigsaw puzzle" because he was having to go and try and pick up pieces of information that were lost to him or had not been passed on to him.

Of all the participants, Maggie had the easiest time transitioning financially. She was able to access and receive the Chaffee Grant while obtaining a certificate in her home state. Now, enrolled in Oregon, she was using additional financial aid and her job to cover her other expenses while working toward her academic goals. Maggie, however, acknowledged that many foster youth are unaware of the Chaffee Grants and miss out on opportunities to access the funds.

\section{Emerging Theme 8: Academic Literacy}

The foster alumni in this study lacked academic literacy. They had no idea how higher education works ranging from understanding the vocabulary used in colleges to 
the process of building a degree with curricular and co-curricular components, to accessing services designed to help students persist. Their lack of familiarity with academic literacy impacted this group of students in various ways, including costing them opportunities along their college pathway.

In interviews with Charlie, he fully acknowledged that he had no concept of what “academic support" was or how accessing different academic supports would help him. Charlie viewed academic support strictly as advising or tutoring. When asked if he would like to transfer on to a 4-year university, he replied in the affirmative but was confused as to the availability of financial aid or the planning involved in transferring to a 4-year university. Charlie covered his lack of knowledge by stating "I have plenty of time to figure that out." It is this lack of insider knowledge about how college works, how to identify, and successfully apply to, a 4-year university that many foster youth do not have.

Charlie found the process of applying for admission difficult. He felt that the many questions asked in the process were intrusive, while acknowledging that "they are trying to get all the input they can." Regardless, Charlie felt uncomfortable with his experience as he had nothing to compare it to and did not realize that the questions were fairly standard. Although Charlie understood that college was different from high school, he lacked the knowledge and the vocabulary to articulate the differences.

As Charlie was at the beginning of his college career and had limited support, his understanding of the system was significantly limited. Charlie was vague about the services: "I know there are a couple of places ... and if I need help academically, I can go there, I think." He was hesitant to reach out for help and support from different offices, specifically seeing that as a last resort. In the interview, it became apparent that Charlie 
was equating his experiences in the foster care system to higher education, one system for another system. He did not believe that the people and supports at the community college really help individuals. He stated, "When I need it the most, nobody is there, so I do everything on my own."

Several participants in the study mentioned the study institution's TRiO program. TRiO programs are federally funded programs (Upward Bound, Talent Search, and Student Support Service) enacted to support first-generation, low-income students and students with disabilities to persist in college. TRiO programs are highly successful and offer a level of individual academic and personal support to help students navigate and persist toward graduation. Charlie was aware of the TRiO program at the community college and knew that it might be able to help him, but he was unsure of what the program did to support students. He was uncomfortable walking into the office and not knowing what to say to the people there.

Vincent, unlike Charlie, had already spent time at the community college and was trying to navigate the system. He had successfully entered the TRiO program but was also somewhat vague about the services provided to students. Even so, Vincent struggled with a lack of academic capital and not always understanding how things connect. More than any of the other participants, Vincent was able to articulate the barriers in college that prevented him from moving forward. He commented "I still don't know a lot of what those barriers are and what they look like; even though I know that they are there." Vincent identified his lack of academic literacy by noting that he did not understand the "rhythm of classes," the number of courses needed per term, time spent studying, and "how to manage my time." He summed up his academic experiences by saying, "A lot of 
time I miss things that are right in front of me." While Vincent became active on campus in co-curricular activities, his lack of academic literacy cost him time and money.

Gemma was attracted to the study institution because she received positive feedback from others about the community college. She acknowledged that she had no major plan in mind when she started. "I wasn't really sure just yet what I was going to study or what I wanted to go to college for." She felt she would "figure it out" through the process of attending. Much like Vincent, Gemma had struggled with maintaining full time status and working part time. She experienced some health issues that caused her to drop down to part time, which in turn has slowed her progress and made her feel upset that she has not yet completed her degree. Although Gemma knew, at the time of the interviews, that she was planning to transfer to a 4-year university, she was not taking advantage of a dual-enrollment program that would have allowed her to be taking classes at both institutions, possibly easing her transition. Also, Gemma had not yet completed a plan for graduation, mapping out the courses she had taken and the remaining courses needed to complete her associate's degree. Gemma does have direction in that she knows she wants to complete her master's degree, but she appears a little lost in figuring out the best pathway for her.

There are still a lot of options out there that I'm trying to figure out, what would be best for my career path and just staying on track in general. There are other things that I can pursue out there, but I'm not going to get a bachelors' in something else unless I know it would be beneficial.

Gemma felt that college "was going to be open" and would be much like high school but found the experience in college to be "definitely more independent. Every term you are switching classes ... and then you are switching again.” Much like Charlie's experience, Gemma tried to do everything on her own and not reach out for supports. She 
commented "I can do everything on my own." Through her time at the community college, Gemma has come to realize that the supports are there to help her: "If I need the help, I can reach out for it." While Gemma found the community, much as Vincent did, to be welcoming and engaging, she struggled with the process of putting together her degree and the academic literacy and educational planning needed to transition through college.

Maggie, however, was lucky to have college graduates in her life who were able to help her understand and develop the academic literacy needed to be a successful student. Although they did not lecture her, they were clever in opening up opportunities for her and challenging her to just take one step, thereby scaffolding experiences and building the academic literacy needed. Maggie found college to be "really hard; it is hard intellectually." She talked about how she did not know how to study and the pieces she was missing that made it difficult for her to learn.

If I could have had that in the beginning, like okay, you did all this crap and all the financial stuff, but this is how you should study, this is how you should think about homework or how not to study, how to waste your time. I took a lot of classes, like remedial classes that I had to retake because I didn't really know how to study in college. So, I wasted probably a year and a half, having to retake classes.

At the time of the interviews Maggie had developed a cadre of study skills and had increased her academic literacy. Even so, she was aware of the time she had lost due to lacking knowledge earlier in her academic career. Maggie noted that if there had been a foster care advocate at the study institution, they would have helped guide her through the system. Initially after moving to Oregon, she attempted to go to a 4-year public university but chose to leave and go to the community college because she felt alienated by a lack of information from the university. Processes and costs for out-of-state students 
were not explained well to her and Maggie ended up having to cancel her admissions and go to the community college. Maggie later found that if she had the right information to fill out her admissions and financial-aid forms she would have received more aid. She stated "I had to use a different wording on my application. I didn't know what that was. I would have stayed there." Maggie was clearly frustrated from her experience and yet she had already successfully received training in a vocational program at a community college. Even so, Maggie still lacked the academic capital and knowledge to be able to work through the system.

Subtheme to 8: Vague dreams and undefined goals. Although all study participants were pursuing a college education, they were all a little vague about their dreams and goals for their degree. Many students waver between majors and try different options when attending college, but participants in this study were not always in a position to articulate their goals. Perhaps one of the effects of having been in foster care is living in the now. When a child can leave a foster home in the morning and then be placed in another one at the end of the day, they begin to live in the immediate. Trouble with long-range planning was evident. In addition, as noted earlier, Charlie's comments suggested the desire not to be disappointed; rather than face disappointment, Charlie does not plan. All of the participants except Charlie indicated they wanted to transfer to a 4year university, yet none of them really understood the process. Gemma had at least talked to someone in the program she was interested in attending and had the opportunity to be involved in a dual-enrollment program between the college and university but did not take that opportunity. Taking individual dreams and turning them into goals with achievable steps seemed to be a skill the participants had not yet developed. 
Gemma considered several careers but had become intrigued by one due to a woman she met. She is interested in pursuing it, as the field connects many areas of interest for her. However, Gemma was struggling with what to do for her bachelor's degree because the final degree she is interested in is a specialized master's program. Gemma noted that she loved school as a child, so it became her safe place. Going to college was a place where she could feel good and safe.

Maggie commented that she did not even know that she wanted to go to college, but the doctors in her life encouraged her to do an internship after emancipation, just to see if she liked it, and she did. She commented that they were the people in her corner telling her she could do it, even though she had not yet defined what "it" was.

Stephanie was surprised to find herself in college, initially believing she would be "just stuck with my high school diploma." She had, however, a desire to go to college. Although Stephanie had a defined vision of what she wanted to achieve by going to college, she also lacked the academic literacy of the other participants. At one point She stated she would go "get my associates and from my associates and then my masters and so forth." Stephanie was unaware that her progression was a bachelor's degree and then on to law school for a juris doctorate. Stephanie, however, accessed services and support through the Women's Resource Center taking "little courses" that helped her develop skills. Stephanie was surprised that she was actually in college, but she had an internal drive to succeed, so she was trying to take advantage of every opportunity to develop skills to move her forward. As her first interview progressed she wavered about her goal to be a lawyer and talked about possibly switching to counseling. Her comment "I think I might end up going back to school, starting over in doing something with children” 
showed that she was unsure how major changes are made and how transferability of credits works.

\section{Emerging Theme 9: Academic Advisors as Neutral Resources}

All study participants, with the exception of Charlie, wanted to see foster care advocates or liaisons in the college. Charlie's reluctance may have been in part because he had just emancipated from foster care and was trying to leave that part of his life behind. In an ideal world, having foster care advocates in colleges would be beneficial and fine examples exist of higher education institutions that have developed programs targeted to foster alumni. However, many institutions do not have the resources or lack the knowledge needed to develop such programs. Academic advisors, however, are a resource available to all students.

At the time of the interviews, Charlie was adamant about wanting to leave foster care behind and to no longer be identified as a foster youth. The other participants believed that if higher education individuals had knowledge of the foster care system, the resources available to foster youth would empower foster youth to transition more effectively into and through post-secondary education. Although the study institution previously had at one point such an office, it was only funded for a short time. Some participants had the opportunity to work with the office and found the experience beneficial. Not having to constantly explain their situation to someone who lacked understanding of foster care was considered a bonus. Vincent and Maggie started at different higher education institutions and then left them to go to the study institution because the other institutions were unfamiliar with resources for foster youth. The 
ignorance of practitioners in the field of higher education can cost foster alumni access, not only to financial resources, but other resources as well.

Vincent felt strongly that colleges need to support foster alumni. He commented that he really needed to have "somebody who understands the Oregon foster care system." At the same time, he recognized that not all foster youth need that, but for him it matters to work with people who are able to understand his experiences in foster care: The student group "took the time to understand my story and where I was coming from and they gave me a chance." Vincent expanded on what a foster care liaison would look like:

In my mind, I picture like a representative, like someone who knows the system of DHS, and most likely a foster alumni... To have a foster youth alumni in the school who has graduated so it is a paid position, sort of like a foster youth ombudsman so to speak so could answer all our questions about what services are offered for foster youth at that school.

Maggie was fortunate to get her first certification from a community college that had a foster care liaison and found that particularly helpful.

Just having a face that you can talk to and not like some stupid phone line you can call ... but there is actually a person you could talk to. She was a foster care liaison and she could help you with any questions about college or even like housing or like if you were going to be homeless. That helped me a lot.

Academic advisors, by virtue of their accessibility to all students and their overall knowledge of academic programs and resources, are a logical choice as a support for foster alumni. Today, most academic advisors enter the career field with a master's degree and have knowledge of student development theory and advising theory. Despite the lack of current theories that specifically address the experiences of foster youth, there are numerous theories in the field of student development which are applicable to foster youth. Academic advisors serve as guides, mentors, and academic coaches through higher education; however, this resource appears to be underused by foster alumni. 
All of the study participants except for Charlie, who had yet to begin at the community college, accessed academic advising. Study participants viewed academic advisors as neutral resources, meaning they were supportive and helpful. Charlie was adamant about not going into a specific office that worked with foster youth, as he was trying to distance himself from his life as a foster child. Academic advising, however, has no stigma attached to it. As all students have access to academic advising, it not only becomes a resource, but a resource that is neutral and accessible.

Stephanie phrased her experiences with advising by stating, "Like I can go to him whenever I need something to talk about.” Her experiences with academic advising informed her belief that the advisor was a source of information and if she was not doing well in a class, the academic advisor would help steer her in another direction. Although Stephanie was clear that she did not access her advisor often, she felt comfortable knowing that he was there and willing to help when she determined she needed assistance.

Maggie, unlike Stephanie, had some difficult experiences with advising. When first attempting to attend a 4-year public university, Maggie had specifically asked for a foster care advisor or anyone with foster care experience who could advise her. She felt that everyone was too busy to help her and she ended up enrolled in the wrong classes. Combined with the financial issues she encountered there, Maggie opted to go to the study institution and found more assistance getting into the appropriate courses. She noted a lack of support for foster youth:

I thought maybe if they had someone with a little bit more experience and more credentials in that spot they could understand where I was coming from maybe, and not been so dismissive. Nobody really cares much about foster kids, because they have no money and there is nobody supporting them. 
Due to Maggie's major, academic advising was required to ensure she was on track with the sequence of courses needed for her program. Maggie found advising "boring" because she felt she already knew what she needed to take. In addition, the advisor, although trying to be realistic with Maggie's future goals, ended up shutting Maggie down completely by telling her not to apply to a particular program due to her gradepoint average. The professional program Maggie aspires to requires a high cumulative grade-point average; however, Maggie does have high grades, though according to the advisor, not high enough. The advisor missed an opportunity to talk about different options with Maggie and to consider that program as a reach. As a foster youth, all Maggie heard was "no" without understanding that there were other ways to get into such a competitive program.

Gemma, however, was looking forward to meeting with her academic advisor to set out her courses so she would have a concrete plan to finish her associate's degree.

I know for this term I actually want to go set an appointment with an advisor again. That way I can actually make a course plan for each term. ... This year I am really going to dedicate myself to completely more each term and actually setting up an academic plan, they call it a grad plan here, and actually meeting with an advisor and checking in.

Gemma did comment that she thought advisors should follow through with students, check in with them, and see how things were going. One of her experiences with an advisor made Gemma feel like the advisor was just "writing out a receipt" by telling Gemma what courses to take. Gemma had talked with other students that felt they got "some help" from advisors, "but most of it is you just have to kind of do it on your own." Gemma felt that much of academic advising for students meant students had to be selfdirected and take ownership. 
I have to reach out and set an appointment with that academic advisor each term, just to check and see how I am doing. A lot of it is self-directed, self-motivated. They are not going to check in with you. They are not going to post anything on your student account. They are not going to say, "Hey it is time to come in for another appointment." There is no follow through, so if you really want that academic advising, you just have to kind of go and do it yourself.

Gemma commented that she felt better when she reached out for support and used the supports offered, but with advising she wanted to feel that the advisor was also invested in her best interests.

Vincent had accessed academic advisors and the advisors in the TRiO program and both of those experiences had been positive for him. "I am thankful for the advisors there, who have really provided me a little bit more of a mental compass than I would have without them." He felt the advisors kept him "on track" by "making an academic plan, setting goals ... and then making those goals realistic."

In his second interview, Vincent described his most recent visit to an academic advisor by stating his visit had gone well. He felt the advisor had listened to him, helped him out, and shared stories with Vincent to establish a bond. The academic advisors he has met with have served to motivate Vincent and encourage him to continue his educational path.

\section{Subtheme to 9: Institutional agents make a difference (i.e., tutoring, women's}

center, multicultural). For each of the participants, there were institutional agents who made a difference in their college experience. Faculty members who took the time to get to know students or let students register for classes after they had begun opened up opportunities for conversations with foster youth. Stephanie was actively engaging in ongoing dialogues with a member of the faculty. She was encouraged by one faculty member to stop by his office any time, whereas another faculty member would e-mail to 
check in on her. "Also like they know that I've been going through a lot this term, so they e-mail me, and they understand. I just love it, as long as I get all the support I need." Stephanie made a point to sit in the front of the class and ask questions. She noted, Once they start knowing your name, it is you have a little bond of connection. You feel comfortable where you can go to your teacher, even before or after class and "Hey, look" and they are actually willing to help you. They are willing to have the class a little late, just to talk to you. And I'm just shocked.

Stephanie, of all the participants, used the resources available to her. Aside from going to office hours, she regularly used tutoring "because when I don't know something that they explain to me I need it explained a better way where I can understand, and I am able to do the work." She found it helpful that the tutors were patient and willing to help her go over the work until she understood.

Stephanie also accessed the Women's Resource Center on campus. She has been surprised at the myriad resources offered including academic, financial, and personal through the center. Stephanie has identified that making connections with institutional agents provides benefits as they offer many programs and opportunities for students. Stephanie commented "It is just amazing what you can find out, once like actually get out there and speak to people." Stephanie regularly used study groups, e-mailed faculty with questions, and went to office hours for assistance. As Stephanie found institutional agents to be helpful and supportive, she chose to access them more regularly. Stephanie felt she had cracked the code to being successful in college.

Don't play around. Don't just come and not do anything or don't just come and not be seen. Make sure your teacher knows your name. Sit in front of the classroom, pay attention, take notes, ask questions don't be afraid. 


\section{Emerging Theme 10: The Effects of Having Been in Foster Care Impacts Higher Education Success}

Foster care may be seen by those outside the system as a finite experience that ends either upon reunification with family or emancipation. For the foster youth in this study, the effects of foster care linger long after they have exited the foster care system. Many foster youth came from family situations where substance abuse was prevalent along with mental health issues. Some participants talked about leaving their dysfunctional families to save themselves, but still feeling the pull of their biological families. Each participant mentioned they were on their own and had to do things for themselves. The impacts not only were felt by participants but were clearly influencing them as they pursued their goals of degree completion.

Gemma commented, "my parents were never there for me." She talked about poor decisions she made "because I had such low self-esteem." Vincent stated "I can't really rely on my parents for a whole lot. I'm trying to forgive them the best I can and to accept that forgiveness into my heart, so I can move on and feel good.” He too, struggled to believe in himself saying, "I sell myself short." Vincent noted that "I have a desire to go to school and I haven't applied myself the way I've wanted to, and it's because I've not always seen myself as a good person." He was struggling with "fear and doubt" as he tried to pursue his education. When pressed about the fear, Vincent acknowledged that it came from a "fear of failure." For foster youth failed by their families and then by the system, fear can become an emotion with which they are only too familiar. Vincent also commented about his experiences "But yeah, solid ground is hard to come by. And when the ground is shaky, you have to find a way to balance. I am really trying to find a 
balance, I really am." For Vincent, the struggle of wanting to connect with his biological family and self-preservation was a constant tug of war.

Gemma had overcome significant struggles to get to college and was doing well as a student, even earning a scholarship. The validation from being chosen to be a scholarship recipient was powerful. When later on she became ill and could not complete as many credits as the previous year, she devalued herself, "I feel, like, wow, this is taking too long, I'm a loser." Instead of recognizing that the illness was a minor setback she could overcome, Gemma internalized it and blamed herself. In transitioning from high school to college, Gemma felt she had no help to bridge that gap, leaving her to flounder while she figured out how higher education worked. At the time of the interviews, Gemma had realized she needed to be "open to all the services and reaching out more." Like the other participants, being in foster care had taught Gemma that the only person she could rely on was herself and she was trying to adapt to a situation where support was offered to all, but that she could access and rely on the offered support.

I've had to learn that the hard way, as well, that I really can't do it on my own. I've been used to being independent and alone all my life. But I've learned that I'm really the happiest and do my best when I can reach out to others and have that support.

For Maggie, her struggle was about the emotional issues attached to having been in care and her lack of belief in herself.

I didn't think I was as smart as I am today. Like I had such low esteem and didn't really have anybody helping me. It was more about the confidence issue rather than knowing that I could do it right away.

And for Charlie, he chose to save himself when he realized he could not save his mother. Charlie ended up putting a great deal of physical distance between himself and 
his mother because "I don't know; I just couldn't do it anymore. She was killing herself slowly and I didn't want to sit there and watch it happen."

Several participants were addressing their own mental health issues as they tried to build new lives for themselves. Some were resistant to access services based on their experiences in foster care when they were mandated into treatment. Others were openly trying to get help and move beyond their pain.

\section{Chapter Summary}

This chapter gives voice to the rich, deep dialogue and experiences of foster alumni entering and progressing through higher education. Their voices shared the barriers that have hindered them from smooth transitions into and through their postsecondary experiences. Each of the young people in the study was struggling with similar issues that emerged in the themes. The trauma of having been removed from their biological families continues to have implications far beyond the point of emancipation. For most young people, attending college is a period of transition, but for foster youth the transitions they experience are more layered, due to their experiences. Navigating college for this group of students becomes increasingly difficult as they struggle to address the desire to be loved by their families, while recognizing those relationships may never be healthy for them. In addition, they harbor feelings of being alone in the world and trying to understand the world of higher education, with no security to fall back on in times of crisis.

While higher education is a time of searching, reflecting, and growing academically and socially, most young people are experiencing college without the negative experiences that foster youth have weighing them down. At a time of intellectual 
growth and development, foster youth are trying to understand and confront the trauma of their childhoods. Going from the overly controlled foster care system into complete freedom overnight causes an overwhelming period of disequilibrium. For former foster youth, their often disjointed and fragmented time in foster care has not prepared them to transition easily into higher education. 
Chapter 5: Discussion and Conclusions

Findings

The quantitative data presented in this study revealed that the community college is the gateway for former foster youth. The chi-square analysis described in Chapter 4 showed that participants in the survey who had not been a former foster youth were nearly twice as likely to enter a university directly from high school, whereas those who had been in foster care were nearly twice as likely to transfer from a community college to a 4-year institution. In this study community colleges act as gateway institutions for foster youth pursuing higher education.

In addition, the reasons former foster youth attend a community college did not differ from those of students who had not been in foster care. These findings suggest that, for at least those who attend community colleges, the aspirations of former foster youth do not differ from those of other students. However, although the number of participants in this study was small, their voices emerged to share the unique transitions experienced by foster youth in accessing and persisting in higher education. Findings from this study suggest that foster alumni experience higher education differently from young people who have not been in the foster care system. Whether these differences hold true for a larger cohort remains to be seen, but the findings pose the possibility that by ignoring the unique transitions of foster youth, institutions and institutional agents are failing this group of students.

Lack of or poor educational planning is considered an issue for members of the millennial generation (Keeling, 2003), but for foster youth, it goes deeper as they see time differently. When fostered children have grown up in a system whereby they are living in one home in the morning and moved to another after school, their sense of time 
becomes skewed to immediacy. The ability to do long-range planning, especially educational planning, is compromised if a young person does not have the opportunity to dream and set goals. Each of the participants in this study had dreams and goals for their life, but they struggled with educational planning because they were not able to articulate how to achieve their goals and leverage available supports.

For the foster youth who made it to community college, their struggles continued. Lack of finances; insecure housing; the need to love, be loved, and belong; and academic shortfalls conspired to cause foster alumni to have multiple departure or pivot points that can lead them to withdraw at any time. The first is high school graduation and whether youth can remain in care or have to leave. If they have gained admission to a college, they can suddenly find themselves homeless with no support, prior to beginning the term. Once matriculated, the lack of resources can result in an inability to buy textbooks, supplies, and other necessities. The emotional burden of people thinking that foster youth are bad takes a toll on alumni, as does the tug of emotions concerning biological family. Trying to mature and make sense of their time in care and in many cases, the trauma experienced in their lives, is beyond difficult. Attempting to work and go to college is yet another departure point, especially when a young person has no other source of support. Learning to be in a system and trust the institutional agents in that system, after coming out of a system where foster youth had little or no say in their lives is exceedingly difficult. Finally, the lack of safe, welcoming places to go to during holidays yet again signals that foster alumni are different. Aside from the emotional impact of being alone, they experience a practical aspect of being homeless if an institution has residence halls that close during holidays. 
Figure 1 presents a model showing the transitions described by the participants in this study. The text box on the far left refers to the experiences and trauma experienced by youth with their biological families and during their time in foster care. The box represents the traumas foster alumni carry with them as they attempt to move into and through post-secondary education. Each participant in this study was impacted by their time in foster care. To pretend that there is no on-going impact as they move forward into higher education is wrong and does them a disservice. Tinto (1975) based his theory on a rite of passage that young people experience, as they must leave behind what they know as they move forward into the world of academia. Tinto (1993) identified a period between the old way and the adoption of the new norms. Tierney (1997) cautioned that for some students this might be cultural suicide; for foster youth, this transition from the old way to a new way may be necessary. As emerged in interviews, three of the study participants moved away from their home states to Oregon. The decision to move was not arbitrary, but a deliberate decision to separate from their pasts and necessary for them to move forward and be successful in their lives. They essentially left behind the old to adopt new norms. Even so, they experienced conflict and pull to their families. Unlike Rendón (1992), who says a person can walk in two worlds, for these students one world is full of pain and the new world is full of unknowns. The findings here may be differently applicable to youth in state. The boxes in the middle represent the challenges foster youth/alumni experience as they attempt to go to college. The arrows to the right indicate the pivot points where foster youth and alumni make decisions that lead them to depart from the path to post-secondary education and the results that can occur from turning away from higher education. 


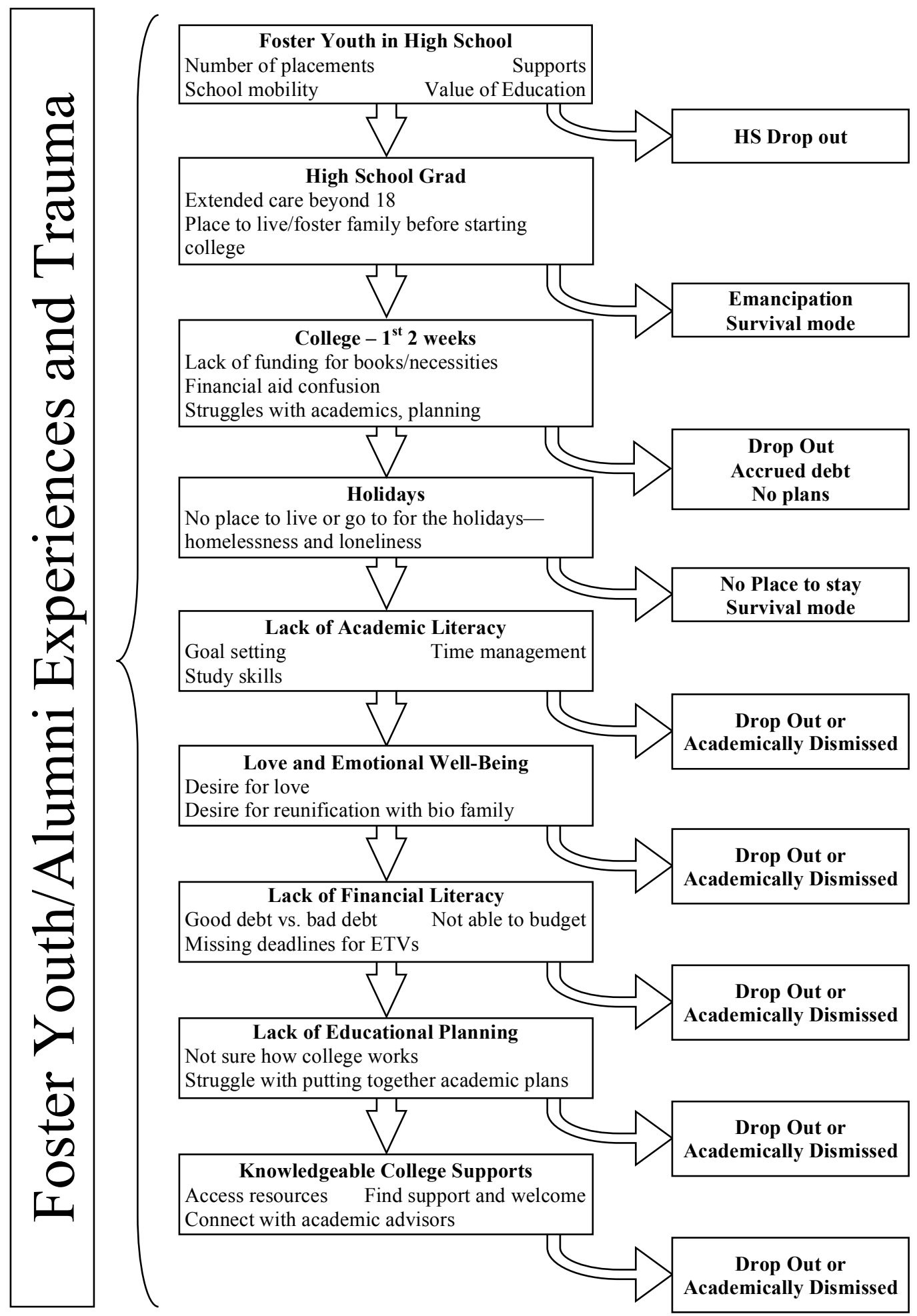

Figure 1. Model of foster youth transition from high school to higher education. 
Foster youth in college must address several high-risk pivot points. The first is when they are accepted into a post-secondary institution and graduate from high school. Many young people will leave the foster-care system and find themselves homeless prior to the start of the college academic year. The risk here is that the struggle to survive may take up all of their time and they end up not enrolling. The second high-risk pivot point occurs during the first 2 weeks of the term. If foster alumni have not sorted out their financial aid and are struggling to buy textbooks, they can easily opt to drop out. The third high-risk pivot point occurs around the holidays: Thanksgiving and Christmas breaks pose a significant issue for foster youth, as the only stable home environment they may have is their room in a residence hall. If the college closes the residence hall, foster alumni may find themselves homeless over a break. While some community colleges have residence halls, for the participants in this study, each lived off campus. However, for foster alumni attending a 4-year campus, this would be a possible pivot point to exit from the university. Nonetheless, the loneliness that foster youth feel at the holidays, when they do not have family to celebrate with, is real and highlights their foster-youth status.

At any time along the progression through higher education, foster youth can address a variety of issues including lack of academic and financial literacy, love and well-being issues, and poor educational planning skills. These issues singularly or in combination will lead foster youth to a pivot point where they must decide whether to continue or exit from higher education. Each of the participants in this study expressed that they had nothing to lose and therefore needed to move forward; however, one of the participants (Vincent) had already stopped out at one point. 
For foster youth, the process of attending college is different from that of other student populations. The trauma of having been in care in some cases is a distant memory, but a motivating force to move forward. Other foster youth experience a daily reminder and a pull between the love they want from a family and the reality of disturbed family functioning. Combine the experiences of foster care, coming to terms with biological family issues, and attempting college, while also being solely responsible for oneself is difficult. Pivot points become the time when the transition is too great and exiting becomes the option.

\section{Conceptual Framework}

As noted earlier, the conceptual framework for this study drew on Schlossberg's transition theory (Schlossberg, 1981; Schlossberg et al., 1995) along with an underpinning of Bourdieu's forms of capital $(1973,1986)$ and Tinto's theory of student departure $(1975,1993)$. The reality is that not all students are equal. Students have advantages and disadvantages based on their family and economic situations. Some students are able to accumulate capital, but for others the deficit is too much to overcome.

The 4 S's help individuals move through transitions: situation, self, support, and strategies (Schlossberg, 1981). Institutional agents can be of great benefits to foster alumni by guiding them to assess their situation (housing instability, lack of books, no food, etc.) and examine what talents they bring (determination, survivor). Institutional agents can also help students identify supports (housing options, food bank, emergency loans) and strategies to address concerns. Foster youth bring their entire life experiences to the table of higher education and those are valid and valued. Being able to critically work through Schlossberg's 4 S's allows foster youth to move from surviving to thriving. 
Figure 2 shows Schlossberg's Four S's in relation to foster youth transitions to higher education. The column on the left is labeled situation, denoting the situation of a foster youth; self describes the skills and abilities they bring with them; supports lists the resources available to help them persist; and strategies are the actions they can do and use to be successful. The right-hand column lists the various elements that participants discussed in their interviews. Included were their feelings about themselves, their abilities, and the acknowledgement of the different resources available to them to help them persist in higher education.

\begin{tabular}{|l|l|}
\hline Situation & Alone \\
& $\begin{array}{l}\text { No support system } \\
\text { Imposter Phenomenon } \\
\text { Lacking Social and Cultural Capital }\end{array}$ \\
\hline Self & $\begin{array}{l}\text { Resilient } \\
\text { Reliant on Self } \\
\text { Intelligent } \\
\text { Adaptable }\end{array}$ \\
\hline Supports & $\begin{array}{l}\text { Individuals who believe in them } \\
\text { Faculty } \\
\text { Academic Advisors } \\
\text { Independent Living Program } \\
\text { Financial Aid/Chaffee }\end{array}$ \\
\hline Strategies & $\begin{array}{l}\text { Utilize Financial Aid } \\
\text { Educational Planning with Academic Advisors } \\
\text { Use Tutoring and Support Resources on Campus } \\
\text { Get Involved }\end{array}$ \\
\hline
\end{tabular}

Figure 2. Schlossberg's Four S's in relation to foster youth transitions in college.

\section{Discussion of Emerging Themes}

Community colleges have long been the gateway to higher education for many traditionally underrepresented groups of students. The same is true for many foster alumni. The aspirations of foster youth are identical to those of youth who were not in 
foster care in that they want an education to have a career, financial stability, and a good life. When looking at the numbers of foster youth at post-secondary institutions in Oregon, it is apparent from the data in this study that the community colleges do act as gateway institutions for foster youth. Also, those 4-year institutions that have missions focused on supporting traditionally underrepresented students create a welcoming environment that helps foster youth succeed in higher education.

In looking at the numbers for Portland State University and Western Oregon University, it is interesting that two such dissimilar institutions would also have high numbers of foster youth. Portland State University is in an urban setting, whereas Western Oregon University is in a small town in a rural area of the state. Possibly the numbers for Portland State University rest on the notion that the university is in the largest city in the state and is surrounded by the three counties with the highest number of foster youth. In addition, Portland State University has served a diverse study population. Western Oregon University also has a specific mission to serve traditionally underrepresented students; foster youth may find the community and university to be welcoming and supportive. In addition, whilst located in a rural setting, the university is only an hour from Portland. Monmouth is only 20 minutes from the state capital where many state services are located, and Salem is the second largest metropolitan area in the state. For some foster youth, accessing an educational institution that is close to what is familiar to them, along with maintaining their housing and work, is appealing.

The quantitative data showed that $4.6 \%$ of students in Oregon higher education institutions in 2010-2011 identified as being or having been in foster care. Given that students self-identified, and the stigma surrounding foster care, it is safe to assume that 
the actual number is higher, most likely $5-6 \%$ of the student population. A significant number of young people are in the higher education system with educational needs and experiences that are largely ignored.

While the quantitative data detailed the numbers of foster youth and their gateways into higher education institutions, the qualitative data showed that foster youth's transitions into higher education are indeed different from other students. They enter higher education with their experiences, and in many cases, trauma from having been in foster care. The Bourdieuian $(1973,1986)$ framework explored in Chapter 2 allows us to see that the lack of family privilege severely impedes social and cultural capital acquisition for foster youth. It must not be ignored but acknowledged that foster youth enter higher education with deficits that impact them in multiple ways.

In addition, Schlossberg's transition theory (1981) provides a framework to examine the situations of foster youth. Rather than leave it at deficits, Schlossberg (1981) provided a practical way for institutional agents to understand and support foster youth in their educational transitions. Following, I examine the emerging themes and discuss them more closely.

\section{Emerging Theme 1. From Foster Care to the World (From Dependence to Independence)}

For all young people, the transition from their teen years to adulthood is difficult: a time to separate from family and determine their own values and a time to grow and change. Arnett $(2000,2007)$ described the theory of emerging adulthood, which concerns the time between late teen years and mid to late 20 s. Arnett noted that "emerging adulthood is distinguished by relative independence from social roles and from normative expectations" (p. 469). Unfortunately, for foster youth there is no period of emerging, as 
they must emancipate and fully move into adult roles in order to support themselves.

Going from a system where others are paid to make decisions about one's life and where one has little control into complete freedom is disorienting. For each of the youth in this study, that period of disequilibrium was an ongoing and difficult transition.

While several of the foster youth were making good progress, it is perhaps the unseen scars that are the most damaging as they make the transition from foster care to the world of higher education. These scars from being in foster care are present when they come to college and interact with others. When children wake up one day in a home and at the end of the day are moved to another placement, their sense of time is skewed. If they lack permanency in a loving home and every day are taught to live in the moment, because in the next moment they may be moved, they begin to live in the immediate. Their ability to do long-range planning and stick to those plans can be damaged.

This reflects Schlossberg's matter versus marginality (1981). Many foster youth feel they did not matter in the foster care system. Their experiences have left them feeling marginalized and unvalued by their time in foster care. Foster youth going into higher education are going into a new environment and do not know the rules, rendering them once again feeling marginalized. They have come from one system into another system without knowing the social mores of this new system and what is expected of them. Their lack of insider knowledge makes them feel marginalized in the environment of higher education. Charlie talked about living in the moment because planning things always meant they would not work out for him. Life has taught him he does not matter. As foster youth are trying to transition from state care to being responsible for themselves and transition into post-secondary education, it must be recognized that the transitions come 
with great difficulty. When someone has been conditioned by their experiences, they will act in a particular way; learning to unlearn the conditioning takes time.

\section{Emerging Theme 2: Moving to Oregon to Start Over}

One of the most surprising aspects of this study was that three of the participants actively chose to move to Oregon to begin their life over. Charlie made the decision based on purely practical reasons, because Portland was as far as his money would get him. Gemma came back to a place she had been before, where she did have some biological family, and Maggie wanted something more serene than the large metropolitan city she was from. It makes sense that if a person has had a difficult youth, they might want a clean slate to start over again. Also, as Tinto (1993) noted, it is easier to adopt new norms if one is no longer being held back by the past.

For some foster youth, putting distance between themselves and their biological families is about survival and leaving chaos. Moving from the pull of an environment unsupportive of higher education was essential for these foster youth to move forward with their lives. While the tug of the biological family persists, and all of the youth felt it, they recognized that they needed to take care of themselves first and that their families were not in any way able to support them. Most participants articulated a sense of grief in that their primary familial relationships are fractured. Tinto $(1975,1993)$ based the theory on a rite of passage, especially noting that people must leave what is behind them to move forward and embrace their future. And even though Tierney (2000) considered this separation from the past to be a form of cultural suicide, in this study, students moved from another state to get away from the disruptive functions of their biological families. This confirms what Tinto $(1975,1993)$ said about the need to leave the old norms behind 
and the adoption of new norms. However, the pull of the biological family still exists. Physical distance can help foster youth begin to build their own lives.

Knowing logically that someone is unable or unwilling to care for and love a person and emotionally still wanting love from them are different. Whether any of the participants will have relationships with their families in the future remains unknown. The pull of family will likely cause foster youth to try to establish healthy relationships with their biological families, but realistically, those may never be healthy relationships for foster alumni.

Even so, the act of moving away and starting over gave the foster youth in this study the opportunity to begin to craft their own lives. Moving out of state is a big decision at any age, but at such a young age, with little to no support, also shows a spirit that wants to not only survive, but also succeed. Charlie's desperation to remove himself from his mother's spiral into drugs and arrive in a community where he was homeless and had no resources showed a resilience and drive to thrive. By moving away from negative experiences, these youth have the chance to write a new chapter in their lives.

\section{Emerging Theme 3: The Need to Help Others}

To make sense of their experiences, each of the foster youth had a desire to help others. While some of that desire may come from altruism, it may also go much deeper. To understand the transitions they have experienced, and to develop self-esteem, these youth have found personal value in helping others. Their actions are not entirely unselfish but include an element of self-care. Seibert 1998) researched survivors and noted that having such opposite responses helps people survive difficult situations. Seibert found 
support for this concept in the works of Schneirla (1959), who described that moving toward or moving away from things forms a "biphasic pattern of adjustment" (p. 28).

Also, if we look at Bourdieu's social and cultural capital $(1973,1986)$ which one would normally accrue through familial relationships; however, many foster youth have a deficit in this area. Connections with adults in various forms puts foster youth in situations where they can begin to learn the hidden clues that are passed down to each generation through the transmission of social and cultural capital. Having been on the receiving end of being helped through the care system, foster youth are now in a more powerful position where they can help others. To help someone else is empowering and puts the foster youth in control of their lives for the first time.

Helping people makes study participants realize that others go through their own difficulties. As Vincent commented, helping others allows one to begin to try and make sense of their own situation. He felt he had been "left in the dark" and did not want other people to experience that. In a sense, they are reframing their experiences by making something good come of being of service to others. At the most basic level, helping others begins to aid foster alumni in healing themselves from their own experiences along with teaching them to value themselves.

\section{Emerging Theme 4. Education as a Pathway (Future)}

For each of the foster youth in this study, higher education was a ticket to a better future. Even when they could not articulate what that future will look like, they were aware that pursuing an education and receiving a degree would give them financial stability and opportunities to build their own lives. Education then became a means to an end for foster alumni, providing the life they did not have in the foster care system and 
the freedom to define their own futures. As Maggie put it, "when you have nothing there is nothing to lose."

In the case of Stephanie, education is a way to say that she is a successful person. "I was to be able to make something of myself and prove those that were not behind me $100 \%$ and were down-talking me, to prove them wrong and let them know like, I made it." Each of the study participants recognized they were missing elements in their lives but could not articulate what those were. This sense of missing something can be explained using Bourdieu's (1973) notion of not possessing the correct social and cultural capital. Participants fully recognized that education is a vehicle that will empower them by giving them opportunities and choices for their futures. Coming out of a system where they had few choices, higher education can be incredibly freeing, but also overwhelming to navigate.

\section{Emerging Theme 5: The Need to Belong (Somewhere/Anywhere)}

Higher education professionals who are unaware of the experiences of youth in foster care may not recognize that college may be the first-time foster alumni begin to address the traumas they have experienced in their lives. For most foster youth, going to college may be the first independent decision in their lives. Being away from the foster care system and in the relative safety of a college campus and making their own decisions may find foster youth finally confronting their family relationships and time in care. The trauma may surface, and foster youth may have trouble reconciling those experiences. Higher education professionals need to be aware that the impact of being in foster care is far reaching and does not dissipate upon emancipation, but instead surfaces at different times, as foster youth find some type of reconciliation with their experiences. 
Vincent stated, "I looked into a lot of the services, because again, it was a support system I was looking for." Everyone feels the basic human need to matter in life to someone else. As Schlossberg (1989) found, when people feel they do not matter they feel marginalized. Of the youth in this study, only Stephanie had a loving support system. She also had the fewest placements. That human need to belong to a community was a strong drive. For some of the study participants they found belonging in the community college. Even Charlie, who had not yet begun classes, was volunteering on campus was a way to begin forming community and to matter.

\section{Emerging Theme 6: Community College as a Safe Haven}

For each of the participants, entering higher education through the community college was a positive experience. Although a couple of the participants initially began elsewhere, they moved to the study institution when they felt they did not matter at their first institutions. Schlossberg's (1989) notion of mattering versus marginality helps explain why the community college environment is so important to foster alumni. Community colleges generally make a concerted effort to present a welcoming and supportive environment that conveys to students that they matter; a feeling vital to this student population.

Provasnik and Planty (2008) found that traditionally underrepresented students tended to enter post-secondary education through community college. The participants in this study found the community college to be welcoming and supportive of them and their goals. Participants found a safe haven and a place where they felt a sense of community and belonging. Those feelings were vital in participants opting to attend and to keep attending. 
Studies that have shown that attempting to earn a bachelor's degree through the gateway of a community college is less effective than for students who attend a 4-year university (Alfonso, 2006; Pascarella \& Terenzini, 2005). Regardless of that, the safe haven provided by the community college makes it an ideal starting place for foster youth. The sense of community and welcome found in community colleges can be replicated in 4-year institutions to help foster alumni transition. Universities could look toward community colleges to see what they are doing to recreate a culture of community, care, and belonging.

\section{Emerging Theme 7: Financial Transitions}

Helping students gain financial literacy is a pressing issue in higher education, given the increasing costs of attending college and students graduating with large debt. Financial-literacy training is becoming more common in post-secondary institutions for all students. However, the training is often geared toward students who know they have families to fall back on in times of need, and the specific needs of foster alumni is not often considered in financial-literacy training.

For foster youth, the thought of taking out loans to attend college is even more daunting. Additionally, some foster youth may not understand "good" debt versus "bad" debt. Charlie was adamant that he did not want a hand out, whereas Stephanie thought of financial aid as being paid for good grades. Others still, like Gemma, get caught between states, where they cannot access Chafee funds. Perhaps many foster youth feel the same confusion and lack of insider knowledge and get caught in the system the way Charlie and Gemma did, depriving them of needed funds to help them pursue their educational goals. Had the participants known ahead of time that leaving their home state would 
impact their ability to get the Chafee Grant, they might have chosen to remain in state to access the grant. Because they were not privy to that information, they could not make an informed decision. Foster youth might still have moved away yet remained in their home state. The decision to leave and get away from their families did have a negative and lasting financial impact on Charlie and Gemma.

For these study participants, the lack of insider knowledge cost them greatly. The absence of cultural capital, which so many people take for granted, is particularly apparent for this population of students. Family units pass on through words and actions how money is handled and to be used. Cultural capital is ingrained in the dynamics of a family unit and often not even openly spoken about, but children grow up learning through the actions of their families. Although Vincent took financial aid, he readily admitted that he did not know how to handle his finances. He stated, "I had a considerable amount of money to live on and I didn't know what to do with that income." Once more the puzzle pieces this population of students receives is missing vital pieces, leaving them to attempt to navigate without all the necessary insider information to be successful.

\section{Emerging Theme 8: Academic Literacy}

Weideman (2014) posited a definition of academic literacy that encompasses vocabulary, metaphors and idioms, arguments, fact and opinion, and inferences. However, the descriptions I am using are broader, encompassing not only the academic literacy that takes place in the discourse of a classroom, but that which goes beyond. Academic literacy is the language, processes, and opportunities embedded in pursuing a degree. Akin to Bourdieu's (1973) cultural capital, academic literacy allows students to 
successfully understand how college works (the ability to understand and navigate the system), college planning (courses, terms and transferring), accessing services (knowing where to go and available support services), building a degree (making the most of their collegiate experience by being involved in extra-curricular activities), and the benefits of a college degree (personal, social, and financial). Ultimately, strong academic literacy gives students the ability to articulate and successfully pursue their educational pathway. Academic literacy allows students to successfully navigate and take advantage of the various opportunities available to them as student scholars. While Vincent articulated it the best, the rest of the foster youth in this study were, for the most part, aware that they were missing pieces of knowledge that would have helped them better navigate the community college.

\section{Emerging Theme 9: Academic Advisors as (Neutral) Resources}

Study participants viewed academic advisors as neutral resources. All students have access to academic advisors, so whereas Charlie would not want to go to a specific foster youth office, he would not feel stigmatized by going to an advisor. Advisors can be cultural navigators (Strayhorn, 2015), helping foster youth transition into higher education by helping them become familiar with its norms and understand how college works. Vincent referred to academic advisors as providing him with a "mental compass" to navigate the system. Advisors were seen as individuals who listen, guide, and share experiences with foster youth. Advisors were seen to be the post markers who let the students know they are on the right track.

At the same time, study participants appeared not to have used their academic advisors as much as they could have to get the most benefit from the relationship. They 
went to academic advisors when in academic trouble or a couple of times to ensure their schedules were on track. Gemma made a comment that she always had to reach out to her advisor and she wanted the advisor to make contact with her, asking Gemma what she needed and checking in to see if she was doing well. This an example of not understanding how colleges work and a lack of insider knowledge. Advisors usually do not reach out to students in the way that Gemma wants, and this may be an unrealistic expectation. Although I do not know the ratio of advisors to students at the study institution, in many community colleges, advisors have large caseloads and may only see students who are proactive about coming to their office, or students who are in difficult academic situations. Gemma wants her advisor to be engaged in her academic plans, but she is unclear in understanding how academic advising works and the partnership that needs to exist between the student and the advisor. Schlossberg's 4 S's model (1981) identifies strategies and supports as central to a successful transition. Advising can be seen as a strategy and a support. Although some of the study participants were aware and used advisors that way, others in the group did not recognize the role academic advisors can play in their success.

\section{Emerging Theme 10: The Effects of Having Been in Foster Care Impacts Higher Education Success}

While each of the foster youth in this study was on his/her own journey, it was obvious that some participants were further along than others. Charlie was just at the beginning, needing housing security, a job, and to build a life in a new city. At the opposite end of the spectrum was Stephanie. Of all the foster alumni, she appeared in her interview to be the most self-actualized. In looking at her objectively, Stephanie had several advantages. First, she had experienced fewer foster home and school placements 
than the others. While most of the others experienced more than 10, Stephanie had not had multiple school placements and had stayed in the same schools. In addition, she only had three foster home placements, so relatively speaking, Stephanie had more stability growing up than the other youth in the study.

Another benefit Stephanie had was that she got pregnant and decided to keep her children. For Stephanie, being a mother was a grounding experience and she was determined to make something of her life not only to support them, but also to make her children proud of her in a way she was not proud of her own mother. Stephanie had, in a sense, a chance to rewrite history and was determined not to make the same choices her own mother had made. This gave Stephanie a seriousness and drive about her. She was not afraid to ask questions, use resources, or serve as a role model to others. Finally, and perhaps most importantly, Stephanie had a family of choice around her who were supportive. Her family of choice was her former foster parent who was readily available to help Stephanie and supported her educational endeavors. While she wanted to do things on her own, she did them always knowing that if she needed help, it was available to her. Stephanie knew she was loved and genuinely mattered to her foster parent. This knowledge gave Stephanie a sense of belonging and added stability in her life.

The primary fundamental relationship in each person's life is with their parents. As Bourdieu $(1973,1986)$ and Seita $(2001,2005)$ noted, invisible assets are passed down in a family. When that family relationship is fractured, for whatever reason, there are repercussions that extend far beyond. The lack of trust in institutions and those representing institutions causes many foster youth to not seek out services that would benefit them in pursuit of higher education. In the minds of the students in this study, a 
system is a system, with bureaucracy that is designed not to help them. Dysfunctional relationships, lack of trust, depression, low self-esteem, financial stress, and lack of confidence are some of the long-term effects that impact foster youth when accessing higher education.

Trying to learn how to navigate the world of higher education and survive with no supports can be too much for some foster youth. Gemma noted that her health had suffered at one point when trying to keep everything together. Although she was back on track when the interviews were conducted, that slip made the feelings of low self-esteem resurface and she was doubting herself by creating an imaginary yardstick of where she should be by that time in her life. I do not think it goes too far to state that the impact of having been in foster care can impact foster alumni all their lives.

\section{Limitations}

This study had several limitations that need to be included and discussed.

\section{Participants}

The five individuals who agreed to participate in the study were a limited group. In addition, participants chose to participate in the study and it is possible that another group of students might have yielded different results. Self-selection to move forward may have come from a different desire than solely to be a part of the research. Also, participants did receive gift cards for participating and although the amount was nominal, a group that was not compensated might have responded different. Because the sample group was small, a larger study may have resulted in different or additional themes and categories emerging from the data. 
Ideally, I would have liked more participants in the study, but although I tried numerous avenues, that was not to be. This is an ongoing issue in any study of foster youth as foster youth must be willing to participate for researchers to get rich data about their experiences. Given that many foster alumni feel stigmatized by their experiences in foster care and that others find it too painful to be reminded of their experiences, it is understandable that foster youth choose to distance themselves from their experiences in foster care. In addition, the participant who chose to only participate in one interview was a loss, as that participant's interview was very informative, but the participant, like the others, had a busy life and was trying to balance multiple responsibilities.

I also did not include race and ethnicity in the data collection and specifically did not ask participants to identify their race and ethnicity. As previous research has shown, disproportionate numbers of African American and Native American youth are in foster care. I wanted this research to focus solely on their transitions into higher education, but in doing so, I may have lost data that is important in understanding foster youth experiences.

\section{Saturation}

To claim total saturation of data would be incorrect for several reasons. While it certainly got to the point that no new data were emerging from the interviews, my own biases may have caused me to miss information. Also, another researcher with more experience may have discerned information I missed in collecting and analyzing the data.

\section{Researcher Bias}

As the researcher and a professional academic advisor, I found it difficult at times not to stop the interviews and provide academic advising to participants. In this way, my 
professional life and research life collided. I managed to resist the temptation, but in a couple of instances, when participants had no idea how to get information (e.g., accessing resources), at the conclusion of the interviews I gave the participants the relevant information to help them navigate through the community college.

Furthermore, as a professional advisor, I have a bias toward academic advising and believe that as a resource, advising can improve students' experiences through higher education. Good academic advisors can help students navigate the often-labyrinthine policies and procedures of a post-secondary institution while also guiding students to take advantage of the multitude of resources and opportunities on campus that support student success and persistence. Advisors mentor students along their collegiate journey and help them to connect the general education to their major, and the co-curricular to the curricular.

Grounded theory uses the researcher as the primary instrument to analyze the data. As such it is vital to note that one of the biggest limitations is that of the researcher. Had another researcher conducted these interviews, and analyzed the data their interpretations of participants' transitions may have been different from my findings.

\section{Omission of Race and Ethnicity}

When I began the study, I opted not to ask the participants to self-disclose their race. I had two reasons for this decision. Other studies have shown that there are disproportionate numbers of African American and Native American youth in foster care. The second reason was that I knew I would be asking participants to share sensitive and deeply personal stories with me and I left it up to them to discuss race if they chose to do so. In hindsight, I think my decision was a mistake. Race is part of the conversation and 
my option not to ask may have resulted in losing some quantitative data. As Schmidt et al. (2015) stated "supporting the positive racial/ethnic identity development of young people in foster care is affirming their racial/ethnic self-identification" (p. 61). Moving forward with the next round of the study, I will include a question on race, so participants can make the choice of whether they want to answer it.

\section{Lack of Foster Youth Background}

Because I did not come from a foster care background, in some cases manifested as a lack of credibility in the foster youth community. Once participants met me in person and understood that my interest was genuine and came from a place of wanting to help, they were open. However, I believe that some potential participants who initially thought about being part of the study did not continue because they may have felt that I could not understand their lived experiences. Several times in the interviews, participants noted it is easier to talk to someone who shares a foster care background, as they understand. As Maggie stated, "You can't really fully have empathy unless you have been there."

At the same time my lack of background may also have helped in that I had no preconceived ideas about foster youth or their experiences in the system. Participants were surprised that someone without a foster care connection was interested in helping foster youth. Each participant wanted to know why I was conducting the research, which I discussed with them prior to beginning the interviews. Although much is discussed in the literature and by participants themselves about the stigma surrounding having been in foster care, I had no knowledge of the stigma, save what I read in articles when I first began my research. I approached the participants openly, sharing my lack of knowledge 
with them. By being open and honest with participants about my lack of experience helped forge a level of transparency and trust.

\section{Stigma of Foster Care}

One of the more interesting aspects of this research was the response from others in higher education. While conducting my research, numerous times people asked what I was studying and, when I responded, it became apparent that the subject matter made people uneasy. Frequently people changed the subject quickly as if talking about foster youth was illegal. I was understandably intrigued by this response and came to realize that having a family is a fundamental aspect of the progression of life for most people. Having the state remove one's children is a cause for shame and people want to separate themselves from shame, but often, when people consider the subject closely, they realize that little separates them and the parent who had their child removed. Although all people like to think they are better or more protected, in some cases a lost job or illness can cause a family to spiral down and be unable to care for their children. Little separates "us" from "them" and people shy away from discussing issues surrounding foster care as it makes them feel uncomfortable.

\section{Implications and Recommendations for Academic Advisors, Student Affairs Personnel, and Higher Education Institutions}

The data presented in this study showed that higher education institutions can take steps to support foster youth. First, foster youth need to be acknowledged as a student population that has specific needs and that foster alumni can be successful, provided they receive support to meet the challenges facing them. Second, a dialogue needs to occur among academic affairs and student affairs professionals regarding students from foster care backgrounds and the multiple barriers to success they encounter when pursuing post- 
secondary education. Third, institutional agents need to be part of the discourse on the best ways to make campuses foster friendly. Once conversation begins across a campus, supports such as programming, policies, and practices can be examined to determine how best to support foster youth. Finally, this group of young people has great strength and potential.

The quotation earlier in this paper from the OUS representative about foster youth not even being on the radar, while appalling, is most likely not unusual and is reflected across the country. Youth who have been in the foster care system are for the most part largely an invisible population. If most people are unaware of the barriers and issues foster youth encounter, then advocacy for these students is also not taking place. Foster alumni cross gender, race, and ethnicity lines, but lack the advocacy of institutional agents to support them in not only seeking but completing post-secondary education. Institutions and their agents must not be allowed to ignore a group of students simply because it causes work or because the concept of foster care makes some people uncomfortable.

\section{Implications and Recommendations for Academic Advisors}

Academic advisors are cultural translators/navigators for students (Strayhorn, 2015). Advisors bring students into the culture of higher education, explaining its unique language and cultural artifacts and thereby allowing students to successfully transition into their new culture. Successful transitions mean being able not only to navigate in the system, but to thrive in higher education.

If educators can continue to look through the lens of the conceptual framework with regard to academic advisors, Bourdieu (1979) described the added value of social 
and cultural capital: the insider knowledge passed down through families that allows young people to successfully navigate an unfamiliar system. Foster youth are often missing social and cultural capital, but advisors can level the playing field by translating higher education mores and teaching students how to navigate the system. Schlossberg's (1981) work on transitions normalizes the transitional experience so that foster youth can understand that throughout their lives, they will go through transitions, but regardless of the transitions foster youth bring with them, the 4 S's of situation, self, supports, and strategies help them actively work through transitions in a positive manner.

Academic advisors serve as a bridge between academic affairs and student affairs. Advisors are in a unique position in higher education to support the educational needs of foster alumni. As Tinto (2003) stated, "no one rises to low expectations" and advisors raise the level of expectations for their students. Strayhorn (2015) said:

Effective academic advisors, as cultural navigators, care about their students and they signal in meaningful ways that students matter. They know their studentstheir names, where they are from, what they bring with them, their strengths and weakness. They do not see this as coddling but rather advising in its truest form. They help make the implicit explicit, the hidden known, and the unfamiliar commonplace. They help students navigate college making clear what student need to know and do to be successful. They help students find a sense of belonging on campus.

That very sense of belonging is what the participants in this study craved: to belong somewhere and to matter (Strayhorn, 2015). Schlossberg (1989) stated "My work on transitions- events or nonevents that alter our lives-convinced me that people in transition often feel marginal and that they do not matter" (p. 1). Schlossberg (1989) explained,

Every time an individual changes roles or experiences a transition, the potential for feeling marginal arises. The larger the difference between the former role and 
the new role the more marginal the person may feel, especially if there are no norms for the new roles. (p. 2)

The foster youth in this study talked about how being in care had left them feeling marginalized. They recognized they were missing elements in their lives, but they were collectively and individually determined to use education as a means to better their lives. Post-secondary education represents an opportunity for a better life.

Bourdieu (1986) talks about the assets individuals acquire through social and cultural capital. Several participants accurately noted they lacked elements in their lives. While they could not always articulate what those elements were, they were very cognizant that deficits existed. Vincent stated, "a lot of times I miss things right in front of me." Family privilege gives young people skills and assets to navigate their lives (Seita, 2001). Foster youth without strong biological or foster family connections spend energy trying to navigate systems and acquire social and cultural capital to improve their lives. It cannot be overestimated that trying to come of age, pursue an education, and know that you are missing pieces of the puzzle puts an enormous strain on foster youth.

Unfortunately, most academic advisors, like most institutional agents, are unaware of the issues facing foster alumni as they transition into higher education. Currently, no student development theories consider foster youth as a population with risk factors. It is highly likely that institutional agents believe foster care happens between birth and emancipation and is a finite experience. Ignorance regarding the issues and challenges facing this group of students upon entering higher education can negatively impact foster youth. Indeed, these views of foster care as a finite experience, with a defined beginning and end, impacts foster alumni negatively; people unfamiliar with the foster care system are unaware of the long-term implications faced by former 
foster youth. By not understanding or even being aware of the lasting impact of foster care on a young person can and does impede foster youth. Well-meaning institutional agents may make assumptions about youth without knowing their background. A former foster youth who applies for an emergency loan may meet a seemingly innocuous comment: "why don't you ask your parents?" Foster youth may not want to have to explain their situation repeatedly to various institutional agents and the agents, through ignorance rather than malice, have made the student feel unwelcome.

As noted previously, only one article about foster youth was written by an academic advisor and directed to those in the field of advising (Klefeker, 2009). While academic advisors can serve the role of cultural navigators, they cannot do so if they are unfamiliar with the struggles and issues impacting youth who have been in foster care. A paucity of literature persists for practitioners in the field of advising, thereby manifesting in an almost complete lack of understanding and programming that could serve to support foster youth in accessing and persisting through higher education.

Academic advisors may not only be ignorant about foster care, but lack training with this population. Across the United States, most academic advisors enter the profession with a master's degree. Graduate programs often focus on issues of social justice and equity, yet do not often teach students about foster youth and their transitions into higher education, thereby creating and perpetuating practitioner ignorance about this group of students. Once again, unless an institutional agent has personal knowledge or works specifically with foster youth, the level of knowledge about this group of vulnerable students is small. While there are some institutions across the country with active programs to support foster alums, they are limited. Although these programs are 
commendable and successful, more needs to occur to empower advisors to learn about and effectively serve and advocate for this vulnerable student population.

Training and development for academic advisors should include teaching the advising community to understand the experiences of foster youth. Advisors can create a welcoming atmosphere and support students as they transition into and through the institution. Advisors can help make foster youth feel not only part of the community but appreciated as well.

\section{Implications and Recommendations for Student Affairs Personnel}

People who go into student affairs professions tend to be concerned with social justice issues and providing all students with a successful higher education experience. The field of student affairs concerns itself with the co-curricular opportunities that provide opportunities for engagement in activities and development of skills, including leadership skills. Student affairs practitioners can provide multiple avenues of support to help foster youth. Encouraging foster youth to participate in activities, student government, and join clubs is one way. Also, providing programming or a specific club is yet another way to support foster youth. Having a food bank on campus so all students, not just foster alumni, can access free food if they are experiencing food insecurity is helpful. Designing a program to provide backpacks for entering foster youth with toiletries, gift cards, and items donated from local businesses is yet another idea. So too would small micro grants be an option to help foster alumni have sufficient funds for items needed to experience college and reduce the chance of exiting prior to graduation.

As Maggie noted in Chapter 4, the holidays are particularly lonely for foster alumni. Student affairs practitioners could look to develop events around the holidays 
whereby foster youth are paired with faculty, staff, or community members so they have a place to go for the day. These are all relatively small ideas, with little cost, yet they provide a profound way to show foster youth that they matter and are not alone as they are progressing through higher education.

\section{Implications and Recommendations for Higher Education Institutions}

First, higher education institutions need to recognize that there are current foster youth and alumni on their campuses. Real action toward educating institutional agents needs to take place on college and university campuses. Being ignorant is not an excuse for ignoring the needs of a population of students. With a bit of work and education, higher education professionals can be made aware of this group of students, their resiliency, desire for education, and the barriers in their way. That way, institutional agents at each institution can work to identify and then eradicate barriers and instead build opportunities for foster alumni.

Higher education institutions also need to work with Independent Living Programs to support transitions into higher education. Holding mandatory training sessions for faculty and staff around foster youth experiences and issues is also essential. Those trainings must include current and former foster youth so that institutional agents hear directly from the students affected. Although ideally it would be advantageous to have programs like the Renaissance or Guardian Scholars on every campus, that may not be realistic for many institutions. Finances, time, and resources will not allow for these types of targeted programs at this time at many post-secondary institutions. Higher education institutions can, however, create an office, or designate an official on campus to work with current and former foster youth. Having an ombudsman to support foster 
youth to navigate the institution would be helpful. If the institution cannot fund an office, then creating foster youth liaisons in different areas would also work. Staff in admissions, advising, financial aid, business office, and TRiO programs could receive additional training to be identified as foster youth allies. A benefit to such a system is that it allows foster youth to access the service if they choose to do so. Charlie commented he would not go into an office specifically listed for foster alumni, due to stigma surrounding foster care, but he would access individuals if he knew they could help him.

\section{Significance for Educational Leaders}

In many states, the move is to extend foster care to age 21 , and in some cases beyond that, to provide ongoing support to foster youth as they begin their transition to independence and adulthood. For foster youth interested in higher education, this extended care can provide them stability to persist toward degree completion, but only if the foster living situation is positive for the youth.

The significance for educational leaders is that there is a group of overlooked, vulnerable students on college campuses and institutions have a responsibility to support those students. In addition, in an era where completion agendas are becoming more important, recruiting students and having them drop out will not benefit higher education institutions aiming for degree completion and the funds attached to persistence.

\section{Policy}

Over the past few years, state and federal governments have begun to advocate more for this group of students. Continued changes in policy could include increasing the time students can access Chafee funds, given that some students need to have stable housing and have employment/job skills prior to going to college. Another aspect of 
Chafee would be to extend it across state lines. Chafee is a federal program, but Gemma and Charlie were going to lose out on accessing it because they moved to another state and left their home state where they had been in foster care. A foster youth should not be punished because they have decided to save themselves by moving away from their biological family. Much like veteran's benefits, a policy change could allow foster youth to access their Chafee benefits wherever they live.

While some states are moving ahead with ways to support foster youth with extended time in care and tuition waivers, most higher education institutions are doing little to support foster youth. More institutions need to look at this population of students and find ways to support them. There are some institutions that have robust programming and offices supporting foster youth and those institutions show that foster youth can be successful in degree completion.

\section{Opportunity Costs}

In the climate of higher education today in the United States, much conversation surrounds completion, time to degree completion, and performance-based funding. Another area of concern for students is the opportunity costs of their educational journey. For each additional year a student is in college beyond 4 years equals approximately over $\$ 150,000$ in lost opportunity costs, which are defined as tuition, living expenses, lost wages, lost promotions, and retirements losses (Complete College America, 2016). For foster youth, the need to get in, get through, and get on with their life is imperative.

\section{Significance to Field of Study}

Studies have shown the impact of foster care on children and youth, but little is known about the experiences of foster youth in higher education. Due to the limited 
numbers of participants in this study, it is necessary to continue to research a larger pool of foster youth to determine if their experiences mirror those of the foster alumni in this study. Findings from this study indicate that foster alumni experience transitions into higher education differently from youth who were not fostered, based on their experiences. Treating foster youth like their peers who were not fostered is a disservice to a group of students who, with the proper supports and resources, can be successful in higher education.

\section{Next Steps in Research}

Ultimately, this study provided a picture of numbers of foster youth in higher education institutions in Oregon. Although not completely accurate, as some foster youth do not wish to self-identify, there are significant numbers in the state to warrant developing programs and supports to help foster youth and youth transition into and through higher education. In addition, an immediate need exists to educate institutional agents about this population of students to better serve foster youth.

The transition experiences described by the youth in this study indicate that further research is necessary to assess if these results are replicated with larger numbers of participants and in other states. My goal is to continue this research by moving beyond Oregon and working with other states to see if the transitional experiences of foster youth are similar or different. I wish to discern if the themes that emerged with this group of foster youth also emerge in other groups of foster youth in different states. This study suggested that foster youth do transition differently from non-foster youth. Having been in foster care adds additional layers of complexity to the pursuit of a degree. Along with looking at a larger pool of participants in several states, I intend to work with a 
quantitative researcher to complete a mixed-methods study to see if these initial findings are replicated on a larger scale.

Finally, with the next round of research, I want to expand the transitions and look not only at foster youth accessing higher education through community colleges, but also the experiences of those who have transferred from the community college to a university. My goal is to give voice to a population of students who are currently underserved in post-secondary education and support advocacy and training for institutional agents. My goal is to provide better services and supports to foster youth.

\section{Dissolution of Oregon University System}

At the start of this study the OUS governed the seven public universities in the state. In 2015, the state opted to disband the system and allow public institutions to form their own governing boards. What this means for higher education in the state remains to be seen. At this time, university presidents and provosts continue to meet and work together; however, considering that foster youth were not on the radar of OUS as a statewide organization, the dissolution of the governing body may mean foster youth in the state will continue to remain largely invisible. While the Oregon Office of University Coordination and the Higher Education Coordinating Commission are now doing some of the administrative work formerly done by OUS, it remains to be seen what impact this will have on foster youth. The Higher Education Coordinating Commission has an Equity Workgroup, but the work of that group tends to be more focused on diversity and race rather than foster youth. However, because the state is moving to a performance-based funding model and is giving credit to institutions that work with traditionally 
underrepresented students, a brighter light may shine on foster youth, providing them additional supports.

\section{Grassroots Efforts}

In the meantime, some institutions are attempting to develop grassroots efforts to work with foster youth on their campuses. Western Oregon University has received a grant from the Oregon Department of Human Services to develop training on campus for institutional agents and to design programs to help foster alumni. The program is a coordinated effort between the Oregon Department of Human Services, Western Oregon University, and Polk County Independent Learning Program. Although this is a positive step, it highlights the fact that often efforts to support foster youth are often done by individuals with a passion for foster youth, rather than as institutional or statewide commitments and educational support. Those efforts can falter when individuals leave an institution.

\section{Conclusion}

People who have been in the foster care system face multiple barriers to success. Indeed, much of the research to date has shown the grim statistics facing foster youth after emancipation. At the same time, these young people are filled with promise, having overcome oftentimes horrific childhoods and multiple barriers to success. Foster youth are tenacious, determined, and resilient. They deserve and need to have supporters on their side to help them overcome the barriers that hinder their transitions into and through higher education. While foster youth come to college with risk factors, institutional agents must never forget that the promise of foster youth far outweighs their risk factors. 
Institutional agents cannot ignore the lived experiences of foster youth in higher education. Foster youth are the experts and higher education professionals must look to them to help in educating and designing programs that support foster yourh in successfully persisting toward degree completion. Access to post-secondary education, whether through a community college or a university, is only the first step. Once foster youth are on campus, the campus community must provide resources, referrals, and support targeted to the specific needs of the foster youth population to help them transition through successfully.

Despite multiple competing demands on funding, institutions that cannot afford programs like the Guardian Scholars can still provide professional development training for faculty and staff to make them aware of the issues facing foster youth, and designate foster youth liaisons on campus to serve as institutional supports. The role of academic advisors is to serve as mentors, guides, and supports for all students; thus, they are a logical choice of institutional agents to help support the educational pursuits of foster youth. Institutions have no legitimate excuses for ignoring the plight of such a vulnerable population. By the time foster alumni have made it to the doors of higher education, they have shown persistence, motivation, and drive: three qualities that will help them pursue and complete a college degree.

Foster youth are young people who, through no fault of their own, have had a difficult start in life, yet foster youth have great promise. They have overcome childhoods often filled with neglect, abuse, and maltreatment. Too often, the narrative surrounding foster alumni focuses on poor outcomes for this population, and although that does exist, that narrative is often a self-fulfilling prophesy. For young people to have overcome 
dysfunctional family situations, a childhood of impermanency often combined with multiple school and foster home placements, and then attempt to attend college shows not only survivorship, but resiliency, fortitude, and determination. While foster youth have risk factors, they are, first and foremost, students with promise.

Cross's presentation in 1994 at the Student Learning Imperative Teleconference at Bowling Green University compared the college experience to a jigsaw puzzle:

Students start college with a bag in which they put puzzle pieces they collect during the course of their time in college. Into the bag goes a puzzle piece for every activity, starting with fall orientation, advising sessions, classes, cultural events, dorm meetings, and so forth. For many students the jumble of pieces does not create a coherent, sensible picture. That is a problem because students who cannot discern meaning from their colleges activities often report academic difficulty or social isolation and are at risk of leaving school. Unlike a jigsaw puzzle that has a picture on the box top, colleges often come without direction; many students are unlikely to know they are constructing a picture, nor do they have strategies for making that picture meaningful for the present or useful for identifying future learning opportunities. This is particularly true for students who are the first in their families to attend college.

The image of the puzzle box top echo's Bourdieu's $(1973,1979)$ cultural capital.

When you have the box top it allows you to see the entire puzzle and suddenly the picture and path are clearer. For foster youth who lack cultural capital, the missing box top and missing puzzle pieces serve as daily reminders that they have missed out and are still missing out on information.

Cross's (1994) work, over 20 years ago, echoes not only the same experiences today for many college students but is a powerful metaphor for foster youth. Legacy students have social and cultural capital accumulated through their families to help them see the bigger picture of higher education and how all the puzzle pieces go together to build not only a degree but learning experiences through the curricular and co-curricular. First-generation and other traditionally underrepresented students typically have 
resources on campus and advocates to work with them specifically to address their needs and issues, helping them transition through higher education. But youth that have been in the foster care system arrive at the table of higher education with not one bag for college puzzle pieces, but a second bag that is jumbled full of pieces from their time in foster care. For those youth, trying to make sense of their experiences in care, along with disturbed family situations and stigma from having been in care, is indeed a puzzle for which foster youth have no box top to show them the clear puzzle picture. As Vincent stated, "it is a million-piece puzzle, because you have to go back and pick up these pieces." When your life is a million-piece puzzle you need a compass and navigators to successfully transition through higher education. 
References

Administration for Children, Youth, Families, Washington, DC. Office of Research Evaluation. (2001). National Survey of Child and Adolescent Well-Being (NSCAW). State Child Welfare Agency Survey Report. S.1.]: Distributed by ERIC Clearinghouse.

The Adoption History Project. (n.d.). Orphan trains. Retrieved February 27, 2012, from http://pages.uoregon.edu/adoption/topics/orphan.html

Alfonso, M. (2006). The impact of community college attendance on baccalaureate attainment. Research in Higher Education, 47, 873-903. Doi:10.1007/s11162-006 $-9019-2$

Allen, Janine M., Smith, Cathleen L., \& Muehleck, Jeanette K. (2013). What Kinds of Advising Are Important to Community College Pre- and Posttransfer Students? Community College Review, 41(4), 330-345.

Allen, J. M., \& Smith, C. L. (2010). Pre-and post-transfer student academic advising: What students say are the similarities and differences (Unpublished manuscript). Retrieved from ERIC database (EJ1033571)

Allen, J. M., Smith, C. L., \& Muehleck, J. K. (2014). Pre-and post-transfer academic advising: What students say are the similarities and differences. Journal of College Student Development, 55, 353-367. doi:10.1353/csd.2014.0034

Allen, J. M., Smith, C. L., \& Sullivan-Vance, K. A. (2011, February). Fostering success: Raising awareness of issues facing foster youth in accessing and succeeding in higher education. Paper presented at the Foster Youth Pathways to College Conference, Portland Community College Rock Creek Campus, Portland, OR. 
Alstadt, D., Schmidt, G., \& Couturier, L. K. (2014). Driving the direction of transfer pathways reform: Helping more students achieve their baccalaureate goals by creating structured transfer pathways "with the end in mind." Boston, MA: Jobs for the Future.

Arnett, J. J. (2000). Emerging adulthood: A theory of development from the late teens through the twenties. American Psychologist, 55(5), 469-480. doi:10.1037/0003 $-066 X .55 .5 .469$

Arnett, J. J. (2007). Emerging adulthood: What is it, and what is it good for? Child Development Perspectives, 1, 68-73. doi:10.1111/j.1750-8606.2007.00016.x

Aschaffenburg, K., \& Maas, I. (1997). Cultural and educational careers: The dynamics of social reproduction. American Sociological Review, 62, 573-587. doi:10.2307 12657427

Astin, A. W. (1984). Student involvement: A developmental theory for higher education. Journal of College Student Personnel, 25(4), 518-529. Retrieved from https:// www.middlesex.mass.edu/ace/downloads/astininv.pdf

Banyard, V. L., \& Cantor, E. N. (2004). Adjustment to college among trauma survivors: An exploratory study of resilience. Journal of College Student Development, 45, 207-221. doi:10.1353/csd.2004.0017

Barth, R. P. (1990). On their own: The experience of foster youth after care. Child \& Adolescent Social Work Journal, 7, 419-446. doi:10.1007/BF00756380

Baum, S., Ma, J., \& Payea, K. (2005). Education pays Update 2005: The benefits of higher education for individuals and society. New York, NY: The CollegeBoard Advocacy \& Policy Center. 
Baum, S., Ma, J., \& Payea, K. (2010). Education pays 2010: The benefits of higher education for individuals and society. Washington DC: The College Board.

Bennett, C., \& Okinaka, A. M. (1990). Factors related to persistence among Asian, Black, Hispanic, and White undergraduates at a predominantly White university: Comparison between first and fourth year cohorts. Urban Review, 22, 33-60. doi:10.1007/BF01110631

Bensimon, E. M. (2007). The underestimated significance of practitioner knowledge in the scholarship on student success. Review of Higher Education, 30, 441-469. doi:10.1353/rhe.2007.0032

Berger, J. B., Ramirez, G. B., \& Lyons, S. (2012). Past to present: A historical look at retention. In A. Seidman (Ed.), College student retention: Formula for success. (2nd ed., pp. 7-34). Lanham, MD: Rowman \& Littlefield.

Bill \& Melinda Gates Foundation. (2008). New initiative to double the number of lowincome students in the U.S. who earn a postsecondary degree [Press room: Press Releases and Statements]. Retrieved June 15, 2015, from https://www .gatesfoundation.org/Media-Center/Press-Releases/2008/12/New-Initiative-to -Double-the-Number-of-LowIncome-Students-in-the-US-Who-Earn-a -Postsecondary-Degree

Blome, W.W. (1997). What happens to foster kids: Educational experiences of a random sample of foster care youth and a matched group of non-foster care youth. Child \& Adolescent Social Work Journal, 14, 41-53. doi:10.1023/A:1024592813809

Bourdieu, P. (1973). Cultural reproduction and social reproduction. London: Tavistock, 178. 
Bourdieu, P. (1986). The forms of capital Handbook of theory and research for the sociology of education (pp. 241-258). R.(1974). The Power Broker: Robert Moses and the Fall of New York.

Bourdieu, P., \& Passeron, J. (1979). The inheritors: French students and their relation to culture (R. Nice, Trans.). Chicago, IL: The University of Chicago Press.

Bowlby, J. (1982). Attachment and loss: Retrospect and prospect. American Journal of Orthopsychiatry, 52, 664-678. doi:10.1111/j.1939-0025.1982.tb01456.x

Boylan, H. R. (2001). Making the case for developmental education. Research in Developmental Education, 12(2), 1-4. Retrieved from https://thenade.org /resources/Pictures/ADVOCACY/MakingtheCase.pdf

Brandford, C., \& English, D. (2004). Foster youth transition to independence study. Seattle, WA: Washington Department of Social and Health Services, Office of Children's Administration Research.

Calvin, E. (2001). Make a difference in a child's life: A manual for helping children and youth get what they need in school. Seattle, WA: Casey Family Programs.

Carnevale, A. P., Smith, N., \& Strohl, J., (2010). Help wanted: Projections of jobs and education requirements through 2018. Washington, DC: The Georgetown University Center of Education and the Workforce.

Casey Family Services. (2008). The Casey young adult survey: Findings over three years. Seattle, WA: Author.

Charmaz, K. (2006). Constructing grounded theory: A practical guide through qualitative analysis. London, England: Sage. 
Charmaz, K. (2014). Constructing grounded theory: Introducing qualitative methods. (2nd ed.). Thousand Oaks, CA: Sage.

Child and Adolescent Well-Being Research Group, 2001.

Children's Advocacy Institute. (2007). Homepage. Retrieved from http://www .caichildlaw.org/

Cho, S. W., \& Karp, M. M. (2013). Student success courses in the community college: Early enrollment and educational outcomes. Community College Review, 41, 86103. doi:10.1177/0091552112472227

Choice, P., D’Andrade, A., Gunther, K., Downes, D., Schaldach, J., Csiszar, C., \& Austin, M. J. (2001). Education for foster children: Removing barriers to academic success. Berkeley, CA: University of California, School of Social Welfare, Center for Social Services Research, Bay Area Social Services Consortium.

Christian, S. (2003). Educating children in foster care. Washington, DC: National Conference of State Legislatures.

The College Board, Advocacy and Policy Center. (2011). The college completion agenda: 2011 progress report. Retrieved June 24, 2012, from https://www.ewa.org /sites/main/files/file-attachments/progress_report_2011.pdf

College Cost Reduction and Access Act, 20 U.S.C. $\S \S 1001$ et seq. (2007).

Complete College America. (2016). Annual summer conference. Minneapolis, MN. Complete College America. (2017). Guided pathways to success: Boosting college completion. Washington, DC: Author. 
Courtney, M. E., Dworsky, A., Cusick, G. R., Havlicek, J., Perez, A., \& Keller, T. (2007). Midwest evaluations of adult functioning of former foster youth: Outcomes at age 21. Chicago, IL: University of Chicago, Chapin Hall Center for Children. Courtney, M. E., Dworsky, A., Lee, J., \& Raap, M. (2009). Midwest evaluation of the adult functioning of former foster youth: Outcomes at age 23 and 24. Chicago, IL: University of Chicago, Chapin Hall Center for Children.

Courtney, M. E., Dworsky, A., Ruth, G., Keller, T., Havlicek, J., \& Bost, N. (2005). Midwest evaluation of adult functioning of former foster youth: Outcomes at age 19. Chicago, IL: University of Chicago, Chapin Hall Center for Children.

Courtney, M. E., Piliavin, I., Grogan-Kaylor, A., \& Nesmith, A. (2001). Foster youth transitions to adulthood: Outcomes 12 to 18 months after leaving out-of-home care. Child Welfare, 80, 685-717.

Courtney, M. E., Terao, S., \& Bost, N. (2004). Midwest evaluation of the adult functioning of former foster youth: Conditions of youth preparing to leave state care. Chicago, IL: University of Chicago, Chapin Hall Center for Children.

Creswell, J. W. (2007). Qualitative inquiry and research design: Choosing among five approaches (2nd ed.). Thousand Oaks, CA: Sage.

Creswell, J. W. (2009). Research design: Qualitative, quantitative and mixed methods approaches (3rd ed.). Thousand Oaks, CA: Sage.

Crookston, B. B. (1972, January). A developmental view of academic advising as teaching. Journal of College Student Personnel, 13(1), 12-17. doi:10.12930 /0271-9517-14.2.5 
Cross, P. (1994). Student learning imperative teleconference. Bowling Green, OH: Bowling Green State University.

Davies, T. G., \& Casey, K. (1999). Transfer student experiences: Comparing their academic and social lives at the community college and university. College Student Journal, 33, 60-71. Retrieved from http://www-vis.lbl.gov/ romano /Ed198-SEM/TransferStudentExperiences.pdf

Davies, T. G., \& Dickmann, E. M. (1998). Student voices in the transfer process: Do we hear them? Do we listen? Community College Journal of Research and Practice, 22, 541-557. doi:10.1080/1066892980220507

Davis, P. M. (2009). Western Michigan University program offers hope for grown foster children [Web log]. Kalamazoo Gazette. Retrieved July 13, 2011, from http:// www.mlive.com/news/kalamazoo/index.ssf/2009/05/western_michigan _university_pr_7.html

Davis, R. J. (2006). College access, financial aid, and college success for undergraduates from foster care. National Association of Student Financial Aid Administrators. Retrieved from https://files.eric.ed.gov/fulltext/ED543361.pdf

Day, A., Dworsky, A., Fogarty, K., \& Damashek, A. (2011). An examination of postsecondary retention and graduation among foster care youth enrolled in a fouryear university. Children and Youth Services Review, 33, 2335-2341. doi:10.1016 /j.childyouth.2011.08.004

Denzin, N. K., \& Lincoln, Y. S. (2011). The Sage handbook of qualitative research (4th ed.). Thousand Oaks, CA: Sage. 
Digest of Education Statistics, 2010. (2011, April 05). Retrieved from

https://nces.ed.gov/pubsearch/pubsinfo.asp?pubid=2011015

Dougherty, K. J. (1992). Community colleges and baccalaureate attainment. Journal of Higher Education, 63, 188-214. doi:10.2307/1982159

Dougherty, K. J., Jones, S. M., Lahr, H., Natow, R. S., Pheatt, L., \& Reddy, V. (2014, November). Implementing performance funding in three leading states:

Instruments, outcomes, obstacles and unintended impacts. doi:10.7916

/D8CZ35WZ

Draeger, J. (2007). Access \& success for the forgotten students. Student aid transcript, Student Aid Transcript, 18(3), 6-15.

Duncan, R. D. (2000). Childhood maltreatment and college drop-out rates: Implications for child abuse researchers. Journal of Interpersonal Violence, 15, 987-995. doi: $10.1177 / 088626000015009005$

Dworsky, A., \& Havlicek, J., (2009). Review of state policies and programs to support young people transitioning out of foster care. University of Chicago, Chapin Hall Center for Children.

Dworsky, A., \& Pérez, A. (2010). Helping former foster youth graduate from college through campus support programs. Children and Youth Services Review, 32, 255263. doi:10.1016/j.childyouth.2009.09.004 
Emerson, J., Duffield, B., Salazar, A., \& Unrau, Y. (2012). The path to success: Creating campus support systems for foster and homeless youth. Leadership Exchange, 10(2) 8-13. Retrieved from http://www.fostercareandeducation.org /DesktopModules/Bring2mind/DMX/Download.aspx?EntryId=1813\&Command= Core_Download\&method $=$ inline \&PortalId $=0 \&$ TabId $=124$

Engle, J., \& Tinto, V. (2008). Moving beyond access: College success for low-income, first-generation students. Washington, DC: The Pell Institute.

Erickson, F. (1986). Qualitative methods in research on teaching. In M. C. Wittrock, Handbook of research on teaching (3rd ed.) New York, NY: Macmillan Library Reference.

Festinger, T. (1983). No one ever asked us: A postscript to foster care. New York, NY: Columbia University.

Foster Care Independence Act 42 U.S.C. $§ \S 1301$ et seq. (1999).

Foster Care to Success. (2012). Care packages. Retrieved March 3, 2012, from http:// www.fc2success.org/

Fostering Connections to Success and Increasing Adoptions Act 42 U.S.C. $\S \S 671$ et seq. (2008).

Friedel, J. N., Thornton, Z. M., D’Amico, M. M., \& Katsinas, S. G. (2013). Performancebased funding: The national landscape. Tuscaloosa, AL: University of Alabama, Education Policy Center. 
Gawley, T., \& McGowan, R. (2006). Learning the ropes: A case study of the academic and social experiences of college transfer students within a developing universitycollege articulation framework. College Quarterly, 9(3). Retrieved from https:// files.eric.ed.gov/fulltext/EJ835416.pdf

Geenen, S., \& Powers, L. (2006). Are we ignoring youths with disabilities in foster care: An examination of their school performance. Social Worker, 51(3), 233-241. doi: $10.1093 / \mathrm{sw} / 51.3 .233$

Glaser, B. G., \& Strauss, A. L. (1967). The discovery of grounded theory: Strategies for qualitative research. London, England: Aldine.

Guardian Scholars Program. (n.d.). The guardian scholars. Retrieved October 12, 2012, from http://www.fullerton.edu/guardianscholars/

Habley, W. R. (2004). Realizing the potential of academic advising (NACADA Session Guide 18th Annual Academic Advising Summer Institute, pp. 21-37). Manhattan, KS: National Agency for the Campaign Against Drug Abuse.

Hagedorn, L. S. (2012). How to define retention: A new look at an old problem In A. Seidman, (Ed). College student retention: Formula for student success (2nd ed., pp. 81-96). New York, NY: Rowman \& Littlefield.

Harris, M. S., Jackson, L. J., O’Brien, K., \& Pecora, P. J. (2009). Disproportionality in education and employment outcomes of adult foster care alumni. Children and Youth Services Review, 31, 1150-1159. doi:10.1016/j.childyouth.2009.08.002

Hill, K. (2012). Permanency and placement planning for older youth with disabilities in out-of-home placement. Children and Youth Services Review, 34, 1418-1424. doi:10.1016/j.childyouth.2012.03.012 
Hill, R. B. (2001, January). The role of race in foster care placement. Paper presented at the Race Matters Forum, Chevy Chase, MD.

Hill, R. B. (2007). An analysis of racial/ethnic disproportionality and disparity at the national, state, and county levels. Seattle, WA: Casey-CSSP Alliance for Racial Equity in Child Welfare.

Hines, A. M., Merdinger, J., \& Wyatt, P. (2005). Former foster youth attending college: Resilience and the transition to young adulthood. American Journal of Orthopsychiatry, 75, 381-94. doi:10.1037/0002-9432.75.3.381

Hochman, G., Hochman, A., \& Miller, J. (2004). Foster care: Voices from the inside. Retrieved from http://jobsfirstnyc.org/docs/voices-complete.pdf

Hoge, C. W., Castro, C. A., Messer, S. C., McGurk, D., Cotting, D. I., \& Koffman, R. L. (2004). Combat duty in Iraq and Afghanistan, mental health problems, and barriers to care. New England Journal of Medicine, 351, 13-22. doi:10.1056 /NEJMoa040603

Horn, L., \& Premo, M. D. (1995). Profile of undergraduates in US postsecondary education institutions: 1992-93 (NCES No. 96237). Education, 1989, 90. https:// nces.ed.gov/pubs/96237.pdf

Keeling, S. (2003). Advising the millennial generation. NACADA Journal, 23(1\&2) 3036. doi:10.12930/0271-9517-23.1-2.30

King, N. (2004, July). Advising underprepared students. Paper presented at the NACADA Summer Institute on Advising, Manhattan, KS. 
Klefeker, C. B. (2009, December). Foster care alumni on campus: Supporting an at-risk first generation student population. Academic Advising Today, 32(4). Retrieved from http://www.nacada.ksu.edu/Resources/Academic-Advising-Today/ViewArticles/Foster-Care-Alumni-on-Campus-Supporting-an-At-Risk-First-Generation -Student-Population.aspx

Kramer, G. (2003). Student academic services: An integrated approach. San Francisco, CA: Jossey-Bass.

Krebs, B., \& Pitcoff, P. (2004). Reversing the failure of the foster care system. Harvard Women's Law Journal, 27, 357-366. Retrieved from http://www.law.harvard.edu /students/orgs/jlg/vol27/krebs.pdf

Kuh, G. D. (1997) The student learning agenda: Implications for academic advisors. NACADA Journal, 17(2), 7-12. doi:10.12930/0271-9517-17.2.7

Kuh, G. D. (2008). Advising for student success. In V. N. Gordon, W. R. Habley, \& T. J. Grites (Eds.), Academic advising: A comprehensive handbook (2nd ed., pp. 6883). San Francisco, CA: Jossey-Bass.

Kuh, G. D., Schuh, J. H., \& Whitt, E. J. (1991). Some good news about campus life: How "involving colleges" promote learning outside the classroom. Change, 23(5), 4855. doi:10.1080/00091383.1991.9939880

Kulka, R. A., Fairbank, J. A., Jordan, K., \& Weiss, D. (1990). Trauma and the Vietnam War generation: Report of findings from the National Vietnam veterans readjustment study. New York, NY: Brunner Mazel.

Laanan, F. S. (2001). Transfer student adjustment. New Directions for Community Colleges, 2001(114), 5-13. doi:10.1002/cc.16 
Light, R. J. (2001). Making the most of college: Students speak their minds. Cambridge, MA: Harvard University Press.

Lincoln, Y. S., \& Guba, E. G. (1985). Naturalistic inquiry. Beverly Hills, CA: Sage.

Lovitt, T., \& Emerson, J. (2008). Foster youth who have succeeded in higher education: Common themes. National Center on Secondary Education and Transition, 7(1), 1-5. Retrieved from http://purl.umn.edu/49249

Lowenstein, M. (2005). If advising is teaching, what do advisors teach? NACADA Journal, 25(2), 65-73. doi:10.12930/0271-9517-25.2.65

Lumina Foundation. (2017). Homepage. Retrieved from http://www.luminafoundation . org/

Martin, J. (2003, October). Foster youth desire college, study shows, but face roadblocks to learning. St. Louis, MO: Washington University in St. Louis.

Martin, P. Y., \& Jackson, S. (2002). Educational success for children in public care: Advice from a group of high achievers. Child \& Family Social Work, 7, 121130. doi:10.1046/j.1365-2206.2002.00240.x

Maxwell, M. (1980). Improving student learning skills. San Francisco, CA: Jossey-Bass. McCabe, R. (2000). Underprepared students. In National Center for Public Policy and Higher Education (Ed.), Measuring up 2000: The state by state report card for higher education. Retrieved from http://measuringup.highereducation.org/2000 /articles/UnderpreparedStudents

McIntosh, P. (1988). White privilege: Unpacking the invisible knapsack. In P. S. Rothenberg (Ed.), Race, class, and gender in the United States: An integrated study (4th ed., pp. 165-169). New York, NY: St. Martin's Press. 
Newton, R. R., Litrownik, A. J., \& Landsverk, J. A. (2000). Children and youth in foster care: Disentangling the relationship between problem behaviors and number of placements. Child Abuse \& Neglect, 24, 1363-1374. doi:10.1016/S0145-2134 (00)00189-7

Obama, B. (2013, August). Presentation on college affordability. University of Buffalo, Buffalo, NY. Retrieved from https://obamawhitehouse.archives.gov/the-pressoffice/2013/08/22/remarks-president-college-affordability-buffalo-ny

Pascarella, E. T., \& Terenzini, P. T. (2005). How college affects students: A third decade of research (Vol. 2). San Francisco, CA: Jossey-Bass.

Pascarella, E. T., Wolniak, G. C., Pierson, C. T., \& Terenzini, P. T. (2003). Experiences and outcomes of first-generation students in community colleges. Journal of College Student Development, 44, 420-429. doi:10.1353/csd.2003.0030

Pecora, P. J., Kessler, R. C., Williams, J., Downs, A. C., English, D. J., White, J., \& O’Brien, K. (2010). What works in foster care? Key components of success from the Northwest Foster Care Alumni Study. Oxford, England: Oxford University Press.

Pecora, P. J., Kessler, R. C., Williams, J., O’Brien, K., Downs, A. C., English, ... Holmes, K. (2005). Improving family foster care: findings from the Northwest Foster Care Alumni Study. Seattle, WA: Casey Family Programs.

Pecora, P. J., Williams, J., Kessler, R. C., Downs, A. C., O’Brien, K., Hiripi, E., \& Morello, S. (2003). Assessing the effects of foster care: Early results from the Casey National Alumni Study. Seattle, WA: Casey Family Programs. 
The Pew Charitable Trust. (2007). Time to reform: Preventing youth from aging out and on their own. Philadelphia, PA: Author.

President Obama on Higher Education in Austin: "We Are Not Playing for Second Place". (n.d.). Retrieved from https://obamawhitehouse.archives.gov/blog/2010/08/09/president-obama-highereducation-austin-we-are-not-playing-second-place

Preventing Sex Trafficking and Strengthening Families Act, H.R. 4980, 113th Cong. (2014).

Provasnik, S., \& Planty, M. (2008). Community colleges: Special supplement to the condition of education 2008 (Research Report No. 2008-033). Retrieved from https://nces.ed.gov/pubs2008/2008033.pdf

Relating to higher education, ORS $\S \S 348.205,348.270$, and 348.570 (2011).

Rendón, L. I. (1992). From the barrio to the academy: Revelations of a Mexican American “scholarship girl.” New Directions for Community Colleges, 1992(80), 55-64. doi:10.1002/cc.36819928007

Richardson, R. C., \& Bender, L. W. (1987). Fostering minority access and achievement in higher education: The role of urban community colleges and universities. Jossey-Bass.

Rowley, L. L., \& Hurtado, S. (2002). The non-monetary benefits of an undergraduate education. Ann Arbor: University of Michigan, Center for the Study of Higher and Postsecondary Education. 
Salazar, A. M. (2011). Investigating the predictors of postsecondary education success and post-college life circumstances of foster care alumni. Portland, OR: Portland State University.

Schlossberg, N. K. (1981). A model for analyzing human adaptation to transition. Counseling Psychologist, 9, 2-18. doi:10.1177/001100008100900202

Schlossberg, N. K. (1989). Marginality and mattering: Key issues in building community. New Directions for Student Services, 1989(48), 5-15. doi:10.1002/ss .37119894803

Schlossberg, N., Waters, E. B., \& Goodman, J., (1995). Counseling adults in transition: Linking practice with theory (2nd ed.). New York, NY: Springer.

Schmidt, J., Dubey, S., Dalton, L., Nelson, M., Lee, J., Kennedy, M. O., ... Geenen, S. (2015). Who am I? Who do you think I am? Stability of racial/ethnic selfidentification among youth in foster care and concordance with agency categorization. Child and Youth Services Review, 56, 61-67. doi:10.1016 /j.childyouth.2015.06.011

Schneirla, T. C. (1959) An evolutionary and developmental theory of biphasic process underlying approach and withdrawal. In M. R. Jones (Ed.), Nebraska Symposium on Motivation, 1959 (pp. 1-42). Oxford, England: University of Nebraska Press. Reprinted in Schneirla, T. C. (1972). Selected writings. New York, NY: W. H. Freeman.

Schultz, T. (1961). Investment in human capital. American Economic Review, 51, 1-17. doi:10.1086/260106

Siebert, A. (1996). Survivor Personality. Penguin. 
Seita, J. R. (2001). Growing up without family privilege. Reclaiming Children and Youth, 10(3), 130-132. Retrieved from http://reclaimingjournal.com/sites/default/files /journal-article-pdfs/10_3_Seita.pdf

Seita, J. R. (2005). Kids without family privilege: Mobilizing youth development. Reclaiming Children and Youth, 14(2), 80-84.

Seyfried, S., Pecora, P. J., Downs, A. C., Levine, P., \& Emerson, J. (2000). Assessing the educational outcomes of children in long-term foster care: First findings. School Social Work Journal, 24(2), 68-88.

Sima, C., \& Inman, P., (2013, November). Advising matters: Whose advice do students really value? Paper presented at the annual conferences of the Association for the Study of Higher Education, St. Louis, MO.

Smithgall, C., Gladden, R. M., Howard, E., Goerge, R., \& Courtney, M. (2004). Educational experiences of children in out-of-home care. Chicago, IL: University of Chicago, Chapin Hall Center for Children.

Stanton-Salazar, R. D. (1997). A social capital framework for understanding the socialization of racial minority children and youths. Harvard Educational Review, 67, 1-41. doi:10.17763/haer.67.1.140676g74018u73k

Stanton-Salazar, R. D., \& Dornbusch, S. M. (1995). Social capital and the reproduction of inequality: Information networks among Mexican-origin high school students. Sociology of Education, 68, 116-135. doi:10.2307/2112778

Strauss, A., \& Corbin, J. (1998). Basics of qualitative research: Techniques and procedures for developing grounded theory. Thousand Oaks, CA: Sage. 
Strayhorn, T. L. (2015). Reframing academic advising for student success: From advisor to cultural navigator. NACADA Journal, 35(1), 56-63. doi:10.12930/NACADA $-14-199$

Tierney, W. G. (1992). An anthropological analysis of student participation in college. Journal of Higher Education, 63, 603-618. doi:10.1080/00221546.1992 .11778391

Tierney, W. G. (2000). Power, identity, and the dilemma of college student departure. In J. M. Braxton (Ed.), Reworking the student departure puzzle (pp. 213-234). Nashville, TN: Vanderbilt University Press.

Tinto, V. (1975). Dropout from higher education: A theoretical synthesis of recent research. Review of Educational Research, 45, 89-125. doi:10.3102 /00346543045001089

Tinto, V. (1993). Leaving college: Rethinking the causes and cures of student attrition. Chicago, IL: University of Chicago Press.

Tinto, V. (1998). Colleges as communities: Taking research on student persistence seriously. Review of Higher Education, 21, 167-177. Retrieved from ERIC database (EJ557144)

Tinto, V. (2003). Student retention. Paper presented at Oregon State University, Corvallis. Tinto, V. (2005). Keynote. Speech presented at National Conference on Student Retention, Washington, D.C.

Tinto, V. (2005). Moving from theory to action. College student retention: Formula for student success, 3, 317-333. 
Tinto, V. (2006). Research and practice of student retention, What's next? Journal of College Student Retention Research Theory and Practice, 8, 1-19. doi:10.2190 /COC4-EFT9-EG7W-PWP4

Tinto, V. (2012). Completing college: Rethinking institutional action. Chicago, IL: The University of Chicago Press.

Toth, J. (1997). Orphans of the living: Stories of America's children in foster care. New York, NY: Simon \& Schuster.

Townsend, B. K., \& Wilson, K. (2006). A hand hold for a little bit: Factors facilitating the success of community college transfer students to a large research university. Journal of College Student Development, 47, 439-456. doi:10.1353/csd.2006 .0052

Tritelli, D. (2003) From the editor. Peer Review, 5(2). Retrieved from https://www .aacu.org/publications-research/periodicals/editor-29

Troop, D. (2012). For former foster kids, campus is their 'home for the holidays'. Chronicle of Higher Education, 58, 19. Retrieved from https://www.chronicle .com/article/Colleges-Help-Alumni-of-Foster/130239

Troxel, W. (2017, March). Determining your level of involvement in the scholarship of advising. Paper presented at the 2nd Annual UK Advising and Tutoring Conference, Leeds, England.

Unrau, Y. A., Seita, J. R., \& Putney, K. S. (2008). Former foster youth remember multiple placement moves: A journey of loss and hope. Children and Youth Services Review, 30, 1256-1266. doi:10.1016/j.childyouth.2008.03.010 
US Department of Health and Human Services. (2006). The AFCARS report: Preliminary FY 2005 estimates as of September 2006. Washington, DC: Author.

U.S. Department of Health and Human Services, Administration for Children and Families, Administration on Children, Youth \& Families, Children's Bureau. (2008). The AFCARS report No. 14: Preliminary FY 2006 estimates as of January 2008. Washington, DC: Author. Retrieved from https://www.acf.hhs.gov/sites /default/files/cb/afcarsreport14.pdf

U.S. Department of Health and Human Services, Administration for Children and Families, Administration on Children, Youth \& Families, Children's' Bureau. (2011). The AFCARS report No. 18: Preliminary FY 2010 estimates as of June 2011. Washington, DC: Author. Retrieved from https://www.acf.hhs.gov/site s/default/files/cb/afcarsreport18.pdf

U.S. Department of Health and Human Services, Administration for Children and Families, Administration on Children, Youth \& Families, Children's' Bureau. (2015). The AFCARS report No. 24: Preliminary FY 2016 estimates as of October 2017. Washington, DC: Author. Retrieved from https://www.acf.hhs.gov/sites /default/files/cb/afcarsreport24.pdf

Usher, C. L., Randolph, K. A., \& Gogan, H. C. (1999). Placement patterns in foster care. Social Service Review, 73, 22-36. doi:10.1086/515794

Vaala, L. D., (1991). Making the transition: Influences on transfer students. NASPA Journal, 28, 305-311. doi:10.1080/00220973.1991.11072224 
Walpole, M. B. (2003). Socioeconomic status and college: How SES affects college experiences and outcomes. Review of Higher Education, 27, 45-73. doi:10.1353 /rhe. 2003.0044

Weideman, A. (2014). Academic literacy: Why is it important? In A. Weideman \& Van Dyk (Eds.), Academic literacy: Five new tests (pp. ii-ix). Bloemfontein, Free State of South Africa: Geronimo.

Weston, M., \& Cheng, K. (2007). Living in survival mode: Foster care youth talk about their needs. Student Aid Transcript, 18(3), 16-23.

White, E. (2015). Academic advising in higher education: A place at the core. Journal of General Education, 64, 263-277.

Wolanin, T. R. (2005). Higher education opportunities for foster youth: A primer for policy makers. Washington, DC: Institute for Higher Education Policy.

Wulczyn, F., Kogan, J., \& Harden, B. J. (2003). Placement stability and movement trajectories. Social Service Review, 77, 212-236. doi:10.1086/373906

Yu, E., Day, P., \& Williams, M. (2002). Improving educational outcomes for youth in care: A national collaboration. Washington, DC: Child Welfare League of America. 
Appendix A: Introduction Letter

\section{Dear Program Director (Financial Aid),}

I am conducting a study looking at the experiences of foster youth beginning their degrees at a community college with the goal of eventually transferring to a four-year university. The research is for my doctoral dissertation in the Graduate School of Education at Portland State University. The focus of my research is specifically around the transitions foster youth experience as they begin at the community college. Many foster youth aspire to higher education, but previous research indicates that few achieve degree attainment. I am interested in learning more about why, so few foster alumni persist.

My research involves personal interviews with foster youth at

and I hope that you will be able to assist me in getting the word out about this opportunity to students. I am looking to interview students that are between the ages of 18-25 years of age who were or are in foster care. Specifically, at $\square$ I want to interview students that have between $0-45$ completed college credits.

I appreciate that you are very busy, but your support and assistance would be greatly appreciated as you will know many of the students that may qualify for this study. Understanding more about the transitional experiences foster youth undergo may provide better support and resources for this frequently marginalized population.

Attached, please find a flyer that I ask you to post in areas that are highly visible to students. Participant involvement will consist of two interviews lasting no more than 180 minutes total.

I thank you in advance for your consideration of my request. Please feel free to contact me if you have any concerns or additional questions. You may contact me at

Sincerely,

Karen Sullivan-Vance

Doctoral Candidate

Graduate School of Education

Portland State University 
Appendix B: Recruitment Poster-Portland Community College

\section{Research Participants Needed}

A research project on former and current foster youth attending PCC is being conducted to better understand the experiences of foster youth in higher education. If you meet the following criteria you are eligible to participate:

- Between 18 and 25 years of age

- Are still in foster care or emancipated from care

- Have enrolled at PCC and completed between 0-45 college credits

- Willing to share your story/experiences in a personal interview

Participation is voluntary, and your confidentiality will be protected. Participants will receive a transcript of the interview and will have a chance to offer feedback. Two in person interviews will be conducted running between 60-90 minutes each. Foster youth still in care will need to have their social work sign consent form.

Compensation: \$20 Visa Gift Card

Interested?

To participate or learn more about this study please contact Karen Sullivan-Vance at 
Appendix C: Letter to Department of Human Services Social Workers Requesting Permission to Interview Foster Youth in Care

Dear Social Worker/Guardian,

I am conducting a study looking at the experiences of foster youth beginning their degrees at a community college. The research is for my doctoral dissertation in the Graduate School of Education at Portland State University. The focus of my research is specifically around the transitions foster youth experience as they begin at the community college. For many foster youth the community college is the gateway to higher education. Foster youth aspire to higher education, but previous research indicates that few achieve degree attainment. I am interested in learning more about why so few foster alumni persist.

My research involves personal interviews with foster youth at Community College. I am looking to interview students that are between the ages of 1825 years of age who were in or are currently in Oregon foster care. Specifically at $\square$ I want to interview students that have between $0-45$ completed college credits. The reason for this is I want to look at the initial transitions foster youth experience as they begin higher education. I recognize that some of the participants may still be in state care and ask your permission to be allowed to interview the foster youth that has brought you this letter. DHS has informed me that as long as I have consent of the social worker and no more than $50 \%$ of my research subjects are still care then I can proceed with the study. For students at that are still in care I will require their Social Worker's signature on the release form. 
I plan to interview between 5 and 10 students for 2 interviews each that will last between 60-90 minutes. Participants can refuse to answer any questions, and participants are free to pull out of the study at any time. All participants will be coded to protect their confidentiality. Research participants will be given a $\$ 20$ gift card as a sign of gratitude, and even if they decide to pull out of the project they may keep the gift card.

The research will be overseen by my doctoral advisor, Dr. Janine Allen, and has been reviewed and approved by Portland State University's Institutional Review Board. While there are some initial questions about the subjects experiences in foster care the main questions are focused on their experiences in college and framed around Schlossberg's Transition Theory, specifically the 4S's of Situation, Self, Support and Strategies.

Understanding the transitions that foster youth experience as they access higher education, may help practitioners to not only understand the challenges faced by this population, but may also increase awareness and programming that will increase degree completion.

Please contact me at $\quad$ or by phone at $\square$ if you have additional questions about this project. I look forward to hearing back from you.

Sincerely,

Karen Sullivan-Vance

Doctoral Candidate

Graduate School of Education

Portland State University 
Appendix D: Interview Invite

Dear

I am conducting a research project in which I will be exploring the experiences of foster youth as they transition into and through their first year at a community college.

The goal is to better understand how former and current foster youth go through higher education and what the transition is like for them. Specifically I am interested in learning about your transition into Community College and how your experiences may be applicable to other foster youth who want to attend college and graduate.

You were selected either from responding to ads I placed, or you contacted me upon hearing about my research project. You are invited to participate in the research by allowing me to interview you. The interview will last approximately 60-90 minutes and will be conducted in a location that is convenient for you. There will be one follow-up interview, also 60-90 minutes long for additional question or to clarify responses from the first interview. If you are currently a foster youth in the state of Oregon I will need permission from your social worker in order to interview you. Both you and your social worker will need to sign the informed consent form.

All of the information you provide during the interview will be kept confidential; only summaries of the interviews will be reported. You will not be personally identified in any reports of the findings. I, as the co-principal investigator will record your interview and make notes during the session. You may turn off the recorder at any time during the interview. You may also opt not to respond to any questions. You may stop the interview at any point.

This research is a chance to tell your story, and special efforts will be taken to keep your identity confidential. Once the interview is over, the notes and tapes of the session will be stored in a secure location to ensure that your participation remains confidential. Only I, and my doctoral advisor, Dr. Janine Allen will have access to the notes and recordings. I may publish or present findings from this research.

You may not receive any direct benefit from taking part in this study, but the study may help increase knowledge that will help others in the future. The purpose of the research is to assist in improving practices in student services and academic advising programs.

Your participation in this study is entirely voluntary. Your willingness or unwillingness to participate will not affect your current or any future relationship with Portland Community College. If you are willing to be interviewed for the study, please reply to this email.

If you have concerns or questions about your rights as a research participant, please contact the Human Subjects Research Review Committee, Post Office Box 751 (RSP), Portland State University, Portland, Oregon 97207-0751, telephone 503-725-4288/email hsrrc@pdx.edu. Should you have any questions about the research itself, please contact 
the researcher Karen Sullivan-Vance via email at

or phone (office) or $\quad$ (cell).

Thank you for considering participating in this important research project.

Sincerely,

\author{
Karen Sullivan-Vance \\ Doctoral Student \\ Educational Leadership and Policy \\ Graduate School of Education \\ Portland State University \\ Portland, Oregon
}


Appendix E: Informed Consent

Silent No More: Voices of Foster Youth in Higher Education

You are invited to participate in a research study conducted by Karen Sullivan-Vance, doctoral student in the Graduate School of Education at Portland State University. The researcher is conducting a study of former foster youths at Community College who have successfully transitioned into higher education. This study is in partial fulfillment of the requirements of a doctoral degree under the supervision of Dr. Janine Allen, advisor. You were selected as a possible participant in this student because of your status as a former foster youth attending Community College. The purpose of the research is to begin to understand the experiences of foster youth as they transition into and through higher education.

You are invited to participate in the research by allowing me to interview you. The project consists of two interviews which will each last approximately 60-90 minutes. The second interview will be used to clarify statements from the first interview. Interviews will take place in a mutually agreeable quiet location. The interviews will be recorded on a digital voice recorder. You will be assigned a number and a pseudonym for the research in order to maintain your confidentiality. The principal investigator will record your interview and make notes during the session. You may turn off the recorder at any time during the interview. You may also opt not to respond to any questions. You may stop the interview at any point. Interviews will be transcribed by a professional transcriptionist and checked by the researcher for accuracy. You will also be able to check your interview and change or delete any section. All data will be kept in password protected files for three years after the study ends.

There are no clear risks to participation in this study, and the researcher will make every effort to respect the time you have agreed to give. You may not receive any direct benefit from taking part in this study, but the study may help increase knowledge that will help others in the future.

Any information that is obtained in connection with this study and that can be linked to you or identify you will be kept confidential. The researcher may publish or present findings from this research, but at no time will your name be revealed. This information will be kept confidential on a secure network server. 
Your participation in this study is voluntary. Your willingness or unwillingness to participate will not affect your relationship with _ or the researcher. You may also withdraw from this study at any time without affecting your relationship with Community College or the researcher.

If you have concerns or problems about your participation in this study or your rights as a research subject, please contact the Human Subjects Research Review Committee, Post Office Box 751 (RSP), Portland State University, Portland, Oregon 97207-075, telephone 503-725-3423/email hsrrc@pdx.edu. Should you have any questions about the study itself, please contact the researcher Karen Sullivan-Vance via email at (office), (PSU) or via phone at (cell). All participants may request a copy of the final report. (office),

Your signature indicates that you have read and understand the above information and agree to take part in this study. Please understand that you may withdraw consent at any time without penalty, and that, by signing, you are not waiving any legal claims, rights or remedies. The researcher will provide you with a copy of this form for your own records.

I agree to participate in this study.

Date: Signature:

Please note: If you are currently still a foster youth in the care of the State of Oregon Department of Human Services you need the permission of your social worker to participate in this research study.

Date: Social Worker Signature: 
Email contact for social worker:

Phone contact for social worker: 
Appendix F: Interview Protocol

Introduce consent form (offer to read it) and obtain signature.

Give participant the $\$ 20$ gift card and have them sign to show they received it.

[To be read at the beginning of the interview.]

Thank you for agreeing to meet with me. I really believe that the information gathered in this research may be beneficial to other foster alumni beginning college and those that are thinking of attending.

As you know, I am investigating the transitions foster alumni experience entering higher education through community college. Your honest responses will help ensure quality data to contribute to understanding the challenges, successes and barriers experienced by foster alumni. I have several prepared questions, but may also follow up on something you say during the course of our conversation for elaboration or clarification. I will also ask all questions even if you have already talked about related issues, at which point you can either elaborate or refer to your earlier response.

I have no expectations of you answering the questions in any particular way. There is no right or wrong response to any question, only your experiences. You also have the right to refuse to answer any question(s) or stop the interview at any time. I want to remind you that our conversation today is completely confidential and will be recorded. The reason for recording is so that I get your words exactly right.

Do you have any questions about the process?

[Await response and proceed.]

Do you have any questions before we begin? 
SELF

I would like to begin by getting a little background information from you first about yourself and your experiences in foster care.

1. How old are you?

2. At what age did you enter foster care?

3. How long were you in foster care?

4. How many placements and school changes did you experience?

5. How would you describe your experience(s) in foster care?

6. What did you want to be when you grew up? What dreams/goals did you have for yourself? Who encouraged you to achieve your dreams/goals?

7. Why did you decide to go to college? Please explain.

8. Are you working? If so, how many hours a week?

\section{SITUATION}

Okay, now I'd like to ask you some questions about your experiences coming in to Community College and your future plans, i.e. work or transfer to a four year university. But before I go on, do you need a break?

[Await response and proceed.]

I'd like to understand more about your college experiences so these next questions will focus on that.

1. Was attending college part of your transition plan out of foster care? Can you tell me what was in your transition plan? Did it influence you and if so, in what ways? 
2. Why did you decide to attend Community College?

3. Did you explore attending any other colleges?

4. Did you apply to any other colleges/universities? If so, why didn't you attend them?

5. When did you decide to attend

6. What term did you begin at

7. What did you do between leaving high school and starting at

8. What are you majoring in? Why did you choose that major?

9. What do you hope to do for a career?

\section{SUPPORT}

1. Do you receive financial support to attend college? Have you applied for and received the Chafee/ETV?

2. Do you receive emotional support to attend college? If yes, from whom? How do they help you?

3. Do you receive academic support? If yes, from whom or what office? How do they help you? 
4. Have you felt hindered at any time in negotiating the college? If so, can you tell me about it? How did it make you feel? What did you do about it?

5. Do you get academic advising?

6. Where do you get your advising from (office/faculty/staff)?

7. Is academic advising required or not at your institution?

8. Can you tell me about your experiences with academic advising?

9. What has your time at Community College been like? What has helped you? What has hindered you?

10. What surprised you about coming to college?

11. Do you feel like you were adequately prepared for college? Please elaborate.

12. What do you know now that you wish you'd known when you started?

13. What has been the most helpful for you in college?

14. What has been the least helpful for you in college? 


\section{STRATEGIES}

1. Is attending community college what you thought it would be like before you started classes?

2. What resources on campus do you utilize? Would you elaborate and tell me why you use those resources? Which ones are most beneficial to you?

3. Are there resources on campus you have heard about but have not yet used? Which ones? Do you plan to use them?

4. If there was a specific support office/person for former foster youth would you use that office/person as a resource? Why or why not?

5. Have you made any connections with faculty/staff on campus? Tell me about them? Do they help you? If so, in what way(s)?

6. If you plan to transfer to a four year university do you know what you need to do in order to transfer?

7. What has helped you/hindered you at the community college?

8. Have your goals/plans changed since you started? If yes, how so?

Thank you for your time. I will be contacting you in a couple of weeks to conduct a follow-up interview with you. At that time I will be asking clarifying questions based on the responses you have provided today. 
Dear Participant,

I want to take this opportunity to thank you for your participation with my dissertation research. I enjoyed meeting with you and am grateful that you shared your story and experiences as a foster youth/alumni at with me. Your experiences as a college student offer insight and valuable information about foster youth/alumni transitioning and persisting through college.

Attached to this letter please find a copy of the transcript of our two interviews. Please take a moment to review the transcript for accuracy and write me back at

if there are any corrections or if you want to add/clarify any of your statements. At the completion of my research I will send you a summary of my findings.

Thank you again for taking the time to be a part of my research.

Best wishes,

Karen Sullivan-Vance 
Appendix H: Confidentiality Agreement for Professional Transcriptionist

It is understood and agreed to that the below identified discloser of confidential information may provide certain information that is and must be kept confidential. To ensure the protection of such information and to preserve any confidentiality necessary, it is agreed that

1. The Confidential Information to be disclosed can be described as and includes: Interviews with current and former foster youth involved in a research study for a doctoral dissertation. Recipient is professionally transcribing the one-on-one interviews conducted by the doctoral student and her research participants.

2. The Recipient agrees not to disclose the confidential information obtained from the discloser to anyone unless required to do so by law.

3. This Agreement states the entire agreement between the parties concerning the disclosure of Confidential Information. Any addition or modification to this Agreement must be made in writing and signed by the parties.

4. If any of the provisions of this Agreement are found to be unenforceable, the remainder shall be enforced as fully as possible and the unenforceable provision(s) shall be deemed modified to the limited extent required to permit enforcement of the Agreement as a whole.

WHEREFORE, the parties acknowledge that they have read and understand this Agreement and voluntarily accept the duties and obligations set forth herein.

Recipient of Confidential Information:

Name (Print or Type):

Signature: 
Date:

Discloser of Confidential Information:

Name (Print or Type): Karen Sullivan-Vance

Signature:

Date: 